\title{
Optimal Monetary Policy in a Currency Union with Interest Rate Spreads*
}

\author{
Saroj Bhattarai \\ Penn State University
}

\author{
Jae Won Lee \\ Rutgers University
}

\author{
Woong Yong Park ${ }^{\dagger}$ \\ University of Hong Kong
}

\begin{abstract}
We study optimal monetary policy in a two-country currency union model with nominal and financial frictions. In addition to, and independent from, the standard transmission mechanism associated with sticky prices, financial frictions combined with asymmetric asset positions introduce a wealth redistribution role for monetary policy in our model. Financial frictions also lead to a spread between the deposit and borrowing interest rate and variation in the spread affects both aggregate variables, by affecting total spending, and relative (cross-country) variables, by redistributing wealth across countries. Moreover, the interactions between nominal and financial frictions amplify the effects of monetary policy; imply that a strict inflation targeting policy of setting union-wide inflation to zero is never optimal and that optimal policy never attains efficiency; and lead to a novel policy trade-off for the central bank in stabilizing relative consumption versus the relative price gap (the deviation of relative prices from their efficient level). Finally, under optimal monetary policy, in response to an aggregate purely financial shock that causes an increase in the interest rate spread, the central bank strongly decreases the deposit rate, which reduces aggregate and distributional inefficiencies by mitigating the drop in output and inflation and the rise in relative consumption and prices. We also show that while a traditional Taylor rule approximates optimal policy imperfectly, especially in response to the financial shock, a spreadadjusted Taylor rule performs better as it helps the real interest rate track the efficient rate of interest.
\end{abstract}

JEL Classification: E31, E51, E52, E61, F33, F41

Keywords: Currency union; Optimal monetary policy; Monetary policy transmission mechanism; Redistributive monetary policy; Policy trade-offs, Sticky prices; Financial frictions; Interest rate spreads; Spread-adjusted Taylor rule

\footnotetext{
${ }^{*}$ We thank Pierpaolo Benigno, Russ Cooper, Huw Dixon, Neil Wallace, Simon Wren-Lewis, seminar participants at University of Hong Kong, University of Exeter, and Cardiff University, and conference participants at the Cornell-Penn State Macro Workshop and the Birmingham Conference in Macroeconomics and Econometrics for valuable comments and suggestions.

†Bhattarai: 615 Kern Building, University Park, PA 16802, sub31@psu.edu. Lee: 75 Hamilton Street, NJ Hall, New Brunswick, NJ 08901, jwlee@econ.rutgers.edu. Park: School of Economics and Finance, University of Hong Kong, Pokfulam Road, Hong Kong, wypark@hku.hk.
} 


\section{Introduction}

The recent global financial crisis has led to a renewed interest in incorporating financial frictions in business cycle models used in positive and normative analysis of monetary policy. ${ }^{1}$ Much of this recent work, especially the subset that analyzes normative implications, has been done in the context of closed economy models of the monetary policy transmission mechanism. In this paper, we take an open economy approach and study optimal monetary policy in a two-country model of the currency union with nominal rigidities and financial imperfections. Distinguishing features of our model are asymmetric net wealth positions across member countries in the currency union, incomplete risk-sharing within the union, and a spread between borrowing and deposit interest rates.

In analyzing optimal monetary policy in a currency union with such features, we are especially motivated by imbalances in net asset positions among Euro Area countries (as is evident from Table 1 below which presents Net International Investment Position as a ratio of GDP for selected Euro Area Countries) coupled with recent developments such as the financial crisis and the rapid increase in interest rate spreads during the crisis (as is evident from Figure 1 below which presents the excess returns on the 10-year government bond of selected Euro Area countries over the 10-year German Bund yield). ${ }^{2}$ We believe that our theoretical results will help shed light on the normative policy implications of these developments for the European Central Bank.

Table 1: Net International Investment Position as a ratio of GDP (\%) in the Euro Area

\begin{tabular}{lrrrr}
\hline Country & $\mathbf{2 0 0 7}$ & $\mathbf{2 0 0 8}$ & $\mathbf{2 0 0 9}$ & $\mathbf{2 0 1 0}$ \\
\hline \hline France & -1.6 & -12.2 & -9.5 & -10.6 \\
Germany & 28.5 & 23.6 & 35.8 & 37.8 \\
Greece & -103.4 & -72.7 & -89.5 & -97.6 \\
Ireland & -21.0 & -68.0 & -101.3 & -96.6 \\
Italy & -26.3 & -22.8 & -26.7 & -24.7 \\
Portugal & -95.4 & -90.9 & -114.9 & -109.1 \\
Spain & -83.9 & -75.0 & -95.4 & -88.6 \\
\hline \multicolumn{4}{c}{ Source: IMF Balance of Payments data }
\end{tabular}

Our currency union model is a standard two-country setup similar to Benigno (2004) where monopolistically competitive firms produce differentiated goods using labor and set prices at stochastic intervals, as in Calvo (1983). The production function is subject to both an aggregate and a countryspecific productivity shock. Representative households in the two countries consume a bundle of the home and foreign goods, provide labor to home firms, make borrowing and saving decisions, and

\footnotetext{
${ }^{1}$ Important recent contributions to the literature include, among others, Christiano, Motto, and Rostagno (2009), Curdia and Woodford (2009, 2010), Gertler and Karadi (2011), and Del Negro et al (2011). Well-known precursors to this literature are Townsend (1979), Williamson (1987), Bernanke and Gertler (1989), Kiyotaki and Moore (1997), Carlstrom and Fuerst (1997), Bernanke, Gertler, and Gilchrist (1999), and Kiyotaki and Moore (2008). Finally, Kiyotaki and Gertler (2010) provide both a canonical model to study credit policies and a literature survey.

${ }^{2}$ For evidence on the crucial role played by credit spreads in U.S. business cycle fluctuations generally, see Gilchrist and Zakrajsek (2012) and for the recent crisis specifically, see see Adrian, Colla, and Shin (2012).
} 


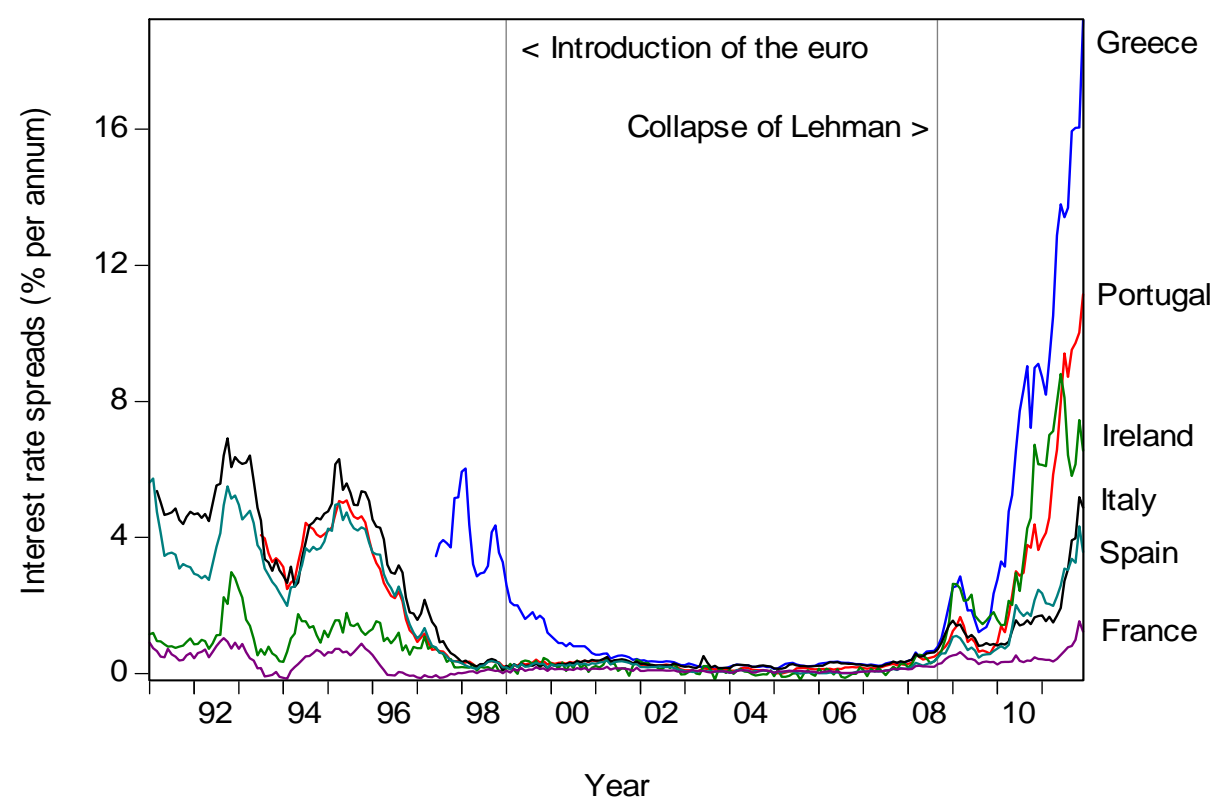

Figure 1: Interest rate spreads in the Euro Area (Source: OECD data)

receive profits from home firms and union-wide financial intermediaries. ${ }^{3}$

In this prototypical set-up, we allow for asymmetric initial and steady-state wealth position across the countries, with one country a borrower and the other a saver. ${ }^{4}$ We then add two sources of financial imperfections. First, the only financial instrument that is traded across countries in the currency union is a non-state contingent nominal bond that is in zero net supply. The lack of a complete set of state-contingent securities that can be traded across countries thus means that cross-country risk-sharing is incomplete within the union. Second, there are frictions in financial intermediation that lead to a spread between the deposit and borrowing rates. To keep our set-up tractable and easily comparable with the literature, we adopt the modelling framework of Curdia and Woodford $(2009,2010)$ in introducing these frictions. Perfectly competitive financial intermediaries that operate union-wide accept deposits and lend to households. Origination of loans is costly and consumes real resources as a function of the real quantity of loans. This implies that the interest rate spread varies endogenously as aggregate debt evolves in the economy. In addition, we also allow for an exogenous loss rate of loans that varies over time. This then constitutes an aggregate

\footnotetext{
${ }^{3}$ For simplicity and to make clear our contributions to the literature on monetary policy in a currency union (in particular, to highlight the role of financial frictions in isolation), the model abstracts from some potentially important sources of ex-ante heterogeneity between member countries, for example, in preferences, shock processes, and the extent of price stickiness. There is also no home bias in consumption.

${ }^{4}$ One country starts with positive wealth while the other starts with negative wealth (of the same amount). In the non-stochastic steady state, the initial wealth positions will coincide with the steady-state ones: one country will have positive wealth while the other will have negative. Moreover, for small enough shocks, in a first-order approximation, which is the case we consider, the financial position of the countries will fluctuate around these non-stochastic steady state values. Thus one country is a borrower while the other a saver over the business cycle as well in our model.
} 
purely financial shock that affects the interest rate spread in our model. Importantly, variations in interest rates and the spread affect both aggregate variables, by affecting aggregate demand, as well as relative (cross-country) variables, by redistributing wealth over the business cycle between the borrower and saver country. ${ }^{5}$

In this environment, our main contribution is to characterize optimal monetary policy of the union-wide common central bank using a linear-quadratic approach, focussing in particular on the role played by financial frictions. Following Woodford (2003), we derive a quadratic welfare-theoretic loss-function of the central bank by taking a second-order approximation of an equally-weighted sum of the household's utilities in the two countries around an efficient non-stochastic steady-state. ${ }^{6} \mathrm{~A}$ first-order approximation of the private sector's optimality conditions as well as market-clearing relations then represent the constraints faced by the central bank. We study this Ramsey problem of minimizing the loss function subject to the constraints under commitment, where the policy instrument is the deposit interest rate.

Our first set of results concerns the transmission mechanism of monetary policy. In our model, nominal and financial frictions lead to two different, and in principle independent, channels of monetary policy transmission. Consider first a version of our model with sticky prices but no initial heterogeneity in wealth positions. ${ }^{7}$ Then, monetary policy has real effects through the usual and well-understood aggregate demand channel: monetary policy can affect the (ex-ante) real interest rate under sticky prices, which enables it to manage the aggregate, union-wide output gap (the deviation of output from the efficient level). Moreover, in this case, monetary policy has no effect at all on cross-country variables like relative prices, consumption, and debt.

Consider next a version of our model without sticky prices, but with financial frictions. Even with flexible prices, monetary policy has real effects as it affects the wealth distribution of the economy. The channel for this is the following. Note that in a first-order approximation of our model, one country is always a borrower while the other is a saver. Moreover, the financial instrument that the countries trade in our model is a nominal bond. Then, if the central bank changes the deposit rate, and thereby inflation, it redistributes wealth between the countries. ${ }^{8}$ This redistribution of wealth naturally affects relative consumption and prices in the currency union. Under flexible prices, monetary policy however, does not affect aggregate, union-wide output, which is determined solely as a function of aggregate and country-specific productivity shocks. ${ }^{9}$ While these mechanisms are

\footnotetext{
${ }^{5}$ We use "relative" and "cross-country" interchangeably in the paper.

${ }^{6}$ In the non-stochastic steady state, there is no interest rate spread and moreover, the distortion due to monopolistic competition is removed through a non-state-contingent sales tax. In addition, in the steady-state, we allow for lumpsum transfers across the countries such that they have the same level of consumption, even though their initial (and steady state) net asset positions are not the same.

${ }^{7}$ A model with complete markets would also yield similar insights.

${ }^{8}$ For an influential empirical study of the redistributive channel of monetary policy that operates through returns on nominal bonds, see Doepke and Schneider (2006).

${ }^{9}$ Obviously, it is well understood that monetary policy does affect relative prices even under complete asset markets, for example, when the degree of nominal rigidities is different across countries as in Benigno (2004). Moreover, under different model environments, reshuffling of consumption and prices between countries could affect aggregate output, which in turn further changes relative consumption and prices even under flexible prices. For simplicity and to highlight the main role of nominal and financial frictions in isolation, we build our model in a way such that these feedback channels are absent. Hence, monetary policy is neutral for cross-country variables in one special case (nominal frictions
} 
in principle independent, in our general model with both frictions, there is a non-trivial interaction between monetary policy, aggregate dynamics, and evolution of cross-country variables, which leads to a very interesting optimal monetary policy problem. In particular, these interactions lead to a more persistent effect of monetary policy on aggregate and relative variables, as well as a novel trade-off for policy that we discuss below.

Our second set of results is related to the terms that appear in the welfare-theoretic quadratic loss function, which illustrate the various distortions present in the model. As is standard in models with staggered price setting, since inflation causes inefficient price dispersion across differentiated goods, the loss function contains inflation of the two countries. It also contains the union-wide output gap. Moreover, as Benigno (2004) has also shown, in a currency union since countries effectively have a fixed exchange rate and prices are sticky, the relative price gap, the deviation of relative (crosscountry) prices from their efficient level, is also present in the loss function. ${ }^{10}$ The next two terms are new to our set-up and arise because of financial imperfections. First, because of imperfect risksharing between the countries, relative consumption appears in the loss function. Second, because financial intermediation consumes real resources and the endogenous interest rate spread is a function of aggregate debt, aggregate debt is also included in the loss function.

Our third set of results, which is the major focus of our paper, is regarding model dynamics under optimal monetary policy and the policy trade-offs that the central bank faces. Before proceeding to the general version of our model with both nominal and financial frictions, it is instructive to consider the two special cases that we discussed before where only one of the two transmission mechanisms is in operation at a time. In particular, for these two special cases, we provide analytical characterization of optimal policy.

So consider first the well-understood case without any financial frictions but with sticky prices, where the transmission mechanism operates through the aggregate demand channel. In this case, the central bank can only affect aggregate output and inflation and not any other cross-country variables. Thus, the central bank's loss function only contains inflation and the output gap. Since, our model does not feature inefficient supply shocks - such as markup shocks - or cross-country heterogeneity in price stickiness, there is no trade-off in stabilizing inflation versus the output gap. Optimal monetary policy then constitutes full stabilization of inflation, and thereby, of the output gap. Such optimal policy however, does not attain the efficient outcome since in the presence of country-specific productivity shocks, the relative price gap is not zero and is in fact outside the control of the central bank.

Next, consider the case without any sticky prices but with financial frictions, where the transmission mechanism operates through the wealth redistribution channel. In this case, the central bank cannot affect aggregate output but can affect cross-country variables. Thus, the central bank's loss function only contains relative consumption and debt. ${ }^{11}$ In the presence of the purely aggregate

only) while it is neutral for aggregate output in the other special case (financial frictions only).

${ }^{10}$ Note that it is possible to also rewrite these first four terms in the loss function in terms of union-wide inflation, union-wide output gap, the relative price gap, and the first difference of relative prices.

${ }^{11}$ Under flexible prices, the central bank does not care about inflation and while the central bank does care about relative price gap variation, there is a one-to-one relationship between relative consumption and relative price gap. 
financial shock, the central bank faces a trade-off since it is not possible to simultaneously achieve zero relative consumption and zero debt. This precludes optimal policy from attaining the efficient outcome. $^{12}$ When a positive financial shock hits and drives the interest rate spread upward, the central bank optimally reduces the distributional inefficiency arising due to the wealth redistribution from the borrower to the saver country by decreasing the deposit rate and driving down the borrowing country's debt. The central bank thus conducts a "leaning against the wind" policy. Finally, in stark contrast to the case of sticky prices, inflation now responds to all shocks and in fact can be quite volatile.

With results for the two specific cases established, it is easy to see that in our general model with both nominal and financial frictions, a strict inflation targeting policy of setting union-wide inflation to zero is not optimal and that optimal policy does not attain the efficient outcome. Our result is thus in contrast with previous finding in Benigno (2004) that complete stabilization of union-wide inflation is optimal when the economy has no inefficient supply shocks - such as markup shocks and no cross-country heterogeneity in price stickiness. Note that this new result does not emerge because there is a trade-off between stabilizing aggregate inflation and output gap in our model. Rather, it holds because the other terms in the loss function, such as relative price gap, relative consumption, and aggregate debt are not generally independent of monetary policy due to financial imperfections that lead to the wealth redistributive role of monetary policy. The central bank thus has to optimally balance the variability of all the target variables, not just inflation and output gap. Moreover, there will generally be a trade-off in mitigating aggregate vs. cross-country distortions. For example, the central bank will not allow inflation to fluctuate as much to mitigate variations in relative consumption when nominal frictions are present in addition to financial frictions.

With country-specific productivity shocks, which lead to a movement in the efficient level of relative prices, the interaction of nominal and financial frictions lead to a novel trade-off for the central bank in stabilizing relative consumption versus the relative price gap. This trade-off is in addition to the one between relative consumption and debt that we discussed above. In the presence of sticky prices and idiosyncratic productivity shocks, it is not possible to simultaneously achieve both a zero relative consumption and a zero relative price gap. In the presence of financial frictions, the central bank also cares about variation in relative consumption. Thus, the interaction of nominal and financial frictions generates this new trade-off: if there were no financial imperfections, then relative consumption and relative price gap would evolve independently of monetary policy, thereby precluding any role of policy; while if prices were completely flexible, then there would be a one-to-one relationship between relative consumption and relative price gap, thereby generating no trade-off for policy. The most important consequence of this new trade-off is that in response to country-specific productivity shocks, under optimal policy, the central bank allows for a higher variability in the relative price gap compared to when there are no financial imperfections, as it now also cares about the variability in relative consumption.

Finally, in our general model, we analyze optimal policy in response to the purely aggregate financial shock that causes an increase in the interest rate spread. To counter this shock, the

\footnotetext{
${ }^{12}$ Note that debt and relative consumption do not respond to shocks other than the financial shock.
} 
central bank strongly decreases the deposit interest rate, thereby mitigating the drop in output and inflation that would otherwise occur. All other target variables, that is, relative price gap, relative consumption, and aggregate debt, fluctuate in response to this shock as the shock redistributes wealth between countries. In addition to decreasing aggregate fluctuations, the central bank's lowering of the deposit rate also optimally reduces the distributional inefficiency caused by wealth redistribution as it mitigates the inefficient rise in relative consumption and prices.

As our final set of results, we provide a comparison of optimal policy with some simple instrument rules such as a standard Taylor rule and a spread-adjusted Taylor rule. In most cases, the dynamics look fairly similar between optimal policy and a simple Taylor rule, where the central bank adjusts the deposit interest rate in response to only inflation and output, even though clearly there is more variability of the terms in the loss-function under a Taylor rule. The biggest difference in model dynamics between optimal policy and a simple Taylor rule is with respect to the aggregate purely financial shock. Under a simple Taylor rule, in response to this shock, the central bank allows a substantial drop in output and inflation, an outcome not observed under optimal policy. Moreover, both relative consumption and price tend to deviate further away from their efficient levels due to the wealth redistribution effect. It is precisely in this situation where a spread-adjusted Taylor rule, in which the deposit rate also responds negatively to the interest rate spread, performs much better. The main intuition for this result is that the interest rate spread affects the efficient rate of interest in our model. Therefore, when the central bank reaction function includes the spread term, it helps the real interest rate track the efficient rate of interest better and improve on aggregate outcomes. In addition, a spread-adjusted Taylor rule leads to better distributional outcomes. By lowering the deposit rate, the central bank can (partially) reverse the inefficient wealth redistribution caused by an increase in the spread, and moderate inefficient variations in relative consumption and prices.

\section{Related Literature}

Our paper builds on several strands of the literature. The core of our model is very similar to the prototypical sticky price two-country model of a currency union introduced in an important paper by Benigno (2004), whose main focus is on the characterization of optimal monetary policy when the degree of price stickiness is different across the countries. Benigno (2004) makes a judicious use of parameter value for the intra-termporal elasticity of substitution between domestic and foreign goods to replicate complete markets outcome and thereby, abstracts from imperfect risk-sharing in the currency union. Our paper, while abstracting from cross-country heterogeneity in price stickiness, explores fully the effects on optimal monetary policy of financial frictions that lead to imperfect risksharing, a spread between lending and deposit interest rates, and a wealth redistributive role for monetary policy. While doing so, we provide new results that are complementary to and extend those of Benigno (2004).

Our paper is also clearly related to the growing literature that introduces financial frictions in standard business cycle sticky price models. In particular, in modelling frictions in financial intermediation that lead to interest rate spreads, we use the set-up provided in closed-economy models by Curdia and Woodford $(2009,2010)$. Our analysis of the financial shock and the spreadadjusted Taylor rule is also related to theirs. Our currency-union model however, provides new 
insights into the welfare-theoretic loss-function of the central bank and the policy trade-offs that it confronts. ${ }^{13}$ In particular, the trade-off between stabilizing the relative price gap and relative consumption is new to our set-up.

In addition, we share with Erceg and Linde (2013), Faia (2007), and Gilchrist, Hairault, and Kempf (2002), the goal of introducing financial frictions in sticky price currency union models. They use financial frictions of the type pioneered by Bernanke and Gertler (1989) and specify a Taylor rule to model monetary policy. Our paper introduces frictions in financial intermediation differently and more importantly, studies its implications for the conduct of optimal monetary policy.

Finally, our paper has some common elements with the models of Benigno (2009), De Fiorre, Teles, and Tristani (2011), and De Fiorre and Tristani (2011, 2012). In a two-country model with incomplete markets, Benigno (2009) allows for asymmetric initial wealth positions and studies its implications for welfare loss if the central bank were to pursue a strict inflation stabilization policy. Benigno (2009) also emphasizes the role of monetary policy in generating valuation effects, that is, affecting ex-post real returns on international assets. ${ }^{14}$ In a currency union setting we show that with richer financial frictions, in particular, the presence of an exogenous financial shock and interest rate spread, this wealth redistribution channel leads to a non-trivial optimal monetary policy problem. We also clearly highlight how nominal and financial frictions channel interact to lead to new policy effects and trade-offs.

De Fiorre, Teles, and Tristani (2011) analyze optimal monetary policy in a closed economy flexible price model. In their model, monetary policy has real effects even under flexible prices because firms' financing conditions are not contingent on aggregate shocks and given nominal assets, inflation has an effect on the dynamics of leverage in the economy. One of the main goals of their paper is analyzing how much of a deviation from the Friedman rule is optimal when a financial shock hits the economy. De Fiorre and Tristani $(2011,2012)$ also present a closed-economy model with sticky prices where monetary policy has real effects under flexible prices. They use a costly state verification framework and show that monetary policy affects the cost of external finance even under flexible prices as long as the debt contract is in nominal terms. In such a set up, De Fiorre and Tristani (2011) focus on defining an appropriate natural rate of interest while De Fiorre and Tristani (2012) characterize optimal monetary policy in a simplified version of the model. Compared to these papers, the financial friction we use and the new monetary policy transmission mechanism we highlight is complementary, but different. Moreover our currency union set-up help provide new results such as those related to monetary policy trade-offs and optimal monetary policy response to country-specific productivity shocks and an aggregate financial shock.

\footnotetext{
${ }^{13}$ For recent surveys of the literature regarding optimal monetary policy in standard closed economy models, see Woodford (2010) and in two-country models, see Corsetti, Dedola, and Leduc (2010).

${ }^{14}$ For an influential empirical study of valuation effects in an international context, see Gourinchas and Rey (2007).
} 


\section{Model}

\subsection{Households}

The currency union consists of two countries indexed by $j \in\{s, b\}$ and country $j$ is populated by households of measure $n_{j}{ }^{15}$ The measure of total population is normalized to be one, and thus $n_{s}+n_{b}=1$. Labor markets are segmented across countries: country- $j$ household works for firms in country $j$ only. Firms in country $j$ are indexed by $i \in \mathcal{I}_{j}$, where $\mathcal{I}_{s}=\left[0, n_{s}\right]$ and $\mathcal{I}_{b}=\left(n_{s}, 1\right] .{ }^{16}$

The representative household in country $j$ has expected lifetime utility given by:

$$
E_{0}\left\{\sum_{t=0}^{\infty} \beta^{t}\left[U\left(C_{j, t}\right)-\frac{1}{n_{j}} \int_{\mathcal{I}_{j}} V\left(N_{j, t}(i)\right) d i\right]\right\},
$$

where $\beta$ is the discount factor; $C_{j, t}$ is country- $j$ household's consumption of the final good; and $N_{j, t}(i)$ is her labor supply to firm $i$ in country $j$. We define $U\left(C_{j, t}\right)$ and $V\left(N_{j, t}(i)\right)$ as:

$$
U\left(C_{j, t}\right)=\frac{C_{j, t}^{1-\sigma}-1}{1-\sigma} \text { and } V\left(N_{j, t}(i)\right)=\frac{N_{j, t}(i)^{1+\varphi}}{1+\varphi}
$$

where $\sigma$ is the coefficient of relative risk aversion and $\varphi$ is the inverse of the Frisch elasticity of the labor supply. ${ }^{17}$

The household maximizes expected lifetime utility (1) subject to the flow budget constraint:

$P_{t} C_{j, t}+Q_{t}^{d}\left[B_{j, t}^{P}\right]^{+}+Q_{t}^{b}\left[B_{j, t}^{P}\right]^{-}=B_{j, t-1}^{P}+\frac{1}{n_{j}} \int_{\mathcal{I}_{j}} W_{j, t}(i) N_{j, t}(i) d i+\frac{1}{n_{j}} \int_{\mathcal{I}_{j}} \Pi_{j, t}^{f i r m s}(i) d i+\Pi_{t}^{i n t}+P_{t} T_{j, t}$,

where $P_{t}$ is the price index of the final consumption good; $W_{j, t}(i)$ is the nominal wage rate that the household receives from firm $i \in \mathcal{I}_{j} ; T_{j, t}$ is lump-sum transfers net of taxes from the government in country $j ; B_{j, t}$ is the quantity of one-period, nominal discount bonds purchased (issued) in period $t$ at the price of $Q_{t}^{d}=1 / R_{t}^{d}\left(Q_{t}^{b}=1 / R_{t}^{b}\right)$ and maturing in period $t+1$ which means the household in period $t$ deposits $B_{j, t}^{P}>0$ at the gross deposit rate $R_{t}^{d}$ or borrows $B_{j, t}^{P}<0$ at the gross borrowing rate $R_{t}^{b}$ (the superscript $P$ indicates "private" deposit and borrowing); and

$$
\left[B^{P}\right]^{+} \equiv \max \left(B^{P}, 0\right) \quad \text { and } \quad\left[B^{P}\right]^{-} \equiv \min \left(B^{P}, 0\right)
$$

Households in country $j$ own equal shares of firms that belong to country $j$, and thus collect profits $\Pi_{j, t}^{f i r m s}(i) / n_{j}$ from firm $i$ in each period. Also, the representative household in country $j$ receives dividends $\Pi_{t}^{i n t} / n_{j}$ from financial intermediaries who operate across the countries. The initial wealth distribution is given and summarized as $B_{s,-1}^{P} \geq B_{b,-1}^{P} \cdot{ }^{18}$

\footnotetext{
${ }^{15}$ We use the notation $s$ and $b$ to denote "saver" and "borrower" since as we mentioned before, in our approximated model, one country is always a saver while the other is always a borrower.

${ }^{16}$ Moreover, labor markets are firm-specific within a country, as in Woodford (2003).

${ }^{17}$ Unlike Curdia and Woodford (2009), household utility from consumption $U(C)$ and disutility from working $V(N(i))$ are common between the households of the two countries.

${ }^{18}$ The same property holds in the non-stochastic steady state (i.e. $\bar{B}_{s}^{P} \geq 0 \geq \bar{B}_{b}^{P}$ ). In principle, country $s$ and
} 
The household chooses consumption, bond holding, and labor supply, taking the price level, wage rates, the interest rates, the government transfers net of taxes, and profits as given. The first order conditions with respect to $C_{j, t}$ and $N_{j, t}(i)$, after using (2) give:

$$
C_{j, t}{ }^{\sigma} N_{j, t}(i)^{\varphi}=\frac{W_{j, t}(i)}{P_{t}}
$$

which determines household labor supply for type $i$. Next, the first order conditions with respect to $B_{j, t}$, after using (2), give the consumption Euler equations:

$$
1=\beta R_{t}^{d} E_{t}\left[\left(\frac{C_{j, t+1}}{C_{j, t}}\right)^{-\sigma}\left(\frac{P_{t}}{P_{t+1}}\right)\right]
$$

for $B_{j, t}>0$ and

$$
1=\beta R_{t}^{b} E_{t}\left[\left(\frac{C_{j, t+1}}{C_{j, t}}\right)^{-\sigma}\left(\frac{P_{t}}{P_{t+1}}\right)\right]
$$

for $B_{j, t}<0$.

As can be seen from (3), the model's financial imperfection stems from two sources. First, the currency union does not trade state-contingent securities. The only financial instrument available to hedge income risks over the currency union is the one-period nominal bond. The presence of the noncontingent bond helps two countries smooth their consumption over time by allowing them to borrow from and lend to each other against future incomes, albeit not perfectly. Another important source of financial market imperfection apart from the absence of state-contingent securities is frictions associated with financial intermediation that lead to a spread between $R_{t}^{d}$ and $R_{t}^{b}$. We discuss this next.

\subsection{Financial intermediation}

Employing the modeling strategy of Curdia and Woodford (2009 and 2010), who build on Goodfriend and McCallum (2007), there exist financial intermediaries through which countries trade one-period nominal bonds (or households deposit with the financial intermediaries and borrow from the financial intermediaries). There are an infinitely many identical financial intermediaries of measure 1 that operate union-wide. Moreover, financial intermediation is perfectly competitive. Financial intermediation is however, not efficient in the sense that the borrowers pay a spread above the interest rate received by the lenders.

Financial intermediation uses up real resources in our model, resources that are produced and consumed in the same period in which the loans are made. In particular, loan origination of quantity $b_{t}=B_{t} / P_{t}$ takes up real resources given by the function $\Xi\left(b_{t}\right)$. Here, the function $\Xi\left(b_{t}\right)$ is nondecreasing and (at least weakly) convex in $b_{t}\left(\Xi_{b} \geq 0 ; \Xi_{b b} \geq 0\right)$. This leads to an endogenous

country $b$ can be either a saver or a borrower depending on realizations of economic shocks. However, to the extent that the gap, $\left|\bar{B}_{s}^{P}-\bar{B}_{b}^{P}\right|$, is sufficiently large and/or the magnitude of shocks is sufficiently small, country $s$ and $b$ will always be "saver" and "borrower" respectively in a neighborhood around the steady state over the business cycle. 
movement in the interest rate spread as aggregate debt evolves in the economy. In addition, we assume that $\Xi(\bar{b})=0$ and $\Xi_{b}(\bar{b})=0$, which implies both that no real resources are lost in steady state and that variation in resource loss are at most second order. ${ }^{19}$

We also allow for exogenous variation in the interest rate spread following Curdia and Woodford (2009 and 2010). We model this by assuming that in order to originate a quantity of loans $b_{t}$ that will be repaid in the following period, it is necessary for an intermediary to also make a quantity $\chi_{t} b_{t}$ of loans that will not be repaid. Here, the loss rate $\chi_{t}$ is an exogenously varying nonnegative quantity, which constitutes an aggregate purely financial shock in our model. For simplicity, we treat these opportunities for fraud as being distributed equally across all households, who take advantage of such opportunities to the extent that they come up. Moreover, these earnings from fraud are treated as lump-sum income by those households and in addition, are independent of the quantity of repayable loans that the same household may take out. Financial intermediaries are unable to distinguish the borrowers who will default from those who will repay, and so must offer loans to both on the same terms. At the same time however, they are able to accurately predict the fraction of loans that will not be repaid as a function of a given scale of their lending activity.

Financial intermediaries collect the largest amount of deposits that can be repaid from the proceeds of loans that they originate. Then, for aggregate deposits $D_{t}$ and aggregate borrowing $B_{t}$, the condition $D_{t}=B_{t}$ or

$$
d_{t}=b_{t}
$$

holds where $d_{t}=D_{t} / P_{t}$ and $b_{t}=B_{t} / P_{t}$. Note that (7) also serves as the clearing condition for borrowing and lending across countries.

To see how the credit spread, $\omega_{t} \equiv \frac{Q_{t}^{d}}{Q_{t}^{b}}=\frac{R_{t}^{b}}{R_{t}^{d}}$, is determined in equilibrium, we consider the financial intermediaries' problem. Given perfect competition, the intermediaries takes $Q_{t}^{d}$ and $Q_{t}^{b}$ as given and choose $b_{t}$ to maximize their profits, $\frac{\tilde{\Pi}_{t}^{i n t}}{P_{t}}$ :

$$
\frac{\tilde{\Pi}_{t}^{i n t}}{P_{t}}=Q_{t}^{d} d_{t}-Q_{t}^{b} b_{t}-Q_{t}^{b} \chi_{t} b_{t}-\Xi\left(b_{t}\right)=\left(Q_{t}^{d}-Q_{t}^{b}\right) b_{t}-Q_{t}^{b} \chi_{t} b_{t}-\Xi\left(b_{t}\right) .
$$

Since $\Xi\left(b_{t}\right)$ is (weakly) convex, the first-order condition then gives that the equilibrium credit spread is implicitly determined as a function of a quantity of borrowing $b_{t}$ as:

$$
Q_{t}^{d}=\left(1+\chi_{t}\right) Q_{t}^{b}+\Xi_{b}\left(b_{t}\right)
$$

This equation has the usual interpretation: competitive, profit maximizing financial intermediaries continue to originate loans until marginal revenue from increased origination is equal to marginal cost. The actual distribution to households $\Pi_{t}^{i n t}$ in the budget constraint (3) includes their earnings from fraud and thus:

$$
\frac{\Pi_{t}^{i n t}}{P_{t}}=\frac{\tilde{\Pi}_{t}^{i n t}}{P_{t}}+Q_{t}^{b} \chi_{t} b_{t}=\left(Q_{t}^{d}-Q_{t}^{b}\right) b_{t}-\Xi\left(b_{t}\right) .
$$

Note that the net credit spread $\left(1-\omega_{t}\right)$ is not zero in general in the small neighborhood of the steady

\footnotetext{
${ }^{19}$ For any variable $Z_{t}$, we let $\bar{Z}$ be the steady state level.
} 
state (in the presence of shocks) though, as we emphasize later, we assume that it is zero in the steady state $\left(\bar{\chi}=0\right.$ and $\left.\bar{Q}^{d}=\bar{Q}^{b}\right)$.

\section{$2.3 \quad$ Firms}

The final consumption good $Y_{t}$ is a CES aggregate of two intermediate goods, $Y_{s, t}$ and $Y_{b, t}$, produced in each country $Y_{t}=\left(\sum_{j} n_{j}^{\frac{1}{\eta}} Y_{j, t}^{\frac{\eta-1}{\eta}}\right)^{\frac{\eta}{\eta-1}}$, where $\eta$ is the elasticity of substitution between the two goods. The final consumption good is used as a numeraire and $Y_{s, t}$ and $Y_{b, t}$ have measure $n_{s}$ and $n_{b}$ respectively. The appropriate price index is found as the minimum value that should be paid for one unit of the consumption good and is given by $P_{t}=\left(\sum_{j} n_{j} P_{j, t}^{1-\eta}\right)^{\frac{1}{1-\eta}}$. Given the demand for the final consumption good $Y_{t}$ and the price levels $P_{j, t}$ for $j \in\{s, b\}$ and $P_{t}$, the optimal demand for the intermediate goods $Y_{j, t}$ is the one that minimizes total expenditure, which is obtained as: $Y_{j, t}=n_{j}\left(\frac{P_{j, t}}{P_{t}}\right)^{-\eta} Y_{t}$.

An intermediate good $Y_{j, t}$ produced by country $j$ is in turn a CES aggregate of a continuum of individual goods $\left\{Y_{j, t}(i)\right\}_{i \in \mathcal{I}_{j}}$ that are produced by the firms in country $j$. We have that $Y_{j, t}=$ $\left[\left(\frac{1}{n_{j}}\right)^{\frac{1}{\theta}} \int_{\mathcal{I}_{j}} Y_{j, t}(i)^{\frac{\theta-1}{\theta}} d i\right]^{\frac{\theta}{\theta-1}}$, with the corresponding price index $P_{j, t}=\left[\frac{1}{n_{j}} \int_{\mathcal{I}_{j}} P_{j, t}(i)^{1-\theta} d i\right]^{\frac{1}{1-\theta}}$. The optimal demand for $Y_{j, t}(i)$ is given by $Y_{j, t}(i)=\frac{1}{n_{j}}\left(\frac{P_{j, t}(i)}{P_{j, t}}\right)^{-\theta} Y_{j, t}, \quad \forall i \in \mathcal{I}_{j}$. Combining the expressions for $Y_{j, t}$ and $Y_{j, t}(i)$, we obtain a consolidated demand function that each individual firm $i$ of country $j$ faces:

$$
Y_{j, t}(i)=\left(\frac{P_{j, t}(i)}{P_{j, t}}\right)^{-\theta}\left(\frac{P_{j, t}}{P_{t}}\right)^{-\eta} Y_{t}, \quad \forall i \in \mathcal{I}_{j} .
$$

Firm $i$ in each country is a monopolistically competitive producer and produces a differentiated good $Y_{j, t}(i)$ using a constant returns to scale technology:

$$
Y_{j, t}(i)=A_{t} A_{j, t} N_{j, t}(i)
$$

for $i \in \mathcal{I}_{j}$ and $j=\{s, b\}$, where $A_{t}$ and $A_{j, t}$ are union-wide and country-specific productivity shocks respectively

We model nominal rigidity following Calvo (1983). Firms in the union adjust their prices with probability $1-\alpha$ each period. A firm that re-optimizes at time $t$ chooses $P_{j, t}^{*}(i)$ to maximize its expected discounted profit:

$$
\max _{P_{j, t}^{*}(i)} E_{t} \sum_{k=0}^{\infty} \alpha^{k} Q_{j, t, t+k} \Pi_{j, t+k}^{f i r m s}\left(P_{j, t}^{*}(i) ; P_{j, t+k}, P_{t+k}, W_{j, t+k}(i), Y_{t+k}, A_{t+k}, A_{j, t+k}\right),
$$

where

$$
Q_{j, t, t+k}=\beta^{k}\left(\frac{C_{j, t+k}}{C_{j, t}}\right)^{-\sigma}\left(\frac{P_{t}}{P_{t+k}}\right)
$$


and

$$
\begin{aligned}
& \Pi_{j, t+k}^{f i r m s}\left(P_{j, t}^{*}(i) ; P_{j, t+k}, P_{t+k}, W_{j, t+k}(i), Y_{t+k}, A_{t+k}, A_{j, t+k}\right) \\
& =(1-\tau) P_{j, t}^{*}(i) Y_{j, t+k}(i)-W_{j, t+k}(i)\left(\frac{Y_{j, t+k}(i)}{A_{t+k} A_{j, t+k}}\right) \\
& =(1-\tau) P_{j, t}^{*}(i)\left(\frac{P_{j, t}^{*}(i)}{P_{j, t+k}}\right)^{-\theta}\left(\frac{P_{j, t+k}}{P_{t+k}}\right)^{-\eta} Y_{t+k}-\frac{W_{j, t+k}(i)}{A_{t+k} A_{j, t+k}}\left(\frac{P_{j, t}^{*}(i)}{P_{j, t+k}}\right)^{-\theta}\left(\frac{P_{j, t+k}}{P_{t+k}}\right)^{-\eta} Y_{t+k} .
\end{aligned}
$$

Note that the nominal marginal cost for firm $i$ is $W_{j, t}(i) / A_{t} A_{j, t}$. Since firms have a positive markup $\left(\frac{\theta}{\theta-1}\right)$, their output would be lower than the efficient level. In this paper, we abstract from this inefficiency originating from imperfect competition in steady-state, by letting $\tau$, a proportional tax on sales of goods, to satisfy the condition $(1-\tau)\left(\frac{\theta}{\theta-1}\right)=1$. The first-order condition that determines price setting is then given by:

$$
E_{t} \sum_{k=0}^{\infty} \alpha^{k} Q_{j, t, t+k}\left(\frac{P_{j, t}^{*}(i)}{P_{j, t+k}}\right)^{-\theta}\left(\frac{P_{j, t+k}}{P_{t+k}}\right)^{-\eta} Y_{t+k}\left[\frac{P_{j, t}^{*}(i)}{P_{t+k}}-\frac{W_{j, t+k}(i)}{P_{t+k} A_{j, t+k} A_{t+k}}\right]=0 .
$$

We focus on a symmetric equilibrium where firms that re-optimize at the same time within a country choose a common price in equilibrium: $P_{j, t}^{*}(i)=P_{j, t}^{*}$. Thus, the price level in country $j$ evolves according to:

$$
P_{j, t}=\left[(1-\alpha) P_{j, t}^{* 1-\theta}+\alpha P_{j, t-1}^{1-\theta}\right]^{\frac{1}{1-\theta}} .
$$

(10) and (11), together with the price index $P_{t}=\left(\sum_{j} n_{j} P_{j, t}^{1-\eta}\right)^{\frac{1}{1-\eta}}$, determine the dynamics of the price level for the union.

\subsection{Government}

The government budget constraint is:

$$
P_{t} G_{j, t}+Q_{t}^{d}\left[B_{j, t}^{G}\right]^{+}+Q_{t}^{b}\left[B_{j, t}^{G}\right]^{-}=B_{j, t-1}^{G}-P_{t} T_{j, t}+\tau \frac{1}{n_{j}} \int_{\mathcal{I}_{j}} P_{j, t}(i) Y_{j, t}(i) d i+P_{t} T R_{j}
$$

where $B_{j, t}^{G}$ denotes the net asset position of the government in country $j$. Note that government debt is then given by $-B_{j, t}^{G}$. There are two potential sources of changes in government revenue in our model: variations in lump-sum transfers $T_{j, t}$ and variations in sales tax revenues. In addition, the government receives (or gives) non-state-contingent and non-time-varying international transfers from (to) other countries $T R_{j}$ (with $\sum_{j} n_{j} T R_{j}=0$ ). While the presence of the international transfer is not critical to the results, it simplifies our analysis by allowing a symmetric steady state value of consumption across countries, as we will discuss in detail later.

We will assume that initial distribution of wealth across the governments, $\left\{B_{s,-1}^{G}, B_{b,-1}^{G}\right\}$, satisfies the following property: if $B_{s,-1}^{P} \geq B_{b,-1}^{P}$, then $B_{s,-1}^{G} \geq B_{b,-1}^{G}$. This simplifying assumption makes the model tractable: if the representative household in a given country is initially in debt, so is its 
government (and hence the county as a whole). We also assume that government spending $G_{j, t}$ is 0 throughout the paper.

\subsection{Market clearing}

The financial market clearing condition is given by (7), where $d_{t}=D_{t} / P_{t}$ and $b_{t}=B_{t} / P_{t}$ and

$$
\begin{aligned}
D_{t} & =\max \left\{n_{s} B_{s, t}^{P}+n_{s} B_{s, t}^{G}, n_{b} B_{b, t}^{P}+n_{b} B_{b, t}^{G}, n_{s} B_{s, t}^{P}+n_{b} B_{b, t}^{G}, n_{b} B_{b, t}^{P}+n_{s} B_{s, t}^{G}\right\}, \\
B_{t} & =-\min \left\{n_{s} B_{s, t}^{P}+n_{s} B_{s, t}^{G}, n_{b} B_{b, t}^{P}+n_{b} B_{b, t}^{G}, n_{s} B_{s, t}^{P}+n_{b} B_{b, t}^{G}, n_{b} B_{b, t}^{P}+n_{s} B_{s, t}^{G}\right\} .
\end{aligned}
$$

Note that $D_{t}, B_{t} \geq 0$.

The goods market clearing condition is obtained by aggregating the household and government budget constraints, (3) and (12):

$$
n_{s} C_{s, t}+n_{b} C_{b, t}+\Xi\left(b_{t}\right)=Y_{t},
$$

which is also the union-wide resource constraint.

\subsection{Equilibrium}

We now characterize the private-sector equilibrium of our model. Before analyzing equilibrium in the decentralized economy with nominal and financial frictions, we first establish a useful benchmark: the efficient (first-best) allocation. It is useful to establish the efficient outcome for two main reasons: first, we will be approximating our model around an efficient steady-state and second, we will show that the quadratic, welfare-theoretic loss function of the union-wide central bank can be written as a deviation of equilibrium from the efficient allocation.

\subsubsection{Efficient allocation}

As usual, the union's efficient allocation can be described as the solution to a social planner's problem:

$$
\max \left\{\sum_{j} n_{j} \varpi_{j}\left[\frac{C_{j, t}^{1-\sigma}-1}{1-\sigma}-\frac{1}{n_{j}}\left(\frac{1}{A_{t} A_{j, t}}\right)^{1+\varphi} \int_{\mathcal{I}_{j}} \frac{Y_{j, t}(i)^{1+\varphi}}{1+\varphi} d i\right]\right\}
$$

subject to the technological and resource constraints:

$$
n_{s} C_{s, t}+n_{b} C_{b, t}=\left\{\sum_{j} n_{j}^{\frac{1}{\eta}}\left(\left[\left(\frac{1}{n_{j}}\right)^{\frac{1}{\theta}} \int_{\mathcal{I}_{j}} Y_{j, t}(i)^{\frac{\theta-1}{\theta}} d i\right]^{\frac{\theta}{\theta-1}}\right)^{\frac{\eta-1}{\eta}}\right\}^{\frac{\eta}{\eta-1}}
$$

Note that the objective function already embeds the production technology of intermediate good producing firms and $\left\{\varpi_{j}\right\}$ denotes Pareto weights. 
First order conditions with respect to $C_{j, t}$ and $Y_{j, t}(i)$ are:

$$
\begin{aligned}
\varpi_{j} C_{j, t}^{-\sigma} & =z \text { and } \\
\varpi_{j}\left(\frac{1}{A_{t} A_{j, t}}\right)^{1+\varphi} Y_{j, t}(i)^{\varphi} & =z Y_{t}^{\frac{1}{\eta}} n_{j}^{\frac{1}{\eta}}\left(\left[\left(\frac{1}{n_{j}}\right)^{\frac{1}{\theta}} \int_{\mathcal{I}_{j}} Y_{j, t}(i)^{\frac{\theta-1}{\theta}} d i\right]^{\frac{\theta}{\theta-1}}\right)^{-\frac{1}{\eta}} \\
& \times\left[\left(\frac{1}{n_{j}}\right)^{\frac{1}{\theta}} \int_{\mathcal{I}_{j}} Y_{j, t}(i)^{\frac{\theta-1}{\theta}} d i\right]^{\frac{1}{\theta-1}}\left(\frac{1}{n_{j}}\right)^{\frac{1}{\theta}} Y_{j, t}(i)^{\frac{-1}{\theta}},
\end{aligned}
$$

respectively, where $z$ is a Lagrange multiplier. Note that the second equation implies that $Y_{j, t}(i)$ should have a common value. Furthermore, it is easy to show that $Y_{j, t}(i)=n_{j}^{-1} Y_{j, t}$. Simplifying the first order conditions yields the efficient allocations in consumption and production across countries: $C_{t}^{R, E}=\frac{C_{s, t}^{E}}{C_{b, t}^{E}}=\left(\frac{\varpi_{s}}{\varpi_{b}}\right)^{\sigma}$ and $Y_{t}^{R, E}=\frac{Y_{s, t}^{E}}{Y_{b, t}^{E}}=\left(\frac{n_{s}}{n_{b}}\right)\left(\frac{\varpi_{s}}{\varpi_{b}}\right)^{-\frac{\eta}{1+\eta \varphi}}\left(\frac{A_{s, t}}{A_{b, t}}\right)^{\frac{\eta(1+\varphi)}{1+\eta \varphi}} \cdot{ }^{20}$

We can see that the first best allocations depend on how a social planner values each household and thus, they are not unique. In other words, there is a continuum of efficient allocations, each of which is a function of Pareto weights $\left(\varpi_{s}, \varpi_{b}\right)$, which are arbitrary. An important case arises when a social planner is a utilitarian $\left(\varpi_{s}=\varpi_{b}\right)$. The efficient level of aggregate output is then obtained as: $Y_{t}^{E}=\left[\sum_{j} n_{j} A_{j, t}^{\frac{(\eta-1)(1+\varphi)}{1+\eta \varphi}} A_{t}^{\frac{(\eta-1)(1+\varphi)}{1+\eta \varphi}}\right]^{\frac{1+\eta \varphi}{(\eta-1)(\sigma+\varphi)}}$. While it is not necessary for our results, we will focus on this case for simplicity. In particular, the market outcome (with no frictions) and the steady-state equilibrium (with and without frictions) will coincide with the solution to a utilitarian social planner's problem. Moreover, we will later assume a utilitarian central bank that maximizes the representative household's utility with equal weight across countries.

\subsubsection{Approximate equilibrium}

We solve the model by log-linearizing the private-sector equilibrium conditions around a deterministic, symmetric, efficient, and zero-inflation steady state. ${ }^{21}$ In particular, in the steady-state, we allow for a proportional sales tax to remove the monopolistic distortion and a lump-sum transfer to ensure that steady-state consumption is the same across countries, even though the countries start with different net asset positions. Moreover, in the first-order approximation of our model, one country is always a borrower while the other is a saver. This is so because in steady state, one country will have positive wealth while the other will have negative. For small enough shocks then, in a first-order approximation, the financial position of the countries will fluctuate around these steady state values without changing whether the country is a borrower or a saver.

We provide a detailed derivation of the steady state equilibrium as well as the full system of log-

\footnotetext{
${ }^{20}$ For any variable $Z_{t}$, we let $Z_{t}^{E}$ be the level when the allocation is efficient. Moreover, throughout the paper, it is convenient to use $Z_{t}^{R}$ ( $R$ stands for "Relative") that denotes $Z_{t}^{R} \equiv \frac{Z_{s, t}}{Z_{b, t}}$, which represents the ratio of a given variable between two countries.

${ }^{21}$ These private-sector equilibrium conditions hold for any monetary policy. Given a description of monetary policy, these conditions then fully characterize the model dynamics.
} 
linear equations in the appendix. ${ }^{22}$ Here we present a simplified system that contains the equations required to characterize optimal monetary policy:

$$
\begin{gathered}
\pi_{t}=\beta E_{t} \pi_{t+1}+\kappa\left(\hat{Y}_{t}-\hat{Y}_{t}^{E}\right) \\
\left(\hat{P}_{t}^{R}-\hat{P}_{t}^{R, E}\right)=\gamma\left(\hat{P}_{t-1}^{R}-\hat{P}_{t-1}^{R, E}\right)+\gamma \beta E_{t}\left[\hat{P}_{t+1}^{R}-\hat{P}_{t+1}^{R, E}\right]+\kappa_{C} \hat{C}_{t}^{R}+\mu_{t} \\
\left(\hat{Y}_{t}-\hat{Y}_{t}^{E}\right)=E_{t}\left(\hat{Y}_{t+1}-\hat{Y}_{t+1}^{E}\right)-\frac{1}{\sigma}\left\{\hat{R}_{t}^{d}-E_{t} \pi_{t+1}-r_{t}^{E}\right\} \\
\hat{C}_{t}^{R}=E_{t} \hat{C}_{t+1}^{R}+\frac{1}{\sigma} \hat{\omega}_{t}, \\
\hat{b}_{t}=\beta^{-1} \hat{b}_{t-1}+\lambda^{B} \hat{R}_{t}^{d}-\beta^{-1} \lambda^{B} \hat{\pi}_{t}-\beta^{-1} n_{s} n_{b}(\eta-1)\left(\hat{P}_{t}^{R}-\hat{P}_{t}^{R, E}\right)-\beta^{-1} n_{s} n_{b} \hat{C}_{t}^{R} \\
+\left(1-n_{b}\right) \lambda^{B} \hat{\omega}_{t}-\beta^{-1} n_{s} n_{b}(\eta-1) \hat{P}_{t}^{R, E}, \text { and } \\
\hat{\omega}_{t} \equiv \hat{R}_{t}^{b}-\hat{R}_{t}^{d}=\hat{\chi}_{t}+\eta_{B} \hat{b}_{t}
\end{gathered}
$$

where $\kappa \equiv \frac{(1-\alpha)(1-\alpha \beta)}{\alpha} \frac{\sigma+\varphi}{1+\theta \varphi}, \gamma \equiv \frac{1}{\left(1+\beta+\kappa\left(\frac{1+\eta \varphi}{\sigma+\varphi}\right)\right)}, \kappa_{C} \equiv \kappa\left(\frac{\sigma}{\sigma+\varphi}\right) \gamma, \lambda^{B} \equiv \frac{\bar{b}}{\bar{Y}}, \eta_{B}=\beta^{-1} \bar{\Xi}_{b b}, \mu_{t}$ is a linear combination of exogenous shocks $\mu_{t} \equiv \gamma\left(\beta E_{t} \hat{P}_{t+1}^{R, E}-(1+\beta) \hat{P}_{t}^{R, E}+\hat{P}_{t-1}^{R, E}\right)$, and the efficient level of output, relative prices, and the real interest rate are given by $\hat{Y}_{t}^{E}=\frac{1+\varphi}{\sigma+\varphi}\left(n_{s} \hat{A}_{s, t}+n_{b} \hat{A}_{b, t}+\hat{A}_{t}\right)$, $\hat{P}_{t}^{R, E}=-\frac{1+\varphi}{1+\eta \varphi}\left(\hat{A}_{s, t}-\hat{A}_{b, t}\right)$, and $r_{t}^{E}=\left[\sigma\left(E_{t} \hat{Y}_{t+1}^{E}-\hat{Y}_{t}^{E}\right)-n_{b} \hat{\omega}_{t}\right]$ respectively. ${ }^{23}$ Note that unlike standard sticky-price models without financial frictions, the efficient rate of real interest $r_{t}^{E}$ in our model is generally endogenous as it depends on the interest rate spread $\hat{\omega}_{t}$. All the exogenous shocks in the model are assumed to follow $\mathrm{AR}(1)$ processes.

(14) is the aggregate Phillips curve that is obtained by summing up the two country-specific Phillips curves. It shows how aggregate inflation $\pi_{t}$ depends critically on the aggregate output gap $\hat{Y}_{t}-\hat{Y}_{t}^{E}$ and expectations of future aggregate inflation. (15) is obtained by subtracting the Phillips curve of country $b$ from that of country $s$. It shows how the relative price gap $\hat{P}_{t}^{R}-\hat{P}_{t}^{R, E}$ (i.e. the deviation of relative prices from its efficient level) depends on relative consumption $\hat{C}_{t}^{R}$ and past and expected future values of the price gap. Just like an increase in output gap leads to an increase in inflation in the Phillips curve given by (14), (15) shows that an increase in relative consumption leads to an increase in relative price gap. The intuition is also analogous. In a traditional Phillips curve like (14), an increase in the output gap captures an increase in the economy's average marginal cost,

\footnotetext{
${ }^{22}$ For $\chi_{t}$, we define their deviation from a steady state as $\hat{\chi}_{t}=\log \left(1+\chi_{t}\right)-\log (1+\bar{\chi})=\log \left(1+\chi_{t}\right)$. For those variables that are lending or borrowing $\left(b_{j, t}^{P}, b_{j, t}, d_{t}, b_{t}\right)$, we define their deviation from a steady state relative to the steady state level of output. For example, $\hat{b}_{t}=\frac{b_{t}-\bar{b}}{\bar{Y}}$. For a variable $Z_{t}$ other than these variables, we let $\hat{Z}_{t}$ denote percentage deviation of $Z_{t}$ from its steady state: $\hat{Z}_{t} \equiv \log Z_{t}-\log \bar{Z}$. Accordingly, in the log-linear approximation, $\hat{Z}_{t}^{R} \equiv \log \frac{Z_{s, t}}{Z_{b, t}}-\log \frac{\bar{Z}_{s}}{Z_{b}}=\hat{Z}_{s, t}-\hat{Z}_{b, t}$. For example, $C_{t}^{R}$ represents the consumption ratio between two countries and $P_{t}^{R}$ stands for the relative price between two countries: it is the terms of trade for country $s$ and the inverse of the terms of trade for country $b$.

${ }^{23}$ The efficient rate of real interest $r_{t}^{E}$ is the one that would prevail if output was at its efficient level. Similarly $P_{t}^{R, E}$ is the relative price that would prevail if relative output was at its efficient level.
} 
which leads to an increase in the price level. In (15), an increase in relative consumption reflects an increase in relative marginal cost (through income effects), which in turn leads to an increase in relative price.

These two equations constitute the supply bloc and clearly highlight the trade-offs that the central bank faces in our model. First, note that from (14) it is clear that the central bank does not face a trade-off in stabilizing aggregate inflation versus the aggregate output gap as there are no random disturbance terms or other endogenous terms in the equation. This is because of the absence of mark-up shocks and heterogeneity in price stickiness across countries. Second, note from (15) that the central bank faces a novel trade-off in stabilizing relative consumption versus the relative price gap as simultaneous stabilization of $\hat{P}_{t}^{R}-\hat{P}_{t}^{R, E}$ and $\hat{C}_{t}^{R}$ is not feasible with idiosyncratic technology shocks, which lead to a movement in $\mu_{t}$. We will show that this new policy trade-off has an important implication for optimal monetary policy.

(16) is the aggregate Euler equation that is obtained by summing up the two country-specific household Euler equations. It shows how the aggregate output gap depends critically on the real interest rate gap $\hat{R}_{t}^{d}-E_{t} \pi_{t+1}-r_{t}^{E}$ (i.e. the deviation of the ex-ante real interest rate from its efficient level) and expectations of future output gap. (17) is obtained by subtracting the two country-specific household Euler equations and shows how relative consumption depends on the interest rate spread and expectations of future relative consumption.

These two equations constitute the demand bloc and clearly highlight the role of financial frictions, in particular of the interest rate spread, in driving aggregate dynamics of the model. First, note from (16) that a positive movement in $\hat{\omega}_{t}$ decreases the efficient level of the real interest rate, which increases the real interest rate gap, and thereby, decreases the output gap. Second, note from (17) that a positive movement in $\hat{\omega}_{t}$ leads to an increase in relative consumption, as the increase in interest rate spread hurts the borrower country by increasing the cost of borrowing.

Finally, (18) and (19) close the private-sector equilibrium part of the model by specifying how the interest rate spread is determined in equilibrium. (19) shows that the interest rate spread can move both for a purely exogenous (due to $\hat{\chi}_{t}$ which constitutes a financial shock in our model) and an endogenous (due to its dependence on aggregate debt $\hat{b}_{t}$ in the economy) reason. (18) tracks the evolution of aggregate debt and is obtained by integrating the two country-specific household and government budget constraints and imposing bond market clearing. Since in our model country $b$ is always a borrower over the business cycle, aggregate debt is proportional to the sum of private and public (net) debt in country $b$. (18) shows that variations in economic variables have expected effects on the evolution of debt. First, unless net asset positions are symmetric ex-ante and in steady-state $\left(\lambda^{B}=0\right)$ and hence no country is in debt initially, an increase in the interest rate $\hat{R}_{t}^{d}$ and/or the spread $\hat{\omega}_{t}$ has a first-order effect on debt dynamics as the borrower country has to make a higher interest payment. ${ }^{24}$ In addition, inflation lowers the real value of debt as the debt is in nominal terms. Second, an increase in the relative price implies a decrease in relative production (i.e. country $b$ produces more relative to country $s$ ), which in turn decreases the amount of debt.

\footnotetext{
${ }^{24}$ Note that the term $n_{b} \lambda^{B} \hat{\omega}_{t}$ captures dividends from financial intermediaries, which decreases the amount of debt. However, the net effect of $\hat{\omega}_{t}$ on debt is still positive as indicated by the coefficient $\left(1-n_{b}\right) \lambda^{B}$.
} 
Finally, a decrease in relative consumption (i.e. country $b$ consumes more relative to country $s$ ) leads to an increase in debt as the borrower country, ceteris paribus, would have to borrow more to finance its consumption.

\section{Monetary policy transmission mechanisms}

Before moving on to analyzing optimal monetary policy, we first discuss the various channels through which monetary policy affects real variables in our model. There are two channels of monetary policy transmission mechanism in our set-up: a wealth redistribution channel and an aggregate demand channel. The first arises due to financial imperfections, in particular due to market incompleteness coupled with the asymmetry in ex-ante wealth positions across the two countries. The second arises due to the usual and well-understood nominal rigidities friction. Since the wealth redistribution channel is new to our paper, we discuss that first. In particular, since it is independent of sticky prices, we discuss it in a special case of our model where prices are completely flexible.

\subsection{Financial imperfections and the wealth redistribution channel}

Consider the flexible-price equilibrium of our model which can be found by taking the limit $\kappa \rightarrow \infty$ in (14)-(19). ${ }^{25}$ This will change only the first two of the equilibrium conditions while the rest, (16)-(19), are unchanged. First, (15) simplifies to:

$$
\hat{P}_{t}^{R, F}-\hat{P}_{t}^{R, E}=\left(\frac{\sigma}{1+\eta \varphi}\right) \hat{C}_{t}^{R, F}
$$

which indicates that, in contrast to the general case considered above, there would be no trade-off in stabilizing relative consumption versus the relative price gap in the flexible-price limit. Second, it can be seen from (14) that $\hat{Y}_{t}^{F}=\hat{Y}_{t}^{E}$. Thus, as in standard New Keynesian models, monetary policy does not affect aggregate output under flexible prices. Moreover, there is no inefficiency at the aggregate level, which reflects our assumption that resource cost of financial intermediation is second-order.

While monetary policy is neutral for aggregate output under flexible price, it nevertheless still has real effects since it can affect cross-country variables through wealth redistribution as can be see in (18). In particular, since $\lambda^{B} \neq 0$ given the ex-ante heterogeneity in wealth positions across countries, a change in the nominal interest rate and/or inflation will redistribute wealth from one country to another as the asset traded across countries is a nominal bond. This will then affect the dynamics of $\hat{b}_{t}^{F}$ and thereby, $\hat{C}_{t}^{R, F}$ and $\hat{P}_{t}^{R, F}$. For example, the central bank's lowering of the deposit interest rate (or increasing of inflation) will redistribute wealth from the saver country to the borrower country and decrease $\hat{b}_{t}^{F}$, which in turn decreases $\hat{C}_{t}^{R, F}$ and $\hat{P}_{t}^{R, F}$. Note that for this channel to be at work, while $\lambda^{B} \neq 0$ is necessary, $\eta_{B} \neq 0$ is not. The critical requirement for wealth redistribution is therefore incomplete markets along with initial heterogeneity in wealth. In the case

\footnotetext{
${ }^{25}$ For any variable $Z_{t}$, we let $\hat{Z}_{t}^{F}$ be the first-order approximation of $Z_{t}$ under flexible prices.
} 
where $\hat{\omega}_{t}^{F}$ is endogenous due to $\eta_{B} \neq 0$, however, the effects on $\hat{C}_{t}^{R, F}$ and $\hat{P}_{t}^{R, F}$ of changes in the deposit rate get magnified. This is because a decrease in $\hat{b}_{t}^{F}$ leads to a decrease in the spread $\hat{\omega}_{t}^{F}$, which means that the cost of borrowing decreases by more now compared to the case where $\eta_{B}=0$.

\subsection{Nominal frictions and the aggregate demand channel}

Next, consider the second transmission mechanism of monetary policy in our model, which arises due to nominal rigidities. Under sticky prices, as is standard, monetary policy affects aggregate variables, in particular aggregate output, in our model. To separate out this aggregate transmission mechanism from the wealth redistribution channel considered above under flexible prices, consider a special case of sticky prices but no initial heterogeneity in wealth $\left(\lambda^{B}=0\right)$. This effectively eliminates the redistributive role of monetary policy that arises due to financial imperfections, even though asset markets are still incomplete and there exists an interest rate spread. In this case, from (14)-(19), we see that the following system determines $\left\{\hat{C}_{t}^{R}, \hat{P}_{t}^{R}, b_{t}\right\}$ as a function of $\hat{\chi}_{t}$ and $\hat{P}_{t}^{R, E}$ only:

$$
\begin{aligned}
\hat{P}_{t}^{R} & =\gamma \hat{P}_{t-1}^{R}+\gamma \beta E_{t}\left[\hat{P}_{t+1}^{R}\right]+\kappa_{C} \hat{C}_{t}^{R}+(1-\gamma(1+\beta)) \hat{P}_{t}^{R, E}, \\
\hat{C}_{t}^{R} & =E_{t}\left[\hat{C}_{t+1}^{R}\right]+\frac{1}{\sigma}\left(\hat{\chi}_{t}+\eta_{B} \hat{b}_{t}\right), \text { and } \\
\hat{b}_{t} & =\beta^{-1} \hat{b}_{t-1}-\beta^{-1} n_{s} n_{b}(\eta-1) \hat{P}_{t}^{R}-\beta^{-1} n_{s} n_{b} \hat{C}_{t}^{R} .
\end{aligned}
$$

The cross-country distributions of quantities and prices $\left\{\hat{C}_{t}^{R}, \hat{P}_{t}^{R}, b_{t}\right\}$ are completely independent of aggregate variables and therefore, of monetary policy. Nevertheless monetary policy still affects aggregate output. This transmission mechanism is captured by (16) which shows how by affecting the ex-ante real interest rate $\hat{R}_{t}^{d}-E_{t} \pi_{t+1}$, the central bank can affect the aggregate output gap. Under sticky prices (and unlike the case above with flexible prices), monetary policy can affect $\hat{R}_{t}^{d}-E_{t} \pi_{t+1}$ because $E_{t} \pi_{t+1}$ is endogenously determined in the model as shown by (14).

\subsection{Interactions of the two channels}

In general, with both nominal and financial imperfections, these two transmission mechanisms interact and there are non-trivial interactions between aggregate dynamics, monetary policy, and cross-country distribution of prices and quantities in our model. In particular, the two mechanisms reinforce each other in a way such that monetary policy has a bigger and more persistent effect on aggregate output and cross-country variables. For example, consider an expansionary monetary policy shock. With respect to the effect on aggregate output, the wealth redistribution channel reinforces the aggregate demand channel by decreasing the amount of debt. A decrease in debt lowers the interest rate spread, which in turn plays a role of a positive aggregate demand shock and thereby increases aggregate output even further. Moreover, since the dynamics of debt is persistent, even if a monetary policy shock is purely transitory, it can affect aggregate output in a persistent manner. Finally, the interaction also implies that the dynamics of relative prices and consumption also become more persistent. This is primarily because the two frictions independently introduce addi- 
tional state variables in the model, thereby generating endogenous persistence. In particular, sticky prices introduce relative prices, while financial imperfections introduce debt as an endogenous state variable. ${ }^{26}$ Under sticky prices, inflation is also naturally persistent, which further imparts complex dynamics. As a simple illustration of these interaction effects, we show the impulse responses to an expansionary monetary policy shock in the appendix in Figure 10. In particular, to highlight how such interactions increase aggregate persistence, we posit a simple Taylor rule with no interest rate smoothing term and with i.i.d. shocks. ${ }^{27}$

In addition, this interaction of the two transmission mechanisms gives rise to a novel trade-off in our model for the central bank in stabilizing relative consumption versus the relative price gap, as given by (15). Without both these mechanisms at work this policy trade-off would not exist: if we shut down the wealth redistribution channel by setting $\lambda^{B}=0$, then relative consumption and the relative price gap would evolve independently of monetary policy, thereby precluding any role of policy; while if we shut down the aggregate demand channel by assuming no nominal rigidities $(\kappa=\infty)$, then since $\hat{P}_{t}^{R, F}-\hat{P}_{t}^{R, E}=\left(\frac{\sigma}{1+\eta \varphi}\right) \hat{C}_{t}^{R, F}$, the central bank would not face a trade-off between stabilizing $\hat{C}_{t}^{R, F}$ versus $\hat{P}_{t}^{R, F}-\hat{P}_{t}^{R, E}$.

The fact that the interaction of two channels allows the central bank to influence forcefully both aggregate dynamics and the cross-country distribution and that a new policy trade-off arises as a result leads to a very non-trivial optimal monetary policy problem in our general model. We explore this in detail next.

\section{Optimal monetary policy}

We now analyze optimal monetary policy in our model, focussing in particular on the role played by the interaction of imbalances in net asset positions across countries with various financial imperfections introduced in our model - such as imperfect risk-sharing due to incomplete markets and endogenous and exogenous variations in the interest rate spread. We use a linear-quadratic approach, following Woodford (2003), and derive a quadratic welfare-theoretic loss-function of the central bank by taking a second-order approximation of an equally-weighted sum of the two household's utilities around the efficient non-stochastic steady-state that we discussed above. A first-order approximation of the private sector equilibrium conditions then represent the constraints faced by the central bank. We study this Ramsey problem of minimizing the loss function subject to the constraints under commitment, where the monetary policy instrument is the deposit rate $\hat{R}_{t}^{d}$.

\subsection{Welfare-theoretic loss function}

The welfare-theoretic loss function of the union-wide central bank is established in the following proposition:

\footnotetext{
${ }^{26}$ Due to nominal rigidities, relative price depends on its lagged value, as can be seen by comparing (15) to (20).

${ }^{27}$ The calibration of the model, as well as more analysis with a Taylor rule, is presented in detail later in the paper. Here the Figure is presented for illustrative purposes only.
} 
Proposition 1 The discounted sum of the utilities of households is given by:

$$
\sum_{t=0}^{\infty} \beta^{t} \sum_{j=s, b} n_{j}\left\{U\left(C_{j, t}\right)-\frac{1}{n_{j}} \int_{\mathcal{I}_{j}} V\left(N_{j, t}(i)\right) d i\right\}=-\frac{U_{C} \bar{Y}}{2} \sum_{t=0}^{\infty} \beta^{t} L_{t}+\text { t.i.p. }+O\left(\|\xi\|^{3}\right)
$$

where

$$
\begin{gathered}
L_{t}=\phi_{s} \pi_{s, t}^{2}+\phi_{b} \pi_{b, t}^{2}+\phi_{Y}\left(\hat{Y}_{t}-\hat{Y}_{t}^{E}\right)^{2}+\phi_{P}\left(\hat{P}_{t}^{R}-\hat{P}_{t}^{R, E}\right)^{2}+\phi_{C}\left(\hat{C}_{t}^{R}\right)^{2}+\phi_{B} \hat{b}_{t}^{2}, \\
\phi_{s}=n_{s} \frac{\theta(\sigma+\varphi)}{\kappa} ; \phi_{b}=n_{b} \frac{\theta(\sigma+\varphi)}{\kappa} ; \phi_{Y}=\sigma+\varphi ; \phi_{P}=n_{s} n_{b} \eta(1+\eta \varphi) ; \phi_{C}=n_{s} n_{b} \sigma ; \phi_{B}=\bar{\Xi}_{b b},
\end{gathered}
$$

t.i.p stands for the terms independent of monetary policy, and $O\left(\|\xi\|^{3}\right)$ denotes all relevant terms that are of third or higher order.

Proof. In appendix.

The terms in the loss function clearly indicate the various distortions and inefficiencies that are present in our model. As is well-known, since sticky-prices cause inefficient dispersion in prices and in production of goods at the micro-level, inflation of the two countries, $\pi_{s, t}$ and $\pi_{b, t}$, appear in the loss function. Moreover, sticky prices cause inefficiency at the aggregate-level as well and hence the output gap $\hat{Y}_{t}-\hat{Y}_{t}^{E}$, the gap between output and its efficient level, is also present in the loss function. These terms are standard when compared to the literature on closed-economy models, such as the one explained in detail in Woodford (2003). In addition, in a currency union, since the countries face effectively a fixed exchange rate, sticky prices also cause a cross-country distortion, and hence the relative price gap $\hat{P}_{t}^{R}-\hat{P}_{t}^{R, E}$ is present in the loss function. ${ }^{28}$ This was shown first in Benigno (2004). The remaining two terms appearing in the loss function are related to financial imperfections in our model. First, since we allow for trade in only non-state contingent bond, there is imperfect risk-sharing across countries. Therefore, the relative consumption term $\hat{C}_{t}^{R}$ captures this inefficiency at the cross-country level. Closed economy or two-country models with incomplete markets in the literature, such as Curdia and Woodford (2009), Benigno (2009), and De Fiorre and Tristani (2012), also feature a similar term in their welfare-theoretic loss functions. Finally, since financial intermediation consumes real resources in our model and the interest rate spread depends endogenously on aggregate debt, there is also aggregate debt $\hat{b}_{t}$ in the loss-function, which captures the aggregate inefficiency caused by financial frictions. ${ }^{29}$

Because the loss function we derived above is micro-founded, the weights on the various terms are economically meaningful and are functions of the structural parameters. As is standard, the

\footnotetext{
${ }^{28}$ In a two-country model with flexible exchange rates and staggered sticky prices, where firms set prices in their country's currency (producer currency pricing), such a distortion is not as relative prices adjust due to exchange rate adjustment, as shown by Clarida, Gali, and Gertler (2002). Even in a two-country model with flexible exchange rates, when firms set prices in the importing country's currency (local currency pricing) however, a similar distortion is present as relative prices do not adjust optimally to shocks, as shown in an important recent paper by Engel (2011).

${ }^{29}$ Note that we have a quadratic term in aggregate debt in the loss function, which is different from Curdia and Woodford (2009). While our set-up is very similar to Curdia and Woodford (2009), which term representing debt appears in the loss-function is different. This is because we make slightly different assumptions on steady-state elasticities related to the financial intermediation process.
} 
weights on the two inflation terms, $\phi_{s}$ and $\phi_{b}$, depends critically on the extent of price-stickiness (or the slope of the Phillips curves) as captured by $\kappa=\frac{(1-\alpha)(1-\alpha \beta)}{\alpha} \frac{\sigma+\varphi}{1+\theta \varphi}$. Moreover, they depend on the elasticity of substitution across varieties $\theta$, because this determines how relative price dispersion across varieties due to inflation translates into relative production dispersion across varieties. Note that $\theta$ also appears while interacted with the elasticity of labor supply $\varphi$ as $\phi_{i}=n_{s} \frac{\theta(1+\theta \varphi) \alpha}{(1-\alpha)(1-\alpha \beta)}$ for $i=s, b$. This is because households dislike the labor misallocation across varieties more when the disutility of supplying labor has a bigger curvature (a larger $\varphi$ ). The interaction term $\theta \varphi$ therefore, disappears when household has a linear disutility $(\varphi=0)$. Moreover, even if $\varphi \neq 0$, the interaction term $\theta \varphi$ would also be dropped from $\theta(1+\theta \varphi)$ if labor markets were not firm-specific in each country: that is, each member country has a common country-wide labor market. Next, the weight on output gap depends on the intertemporal elasticity of substitution of consumption $\sigma$ and the elasticity of labor supply $\varphi$, as these preference parameters determine how households value consumption and leisure.

For the relative price gap, the intra-temporal elasticity of substitution appears in the weight because it determines the extent of distortion in relative output and thereby, in relative labor for a given fluctuation in relative prices. Moreover, we can again see that there is an interaction term $\eta \varphi$ in $\phi_{P}$. This is because households dislike this labor misallocation across countries more when the disutility of supplying labor has a bigger curvature (a larger $\varphi$ ). The interaction term therefore, disappears when household has a linear disutility $(\varphi=0)$, in which case, $\phi_{P}$ is simply given by $n_{s} n_{b} \eta$. This result implies that the elasticity of labor supply may have an important policy implication especially when there is a trade-off between relative price stabilization and other policy objectives (such as relative consumption stabilization in our model). Again, even if $\varphi \neq 0$, the interaction term $\eta \varphi$ would also be dropped from $\eta(1+\eta \varphi)$ if labor markets were not segmented across countries: that is, the economy has a common union-wide labor market. Next, the coefficient of relative risk aversion $\sigma$ matters critically for the weight on relative consumption since it governs the extent of consumption-smoothing preferences of households. Finally, as is natural, the weight on aggregate debt depends on the steady-state elasticity of the spread with respect to debt.

We next establish a result regarding comparative statics of the weights that we discussed above with respect to various important structural parameters.

Proposition 2 Inflation stabilization becomes more important relative to the other policy objectives as the degree of price stickiness and/or the elasticity of substitution increase: $\frac{\partial\left(\frac{\phi_{j}}{\phi_{i}}\right)}{\partial \alpha_{j}}>0$ and $\frac{\partial\left(\frac{\phi_{j}}{\phi_{i}}\right)}{\partial \theta}>0$ for $j=s, b$ and $i=Y, P, C$, and B. Moreover, relative price stabilization becomes relatively more important as the elasticity of substitution between country $s$ and country $b$ goods increases: $\frac{\partial\left(\frac{\phi_{P}}{\phi_{i}}\right)}{\partial \eta}>0$ for $i=s, b, Y, C$, and B. Finally, relative consumption stabilization becomes relatively more important as the coefficient of relative risk aversion increases: $\frac{\partial\left(\frac{\phi_{C}}{\phi_{i}}\right)}{\partial \sigma}>0$ for $i=s, b, Y, P$, and $B$.

Proof. In appendix. 
The comparative static results above are all intuitive. The weights on inflation increase when the extent of price stickiness increases as well as when the elasticity of substitution across varieties increases as both lead to a greater dispersion of production across varieties. Next, $\frac{\partial\left(\frac{\phi_{P}}{\phi_{i}}\right)}{\partial \eta}>0$ because, when $\eta$ is larger, the relative price distortion leads to a bigger distortion in relative output, which in turn affects negatively households' welfare as it allocates labor hours inefficiently across countries (i.e. not justified by variations in $A_{s}$ and $A_{b}$ ). Finally, $\frac{\partial\left(\frac{\phi_{C}}{\phi_{i}}\right)}{\partial \sigma}>0$ as it implies a greater preference for consumption-smoothing by households.

We conclude this subsection with a final observation that the loss function (21) can also be written as

$$
L_{t}=\phi_{\pi} \pi_{t}^{2}+\phi_{Y}\left(\hat{Y}_{t}-\hat{Y}_{t}^{E}\right)^{2}+n_{s} n_{b} \phi_{\pi}\left(\Delta \hat{P}_{t}^{R}\right)^{2}+\phi_{P}\left(\hat{P}_{t}^{R}-\hat{P}_{t}^{R, E}\right)^{2}+\phi_{C}\left(\hat{C}_{t}^{R}\right)^{2}+\phi_{B} \hat{b}_{t}^{2}
$$

where $\phi_{\pi}=\frac{\theta(\sigma+\varphi)}{\kappa}$. This alternative representation will be useful for our analysis below as it naturally partitions the terms in the loss function into the two aggregate (and conventional) target variables $\left\{\pi_{t}, \hat{Y}_{t}\right\}$ and the three distributional target variables $\left\{\hat{P}_{t}^{R}, \hat{C}_{t}^{R}, \hat{b}_{t}\right\}$.

\subsection{Optimal policy under commitment}

In general, we characterize the dynamics of the model under optimal policy numerically, using the method of Sims (2000). In this case, we use the general loss function (21) (or (22)) and characterize the Ramsey problem of the central bank as choosing the target variables in the loss function and the policy instrument $\hat{R}_{t}^{d}$ to minimize $\frac{1}{2} E_{0} \sum_{t=0}^{\infty} \beta^{t} L_{t}$, subject to (14)-(19). The optimality conditions of this problem are contained in the appendix. We later also compare model responses under optimal policy to those under two simple interest rate rules: a standard Taylor rule and a spread-adjusted Taylor rule. For the standard Taylor rule, we use the specification $\hat{R}_{t}^{d}=\Phi_{\pi} \pi_{t}+\Phi_{y} y_{t}$, while for the spread-adjusted Taylor rule, we use the specification $\hat{R}_{t}^{d}=\Phi_{\pi} \pi_{t}+\Phi_{y} y_{t}-\Phi_{\omega} \hat{\omega}_{t}$.

Before presenting the results of the general model, we first analyze the two special cases that we discussed above to illustrate in isolation the role of each channel. For these two cases, analytical results are available and the fact that monetary policy is neutral for cross-country variables in one special case (with the aggregate demand channel only) while it is neutral for aggregate output in the other special case (with the wealth redistribution channel only) allows us to clearly show the implications of the two types of frictions for optimal monetary policy. These also serve as useful reference points for the more general environment where the two mechanisms interact.

\subsubsection{Special cases}

Nominal frictions and the aggregate demand channel We first consider a special case of our model where only the aggregate demand transmission mechanism is in operation because the relevant friction for policy is sticky prices. In particular, we neutralize the effect of financial imperfections by setting $\lambda^{B}=0$ so that countries are ex-ante symmetric in net asset positions and imposing $\eta_{B}=0$ so that the interest rate spread is purely exogenous. As discussed above, the latter condition 
$\left(\eta_{B}=0\right)$ is not required to shut down the wealth redistribution channel and thus not necessary for our analytical result below. It nevertheless makes this particular version of our model similar to the standard framework often considered in the open economy literature, for example in Obstfeld and Rogoff (1996) and Corsetti and Pesenti (2001), where countries frictionlessly trade in a nonstate contingent bond and there is no initial heterogeneity in net foreign asset positions. It thereby allows us to make a straightforward comparison to the literature. ${ }^{30}$ This will also provide a useful benchmark as later, we can clearly see implications of redistributive role of monetary policy and endogenous variations in interest rate spread and financial shocks. In what follows we refer to this case as "NoFF" (for No Financial Frictions). ${ }^{31}$ We summarize our results in the proposition below.

Proposition 3 Under "NoFF," the cross-country distributions of quantities and prices $\left\{\hat{C}_{t}^{R}, \hat{P}_{t}^{R}, \hat{b}_{t}\right\}$ are determined independently from monetary policy, and (22) simplifies to:

$$
L_{t}=\phi_{\pi} \pi_{t}^{2}+\phi_{Y}\left(\hat{Y}_{t}-\hat{Y}_{t}^{E}\right)^{2}
$$

Moreover, the optimal policy is to set $\pi_{t}=0$ and thereby, $\hat{Y}_{t}-\hat{Y}_{t}^{E}=0$, for all $t$. Optimal policy however, does not achieve the efficient outcome.

Proof. In appendix.

With only nominal frictions, as we showed before, the cross-country variables are independent of monetary policy. ${ }^{32}$ Thus, it is easy to see that (22) simplifies to contain only the two aggregate target variables, $\pi_{t}$ and $\hat{Y}_{t}-\hat{Y}_{t}^{E}$. Moreover, since there is no trade-off in stabilizing $\pi_{t}$ vs. $\hat{Y}_{t}-\hat{Y}_{t}^{E}$ (as given by (14)), it is clear that optimal policy sets $\pi_{t}=0$ and thereby, $\hat{Y}_{t}-\hat{Y}_{t}^{E}=0$, for all $t$. In our model, therefore, if sticky prices are the only relevant friction, then complete stabilization of union-wide inflation is optimal. This optimal policy, however, does not achieve first-best because in the presence of country-specific productivity shocks, all the other cross-country target variables are not zero and are in fact outside the control of the central bank.

Financial imperfections and the wealth redistribution channel Consider the other special case of our model where only the wealth redistribution transmission mechanism is in operation because the relevant friction for policy is financial imperfections combined with initial asymmetry in wealth positions. That is, this is the case where prices are completely flexible, $\kappa \rightarrow \infty .{ }^{33}$ In what follows we refer to this case as "NoNF" (for No Nominal Frictions). We summarize our results in the proposition below.

\footnotetext{
${ }^{30}$ In addition, endogenous variations in the interest rate spread amplify the wealth redistribution effect. Therefore, making the interest spread purely exogenous in this benchmark case will enable us to see more clearly the difference the new channel generates.

${ }^{31}$ Once again, to be perfectly clear, this special case still features financial imperfections since markets are incomplete. As discussed however, the frictions become irrelevant for optimal monetary policy in this case, and hence the name.

${ }^{32}$ Benigno (2004) considered effectively complete asset markets, in which case $\hat{C}_{t}^{R}=0$ and $\left\{\hat{Y}_{t}^{R}, \hat{P}_{t}^{R}, \pi_{t}^{R}\right\}$ are independent from monetary policy. Here we show that when the economy has only risk-free bonds, the same result holds only in the limiting case, NoFF.

${ }^{33}$ As we mentioned before, in a different set-up with financial frictions, De Fiorre, Teles, and Tristani (2011) also analyze optimal monetary policy under flexible prices.
} 
Proposition 4 Under "NoNF," aggregate output is determined independently from monetary policy, and (22) simplifies to:

$$
L_{t}=\tilde{\phi}_{C}\left(\hat{C}_{t}^{R, F}\right)^{2}+\phi_{B}\left(\hat{b}_{t}^{F}\right)^{2}
$$

where $\tilde{\phi}_{C} \equiv\left(\phi_{P}\left(\frac{\sigma}{1+\eta \varphi}\right)^{2}+\phi_{C}\right)$. Moreover, under optimal policy, the solution for the target variables is given as:

$$
\begin{aligned}
\hat{b}_{t}^{F} & =\gamma \hat{b}_{t-1}^{F}-\vartheta_{1} \hat{\chi}_{t} \text { and } \\
\hat{C}_{t}^{R, F} & =\vartheta_{2} \hat{b}_{t-1}^{F}+\vartheta_{3} \hat{\chi}_{t},
\end{aligned}
$$

where $\gamma \in(0,1)$ and $\vartheta_{j}>0$ for $j=1,2$, and 3. Optimal policy however, does not achieve the efficient outcome.

Proof. In appendix.

With only financial frictions, as we showed before, $\hat{Y}_{t}^{F}=\hat{Y}_{t}^{E}$. Moreover, since $\kappa \rightarrow \infty, \phi_{\pi} \rightarrow 0$. In addition, as discussed earlier and can be seen from (20), the central bank does not face a trade-off between stabilizing the relative price gap and relative consumption. Thus, it is easy to see that (22) simplifies to contain only $\hat{C}_{t}^{R, F}$ and $\hat{b}_{t}^{F}$.

In this case, the central bank will seek to minimize the loss function subject to the sequence of constraints given by (17), which can be rewritten as:

$$
\hat{C}_{t}^{R, F}=E_{t} \hat{C}_{t+1}^{R, F}+\frac{\eta_{B}}{\sigma} \hat{b}_{t}^{F}+\frac{1}{\sigma} \hat{\chi}_{t}
$$

The other variables, in turn, will be determined residually for a given optimal time path of $\hat{C}_{t}^{R}$ and $\hat{b}_{t}$. It is worth stressing the similarities between this problem and the one in the previous special case of only sticky prices (or in standard New Keynesian models). First, note that (23) looks remarkably similar to the standard Phiilips curve (14) that acts as a constraint in the optimal policy problem under sticky prices. Just like the slope of the Phillips curve, $\kappa$, captures the extent of the conventional trade-off (if any) between the two target variables, inflation and output gap, $\frac{\eta_{B}}{\sigma}$ captures the degree of trade-off between stabilizing relative consumption and debt. Moreover, it is time variation in $\hat{\chi}_{t}$, an inefficient demand-type shock, that generates a trade-off for the central bank by making it impossible to attain simultaneously zero $\hat{C}_{t}^{R, F}$ and $\hat{b}_{t}^{F}$, thereby precluding optimal monetary policy from reaching the efficient outcome. The role of $\hat{\chi}_{t}$ is therefore reminiscent of that of inefficient supply-type shocks, such as variation in mark-up, in a prototypical optimal monetary policy problem. ${ }^{34}$ As a result, the optimal responses of $\hat{C}_{t}^{R, F}$ and $\hat{b}_{t}^{F}$ to a change in $\hat{\chi}_{t}$ will be similar to those of inflation and output gap to a change in mark-up in the conventional set-up. This can be seen clearly from the resulting "targeting rule" which is given as:

$$
\tilde{\phi}_{C} \hat{C}_{t}^{R, F}=-\phi_{B} \frac{\sigma}{\eta_{B}}\left[\hat{b}_{t}^{F}-\beta^{-1} \hat{b}_{t-1}^{F}\right]=-\sigma \beta\left[\hat{b}_{t}^{F}-\beta^{-1} \hat{b}_{t-1}^{F}\right] .
$$

\footnotetext{
${ }^{34}$ Note again that for simplicity, we do not consider markup shocks.
} 
This targeting rule has an analogous interpretation to the usual case in the sticky price model and shows that the optimizing central bank conducts a "leaning against the wind" policy. Suppose a positive financial shock hits and drives the interest rate spread upward. This generates an inefficient wealth redistribution from the borrower to the saver country and forces the latter to consume more relative to the former (i.e. increases $\hat{C}_{t}^{R, F}$ ). The optimizing central bank will dampen the rise in $\hat{C}_{t}^{R, F}$ and thus mitigate the distributional inefficiency by driving lower the debt of the borrower country up to the point where condition (24) is satisfied. ${ }^{35}$

Our closed-form solutions for the target variables in Proposition 4 also make the same point. Relative consumption and debt respond only to the aggregate financial shock $\hat{\chi}_{t}$ and not to the aggregate and idiosyncratic technology shocks. This is again because there would be no trade-off in stabilizing $\hat{C}_{t}^{R}$ vs. $\hat{b}_{t}$ if financial shocks were not hitting the economy, as can be seen in (23). In addition, under optimal policy, $\hat{b}_{t}$ decreases while $\hat{C}_{t}^{R}$ increases in response to the financial shock. Once again, this result is consistent with our discussion of the central bank conducting a "leaning against the wind" policy. In contrast to the previous special case with only nominal frictions (NoFF), inflation on the other hand will fluctuate over time responding to (all) shocks. Variation in inflation, as mentioned above, incurs no welfare costs, and thus the central bank has no incentive to stabilize inflation. ${ }^{36}$

In sum, when each of the frictions is considered in isolation, the central bank faces a single policy trade-off in our model. In the first special case with nominal frictions only $(N o F F)$, we have shown that the central bank balances the variability of $\pi_{t}$ and $\hat{Y}_{t}-\hat{Y}_{t}^{E}$, although the absence of inefficient supply shocks makes this conventional trade-off not relevant in our model. In the other specific case $(N o N F)$, we have highlighted a new policy trade-off $\left(\hat{C}_{t}^{R}\right.$ vs. $\left.\hat{b}_{t}\right)$ that results from the introduction of the wealth redistribution channel as financial imperfections become relevant for monetary policy. While these specific cases are instructive and the policy trade-offs in each specific case will continue to be important, in our general model with financial and nominal frictions, both the channels of monetary policy transmission will be at work, which will enable the central bank to influence both aggregate and distributional variables simultaneously. Moreover, the interaction of these two frictions creates additional policy trade-offs. For example, as we discussed before, a novel trade-off in stabilizing $\hat{C}_{t}^{R}$ vs. $\hat{P}_{t}^{R}-\hat{P}_{t}^{R, E}$ appears in the general model. In addition, there will be a trade-off in mitigating aggregate inefficiency vs. distributional inefficiency. For instance, the central bank will not allow the nominal interest rate (and hence inflation) to fluctuate as much to mitigate variations in relative variables if nominal frictions are present in addition to financial frictions. In general, there will be nontrivial interactions between aggregate dynamics (and hence monetary policy) and cross-country distribution of prices and quantities. The central bank thus has to optimally balance the variability of all the target variables that are present in (21). Since analytical results are not available, we explore this general case numerically next.

\footnotetext{
${ }^{35}$ The central bank can implement this by decreasing its policy instrument, $R_{t}^{d}$. We will illustrate this in the next section numerically.

${ }^{36}$ In fact, under flexible prices, the inflation rate overall will move in the same direction as the nominal rate due to the well-known "Fisher effect."
} 


\subsubsection{General case}

We first present the parameterization of our general model and then show impulse responses under optimal monetary policy and under simple rules.

Parameterization Our parameterization, as given in Table 2, is mostly standard except for a few parameters. We pick the price stickiness parameter $\alpha$ to be 0.55 to match the evidence from Dhyne et al (2006) that the monthly frequency of price changes in the Euro Area is $15.1 \%$. We pick $\lambda_{b}^{B} \equiv \frac{\bar{b}_{b}}{Y}=\frac{b_{b,-1}}{Y}$ to match the average net foreign asset-to-GDP ratio of Spain. ${ }^{37}$ The parameter $\eta_{B}=\bar{\Xi}_{b b} / \beta$ implies a change in $\hat{\omega}_{t}$ associated with a unit change in $\hat{b}_{t}$ while all other variables are fixed. We estimate the long-run impact of a unit increase in the net foreign asset-to-GDP ratio on the interest rate spread using a panel of the seven countries in Table 1 and set $\eta_{B}$ to be consistent with this estimate. It is non-trivial to estimate the process for $\chi_{t}$. Instead, we fix $\rho_{\chi}$ to a large value (0.9) in order to capture a persistent propagation of disruptions in the financial market throughout the economy. A similar value is often used in the literature. We also fix the standard deviation of $\chi_{t}$ to the same value as our estimate of the standard deviation of the country-specific productivity shocks. Our model implies that per-capita output is the sum of the area-wide and country-specific productivity shocks that follow an AR(1) process. We build an empirical model for per-capita output in the Euro Area that has the same shock structure and estimate the parameters. The details of the estimation of $\eta_{B}$ and the parameters of the productivity shock processes are in the appendix.

Table 2: Parameter values used in the numerical analysis

\begin{tabular}{ll|ll|ll|ll|ll}
\hline \hline$\beta$ & 0.99 & $n_{s}=n_{b}$ & 0.5 & $\lambda_{b}^{B}$ & -3.43 & $\rho_{\chi}$ & 0.9 & $\sigma_{\chi}$ & 0.01 \\
$\varphi$ & 1 & $\theta$ & 6 & $\Phi_{\pi}$ & 1.5 & $\rho_{A}$ & 0.73 & $\sigma_{A}$ & 0.002 \\
$\sigma$ & 3 & $\alpha$ & 0.55 & $\Phi_{y}$ & 0.125 & $\rho_{A s}$ & 0.98 & $\sigma_{A s}$ & 0.01 \\
$\eta$ & 3 & $\eta_{B}$ & 0.11 & $\Phi_{\omega}$ & $0.3,0.5,1$ & $\rho_{A b}$ & 0.98 & $\sigma_{A b}$ & 0.01 \\
\hline
\end{tabular}

Impulse responses under optimal policy We show impulses responses of various endogenous variables to the four shocks impinging on the economy where we also plot the response of target (or efficient) level of each variable. ${ }^{38}$ To highlight policy implications of the financial imperfections in our model, our general model (labeled "General") is contrasted with its complete market counterpart (labeled "Complete"). In addition, we also present impulse responses under NoFF.39 As mentioned above, NoFF - where we eliminate the wealth redistribution channel - corresponds to the "frictionless bond economy" often studied in the open economy literature and can also be considered as an intermediate case between Complete and General. The purpose of presenting this special case is to see how optimal monetary policy changes when the conventional aggregate demand channel is supplemented by the wealth redistribution channel.

\footnotetext{
${ }^{37}$ Note that $\lambda^{B}=-n_{b} \lambda_{b}^{B}$. We chose Spain's numbers because it is the median among the PIIGS countries.

${ }^{38}$ The impulse responses are for a one-standard-deviation shock.

${ }^{39}$ To avoid cluttering the figures, we present impulse responses under no nominal frictions ("NoNF") only for the financial shock. We do so for two main reasons. First, in section 4.2.1 we showed that the target variables under $N o N F$ respond only to the financial shock. Second, under NoNF, the response of inflation tends to be so high that it makes visualizing the response of inflation for other model variants very difficult.
} 
Aggregate productivity shock Figure 2 shows the response of endogenous variables to an aggregate productivity shock. In our general model, complete stabilization of the union-wide inflation is not optimal. This is in stark contrast with the case often considered in the literature, that of complete markets (e.g. Benigno (2004)), where complete stabilization of union-wide inflation is optimal under no heterogeneity in price stickiness across countries if the only disturbance hitting the economy is an aggregate productivity shock. As discussed earlier, such strict inflation targeting policy can be optimal even in our model where asset markets are incomplete - but only in the special case, NoFF. The intuition for the general sub-optimality of strict inflation targeting is clear from our earlier discussion. With the two transmission mechanism channels, the central bank can now affect both aggregate and distributional dynamics. The central bank thus optimally balances the variability of all the target variables that are present in (22), instead of closing the "gap" for output and inflation only. Despite this difference, our numerical results suggest that financial imperfections do not create a significant difference in the optimal response to a shock to aggregate productivity. This is because this aggregate shock affects member countries almost symmetrically and thus raises fairly little distributional concern for the central bank. ${ }^{40}$ Overall, our results imply that if the main source of disturbance in the economy is an aggregate productivity shock, then conventional strict inflation targeting policy may not be a bad approximation to fully optimal policy. Finally, Figure 2 also illustrates that while under complete markets, optimal policy (complete stabilization of inflation) leads to an efficient outcome, in our general model, efficiency is not obtained.

Country-specific productivity shocks Financial imperfections matter more for monetary policy when country-specific productivity shocks hit the economy. Figures 3 and 4 show the response of endogenous variables to a productivity shock in the saver and borrower country respectively. While the differences due to financial imperfections are still relatively small with respect to the two aggregate target variables, output gap and inflation, they are more significant with respect to the two cross-country variables, relative consumption and relative prices. ${ }^{41}$ This finding may not be surprising given our earlier discussion that country-specific productivity shocks are the main driver that generate a new policy trade-off between relative consumption stabilization and relative price gap stabilization. Note first that even under complete markets, as emphasized by Benigno (2004), the optimal policy of complete stabilization of union-wide inflation does not achieve the efficient outcome as the relative price gap is not zero. Most importantly, it is clear that, compared either to the complete markets or the NoFF case, relative price deviates further away from its efficient level in our general model. In other words, the central bank allows for less flexibility in relative price. The reason for this important result is that the central bank - due to the new trade-off - optimally balances the variability of relative consumption and relative price gap. Consider the case in which the productivity of country $s$ increases, which decreases the efficient level of relative price $\hat{P}_{t}^{R, E}$. The

\footnotetext{
${ }^{40}$ However, as can be seen from Figure 2, even aggregate productivity shocks have some distributional effects (albeit not significant quantitatively) because an increase in $A_{t}$ generates deflation, which transfers wealth from country $b$ to country $s$. This in turn decreases relative consumption and price.

${ }^{41}$ For output gap and inflation, note that while there are some differences initially, after a couple of quarters, the differences are not quantitatively relevant.
} 
optimizing central bank will then try to lower relative price $\hat{P}_{t}^{R}$ to mitigate the gap between $\hat{P}_{t}^{R}$ and $\hat{P}_{t}^{R, E}$. With the new policy trade-off however, the central bank will not lower $\hat{P}_{t}^{R}$ (or equivalently raise $\left.\hat{Y}_{t}^{R}\right)$ as much - as illustrated in the third row of Figures 3 - because otherwise relative consumption would rise too much above its efficient level $\left(\hat{C}_{t}^{R, E}=0\right) .{ }^{42}$ In addition, as extensively discussed in Section 4.2.1, the central bank counteracts to an increase in relative consumption by driving lower the debt of the borrower country. The insight obtained under the special case, NoNF, therefore still applies in the general environment and to other types of shocks. In contrast, we do not observe this pattern under NoFF (and Complete) as the central bank in that environment has no control over either debt or relative consumption due to the absence of the wealth redistribution channel.

Figures 3 and 4 also reveal that while the response of the economy to an increase in $\hat{A}_{s, t}$ is quite similar to that to an increase in $\hat{A}_{b, t}$ (with one being almost the mirror image of the other in the case of the country-specific variables), they are not exactly the same. Interestingly, the biggest discrepancy is observed in the responses of the aggregate variables such as output, inflation, and the deposit interest rate. In particular, the first panels in the figures show that while $\hat{A}_{s, t}$ and $\hat{A}_{b, t}$ affect the efficient level of output $\hat{Y}_{t}^{E}$ symmetrically, the responses of aggregate output are asymmetric: output stays above the efficient level in the first two quarters after a positive shock to country $s$ while it is below the efficient level after a positive shock to country $b$. This result arises because of the linkage between the aggregate variables and the relative variables generated by the imbalances in net asset positions and financial frictions between member countries. In contrast, in the absence of such a linkage - when a change in the interest rate and inflation have no redistributive role the responses of each of the aggregate variables will coincide after country-specific shocks, and the responses of country-specific variables and debt to a shock in one country will exactly be a mirror image of their counterparts in case of a shock in the other country. This is precisely what we see in Figures 3 and 4 for the complete market and NoFF case.

To understand how the redistributive channel of monetary policy generates asymmetric optimal responses, consider first the case in which a positive shock to $\hat{A}_{s, t}$ is realized. Then, consumption in country $s$ increases relatively more than consumption in country $b$. The optimizing central bank, as discussed above, will conduct the "leaning against the wind" policy: it will try to reduce the consumption gap by lowering the deposit rate and raising inflation (as shown in the second and last panels in Figure 3), thereby decreasing the value of debt, which in turn, leads the aggregate output to respond more than its efficient level. For the same reason, the central bank raises the deposit rate and decreases inflation in response to an increase in $\hat{A}_{b, t}$, which in turn leads to a smaller increase in output relative to the output gap. The only difference is that the central bank in the former case adjusts the deposit rate and inflation by a smaller amount. The intuition is straightforward. An increase in productivity at any levels $\left(\hat{A}_{s, t}, \hat{A}_{b, t}\right.$, or $\left.\hat{A}_{t}\right)$ is deflationary (see also Figure 2). Thus, it is generally more costly for the central bank to raise overall inflation in response to a positive productivity shock. More specifically, after an increase in $\hat{A}_{s, t}$, the central bank wishes to decrease $\hat{P}_{s, t}$ (and thus $\pi_{s, t}$ ), given a corresponding decline in the efficient level of $\hat{P}_{s, t}^{E}$ (and hence $\hat{P}_{t}^{R, E}$ ). But

\footnotetext{
${ }^{42}$ Similar mechanisms are at work while considering a positive shock to the productivity of country $b$, as illustrated in the third row of Figure 4.
} 
at the same time, as discussed above, the central bank has an incentive to raise the overall price level. Therefore, on balance, the central bank would decrease $\hat{P}_{s, t}$ (and thus $\pi_{s, t}$ ) less and at the same time increase $\pi_{t}$ less than it otherwise would. Therefore, the responses of inflation, deposit rate, and output are more dampened in response to a change in $\hat{A}_{s, t}$ than to a change in $\hat{A}_{b, t}$.

Aggregate financial shock Figure 5 shows the response of endogenous variables to a financial shock that causes an increase in the interest rate spread. Here we also present impulse responses under NoNF. This financial disturbance appears to give the most significant challenge to the central bank, as overall, the variables in the central bank's loss function deviate from their respective target levels by a larger degree relative to the other shocks. ${ }^{43}$

A financial shock in general generates both aggregate and distributional inefficiencies. An increase in the spread works as a negative aggregate demand shock, exerting a contractionary pressure on aggregate output and inflation - as discussed earlier and as can be seen from (16). Therefore, under optimal policy, the central bank decreases the policy rate to mitigate the adverse effects on inflation and the output gap that the increase in interest rate spread would cause otherwise. Our numerical results indicates that optimal policy maintains inflation and output close to their respective target levels, which is not surprising given the large weight attached to inflation stabilization relative to the other policy objectives in (22). ${ }^{44}$ In addition, the central bank's lowering of the deposit rate optimally reduces the distributional inefficiency caused by wealth redistribution - which is once again an illustration of the "leaning against the wind" policy discussed in Section 4.2.1. Since an increase in the spread redistributes wealth in favor of the saver country, relative consumption tends to increase. This in turn raises the marginal cost in the saver country relative to the borrower country through income effects, which increases the relative price. By lowering the deposit rate, which also leads to inflation, the central bank can counter such inefficient wealth redistribution, and thereby moderate inefficient variations in relative consumption and prices. In contrast to the general case, variations in relative consumption and price are more pronounced under NoFF, as then the central bank does not (and cannot) control cross-country distributions, and thus focuses entirely on the two aggregate target variables.

Put differently, the results in our general model, perhaps not surprisingly, are a mixture of the two polar cases studied analytically above. The optimal response of inflation after a financial shock in our general model resembles that under NoFF (where the central bank focuses exclusively on inflation stabilization), while the general case is quite close to NoNF (where the central bank focuses exclusively on cross-country distributions) with respect to the dynamics of the cross-country variables, such as relative consumption, relative prices, and debt. In this sense, one can think of coarsely approximating the optimal policy of the general model in response to the financial shock by combining the results on aggregate inflation under NoFF (Proposition 3) and the results on

\footnotetext{
${ }^{43}$ Note here that in our calibration the standard deviation of the financial shock is the same as that of the idiosyncractic productivity shock but the persistence is lower. Therefore, the result that variables deviate from their respective target levels by more in the case of the financial shock is clearly indicative of the substantial pressures that the shock generates for the central bank.

${ }^{44}$ This will become even more apparent below when we compare optimal policy to the standard Taylor rule.
} 
cross-country variables under NoNF (Proposition 4).

Impulse responses under simple rules We now present our results on how model dynamics differ between optimal policy and policy conducted using simple rules. In particular, we consider two simple monetary policy rules: a standard Taylor rule $\left(\Phi_{\omega}=0\right)$ and a spread-adjusted Taylor rule $\left(\Phi_{\omega}=0.3,0.5,1\right)$. Figures $6-9$ show the responses of endogenous variables to an aggregate productivity shock, a productivity shock in the borrower country, a productivity shock in the saver country, and an aggregate financial shock respectively. The simple rules do not, as is expected, replicate the outcomes under optimal policy.

The main difference between the two types of Taylor rules is most evident in Figure 9 when the economy is hit by a financial shock. The standard Taylor rule allows for a significant negative output gap and a negative response of inflation. On the other hand, a spread-adjusted Taylor rule mitigates this outcome. In particular, a value of $\Phi_{\omega}=0.5$ comes close to replicating the response under optimal monetary policy. ${ }^{45}$

This finding may come as no surprise given that most of the discrepancy between the optimal policy and the standard Taylor rule is in the response of aggregate output and inflation - as is evident in the first row of Figure 9. It is well understood in the monetary policy literature that the central bank is able to keep the economy at the efficient level of production if the interest rate is maintained at its efficient counterpart. Moreover, in our model, when aggregate output is at the efficient level, inflation is completely stabilized (see (14)). Since the efficient interest rate - more precisely, the efficient deposit rate - is a decreasing function of the spread in our model, a spread-adjusted Taylor rule comes quite close to the optimal policy with a suitably appropriate degree of spread adjustment. In particular, recall that the efficient interest rate is given as $r_{t}^{E}=\sigma\left(E_{t} \hat{Y}_{t+1}^{E}-\hat{Y}_{t}^{E}\right)-n_{b} \hat{\omega}_{t}$ in our model and $n_{b}=0.5$. It is therefore not a coincidence that a value of $\Phi_{\omega}=0.5$ comes close to replicating the response under optimal monetary policy. Interestingly, the best performing spreadadjusted Taylor rule mimics the "leaning against the wind" policy and replicates the optimal response of not only aggregate output and inflation but also other target variables such as relative price, relative consumption, and debt.

\section{Conclusion}

In this paper, we study optimal monetary policy in a currency union model with nominal and financial frictions. Asymmetric ex-ante net asset positions introduce a wealth redistribution role for monetary policy in our model. This transmission mechanism is in principle independent of sticky prices, which lead to the usual aggregate demand channel of monetary policy transmission. Our derivation of the welfare-theoretic loss-function of the central bank clearly shows the various distortions in our economy: those related to sticky prices; an effectively fixed exchange rate regime coupled with sticky prices; and financial frictions that lead to imperfect cross-country risk-sharing

\footnotetext{
${ }^{45}$ In future work, we will more rigorously determine optimal simple monetary policy rules and compare quantitatively how they compare to optimal monetary policy.
} 
and an endogenous spread between the borrowing and deposit rates. Variation in the interest rate spread affects both aggregate variables, by affecting total spending, and relative (cross-country) variables, by redistributing wealth across countries. Moreover, due to the interaction of nominal and financial frictions, we show that in our economy, monetary policy effects get amplified and the central bank faces a novel trade-off between stabilizing relative consumption versus the relative price gap (the deviation of relative prices from their efficient level).

We show that due to the new terms introduced in the loss-function by financial frictions, a strict inflation targeting policy that sets union-wide inflation to zero is not optimal even when an aggregate productivity shock hits the economy. Moreover, the new trade-off that we identify implies that under optimal policy, in response to country-specific productivity shocks, the relative price gap fluctuates more than it would if there were no financial frictions. Finally, in response to a purely aggregate financial shock that causes an increase in the interest rate spread, the central bank strongly decreases the deposit rate, which reduces aggregate and distributional inefficiency by mitigating the drop in output and inflation and the rise in relative consumption and prices. We also show that while a traditional Taylor rule approximates optimal policy quite imperfectly, especially in response to the financial shock, a spread-adjusted Taylor rule performs better because it helps the real interest rate track the efficient rate of interest.

In future work, it would be of interest to consider three particular extensions. First, we have ignored issues related to the zero lower bound on the nominal interest rate. We see from our analysis of optimal monetary policy that the required reduction in the nominal interest rate is quite substantial when a purely financial shock hits the economy. A large enough shock of this kind, which will lead to a substantial drop in the efficient level of the real interest rate, can thus make the zero lower bound binding in our model and put the currency union in a liquidity trap. This is a situation that is highly relevant given recent events in the global economy and we can evaluate optimal policy implications of such a scenario following the pioneering closed-economy work of Eggertsson and Woodford (2003) and Jung, Teranishi, and Watanabe (2005).

Second, we have focused our analysis solely on monetary policy, thereby not considering the stabilization role of fiscal policy and the interactions between monetary and fiscal policies in a currency union. Analyzing this dimension of policy can have important implications and we can consider these issues following the work of, among others, Cooper and Kempf (2004), Beetsma and Jensen (2005), Kirsanova et al (2007), Gali and Monacelli (2008), Ferrero (2009), Leith and WrenLewis (2011), Farhi, Gopinath, and Itskhoki (2012), and Farhi and Werning (2012).

Third, we have only studied conventional, interest rate based monetary policy in this paper. Given a series of unconventional monetary policy actions by central banks around the world, including the European Central Bank, it might be important to extend our analysis along these lines, as illustrated in closed-economy models by Gertler and Kiyotaki (2010), Gertler and Karadi (2011), Curdia and Woodford (2011), and Del Negro et al (2011). It will be particularly interesting to consider the role of unconventional monetary policy when the zero lower bound is binding. 


\section{References}

[1] Adrian, Tobias, Paolo Colla, and Hyun Song Shin (2012), "Which Financial Frictions? Parsing the Evidence from the Financial Crisis of 2007-9," in Daron Acemoglu, Jonathan Parker, and Michael Woodford (eds), NBER Macroeconomics Annual, Chicago, IL: University of Chicago Press.

[2] Beetsma, Roel M.W.J., and Henrik Jensen (2005), "Monetary and Fiscal Policy Interactions in a Micro-founded Model of a Monetary Union," Journal of International Economics, 67, 320-352.

[3] Benigno, Pierpaolo (2004), "Optimal Monetary Policy in a Currency Area," Journal of International Economics, 63, 293-320.

[4] Benigno, Pierpaolo (2009), "Price Stability with Imperfect Financial Integration," Journal of Money, Credit and Banking, 41(1), 121-149.

[5] Bernanke, Ben, and Mark Gertler (1989), "Agency Costs, Net Worth, and Business Fluctuations," American Economic Review, 79(1), 14-31.

[6] Bernanke, Ben, Mark Gertler, and Simon Gilchrist (1999), "The Financial Accelerator in a Quantitative Business Cycle Framework," in John B. Taylor and Michael Woodford (eds), Handbook of Macroeconomics, Amsterdam: North-Holland.

[7] Carlstrom, Charles T., and Timothy S. Fuerst (1997), "Agency Costs, Net Worth, and Business Fluctuations: A Computable General Equilibrium Analysis," American Economic Review, 87(5), 893-910.

[8] Christiano, Lawrence, Roberto Motto, and Massimo Rostagno (2009), "Financial Factors in Economic Fluctuations," working paper.

[9] Clardia, Richard, Jordi Gali, and Mark Gertler (2002), "A Simple Framework for International Monetary Policy Analysis," Journal of Monetary Economics, 58, 879-904.

[10] Cooper, Russell and Hubert Kempf (2004), "Overturning Mundell: Fiscal Policy in a Monetary Union," Review of Economic Studies, 71(2), 371-396.

[11] Corsetti, Giancarlo, Luca Dedola, and Sylvain Leduc (2010), "Optimal Monetary Policy in Open Economies," in Benjamin M. Friedman and Michael Woodford (eds), Handbook of Monetary Economics, Amsterdam: North-Holland.

[12] Corsetti, Giancarlo, and Paolo Pesenti (2001), "Welfare and Macroeconomic Interdependence," Quarterly Journal of Economics, 116(2), 421-445.

[13] Curdia, Vasco, and Michael Woodford (2009), "Credit Frictions and Optimal Monetary Policy," working paper. 
[14] Curdia, Vasco, and Michael Woodford (2010), "Credit Spreads and Monetary Policy," Journal of Money, Credit and Banking, 42(6), 3-35.

[15] Curdia, Vasco, and Michael Woodford (2011), "The Central-Bank Balance Sheet as an Instrument of Monetary Policy," Journal of Monetary Economics, 58, 54-79.

[16] De Fiorre, Fiorella, and Oreste Tristani (2011), "Credit and the Natural Rate of Interest," Journal of Money, Credit and Banking, 43(2), 407-440.

[17] De Fiorre, Fiorella, Pedro Teles, and Oreste Tristani (2011), "Monetary Policy and the Financing of Firms," American Economic Journal: Macroeconomics, 3(4), 112-42.

[18] De Fiorre, Fiorella, and Oreste Tristani (2012), "Optimal Monetary Policy in a Model of the Credit Channel," The Economic Journal, forthcoming.

[19] Del Negro, Marco, Gauti B. Eggertsson, Andrea Ferrero, and Nobuhiro Kiyotaki (2011), "The Great Escape? A Quantitative Evaluation of the Fed's Liquidity Facilities," working paper.

[20] Dhyne, Emmanuel, Luis J. Alvarez, Hervé Le Bihan, Giovanni Veronese, Daniel Dias, Johannes Hoffmann, Nicole Jonker, Patrick Lunnemann, Fabio Rumler, and Jouko Vilmunen (2006), "Price Changes in the Euro Area and the United States: Some Facts from Individual Consumer Price Data," Journal of Economic Perspectives 20 (Spring): 171-192.

[21] Doepke, Matthias, and Martin Schneider (2006), "Inflation and the Redistribution of Nominal Wealth," Journal of Political Economy, 114(6), 1069-1097.

[22] Eggertsson, Gauti B., and Michael Woodford (2003), "The Zero Bound on Interest Rates and Optimal Monetary Policy," Brookings Papers on Economic Activity, 1, 139-233.

[23] Engel, Charles (2011), "Currency Misalignments and Optimal Monetary Policy: A Reexamination," American Economic Review, 101(6), 2796-2822.

[24] Erceg, Christopher J., and Jesper Linde (2013), "Fiscal Consolidation in a Currency Union: Spending Cuts vs. Tax Hikes," Journal of Economic Dynamics $\&$ Control, 37, 422-445.

[25] Faia, Ester (2007), "Financial Differences and Business Cycle Co-Movements in a Currency Area," Journal of Money, Credit and Banking, 39(1), 151-185.

[26] Farhi, Emmanuel, Gita Gopinath, and Oleg Itskhoki (2012), "Fiscal Devaluations," working paper.

[27] Farhi, Emmanuel, and Ivan Werning (2012), "Fiscal Unions," working paper.

[28] Ferrero, Andrea (2009), "Fiscal and Monetary Rules for a Currency Union," Journal of International Economics, 77, 1-10. 
[29] Gali, Jordi, and Tommaso Monacelli (2008), "Optimal Monetary and Fiscal Policy in a Currency Union," Journal of International Economics, 76, 116-132.

[30] Gertler, Mark, and Peter Karadi (2011), "A Model of Unconventional Monetary Policy," Journal of Monetary Economics, 58, 17-34.

[31] Gertler, Mark, and Nobuhiro Kiyotaki (2010), "Financial Intermediation and Credit Policy in Business Cycle Analysis," in Benjamin M. Friedman and Michael Woodford (eds), Handbook of Monetary Economics, Amsterdam: North-Holland.

[32] Gilchrist, Simon, Jean-Olivier Hairault, and Hubert Kempf (2002), "Monetary Policy and the Financial Accelerator in a Monetary Union," working paper.

[33] Gilchrist, Simon, and Egon Zakrajsek (2012), "Credit Spreads and Business Cycle Fluctuations," American Economic Review, 102(4), 1692-1720.

[34] Goodfriend, Marvin, and Bennett T. McCallum (2007), "Banking and Interest Rates in Monetary Policy Analysis: A Quantitative Exploration," Journal of Monetary Economics, 54, 14801507.

[35] Gourinchas, Pierre-Olivier, and Helene Rey (2007), "International Financial Adjustment," Journal of Political Economy, 115(4), 665-703.

[36] Jung, Taehun, Yuki Teranishi, and Tsutomu Watanade (2001), "Optimal Monetary Policy at the Zero-Interest-Rate Bound," Journal of Money, Credit and Banking, 37(5), 813-835.

[37] Kirsanova, Tatiana, Mathan Satchi, David Vines, and Simon Wren-Lewis (2007), "Optimal Fiscal Policy Rules in a Monetary Union," Journal of Money, Credit and Banking, 39(7), 407440.

[38] Kiyotaki, Nobuhiro, and John Moore (1997), "Credit Cycles," Journal of Political Economy, 105(2), 211-248.

[39] Kiyotaki, Nobuhiro, and John Moore (2008), "Liquidity, Business Cycles, and Monetary Policy," working paper.

[40] Leith, Campbell, and Simon Wren-Lewis (2011), "Discretionary Policy in a Monetary Union with Sovereign Debt," European Economic Review, 55, 93-117.

[41] Obstfeld, Maurice, and Kenneth Rogoff (1996), Foundations of International Macroeconomics, Cambridge, MA: MIT Press.

[42] Pescatori, Andrea (2012), "Monetary Policy and Wealth Redistribution," working paper.

[43] Sims, Christopher A. (2002), "Solving Linear Rational Expectations Models," Computational Economics, 20(1-2), 1-20. 
[44] Townsend, Robert M. (1979), "Optimal Contracts and Competitive Markets with Costly State Verification," Journal of Economic Theory, 21(2), 265-293.

[45] Williamson, Stephen (1987), "Financial Intermediation, Business Failures, and Real Business Cycles," Journal of Political Economy, 95(6), 1196-1216.

[46] Woodford, Michael (2003), Interest and Prices: Foundations of a Theory of Monetary Policy, Princeton, NJ: Princeton University Press.

[47] Woodford, Michael (2010), "Optimal Monetary Stabilization Policy," in Benjamin M. Friedman and Michael Woodford (eds), Handbook of Monetary Economics, Amsterdam: North-Holland. 


\section{$6 \quad$ Figures}
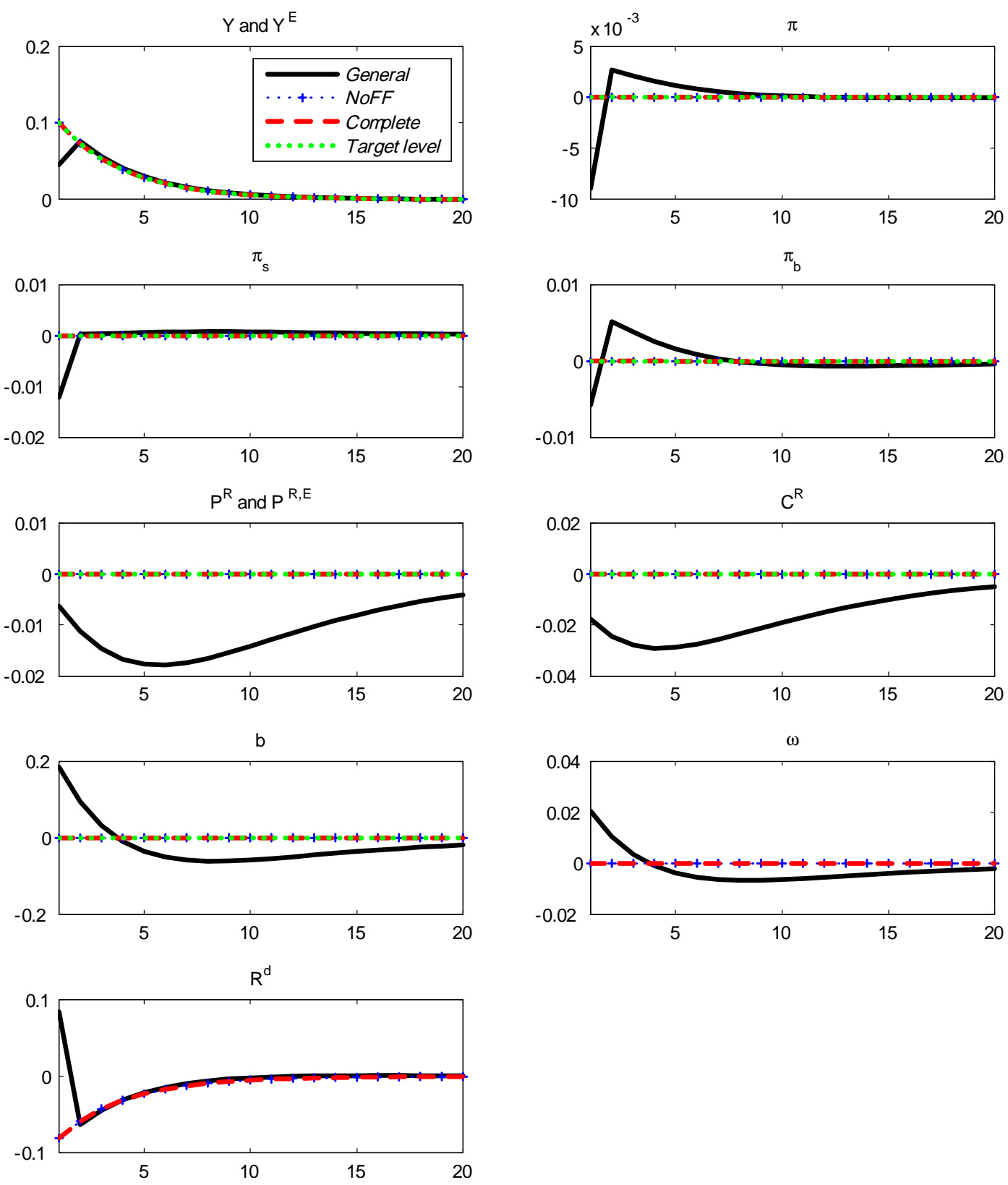

Figure 2: Impulse responses to a one standard deviation increase in $A_{t}$. 

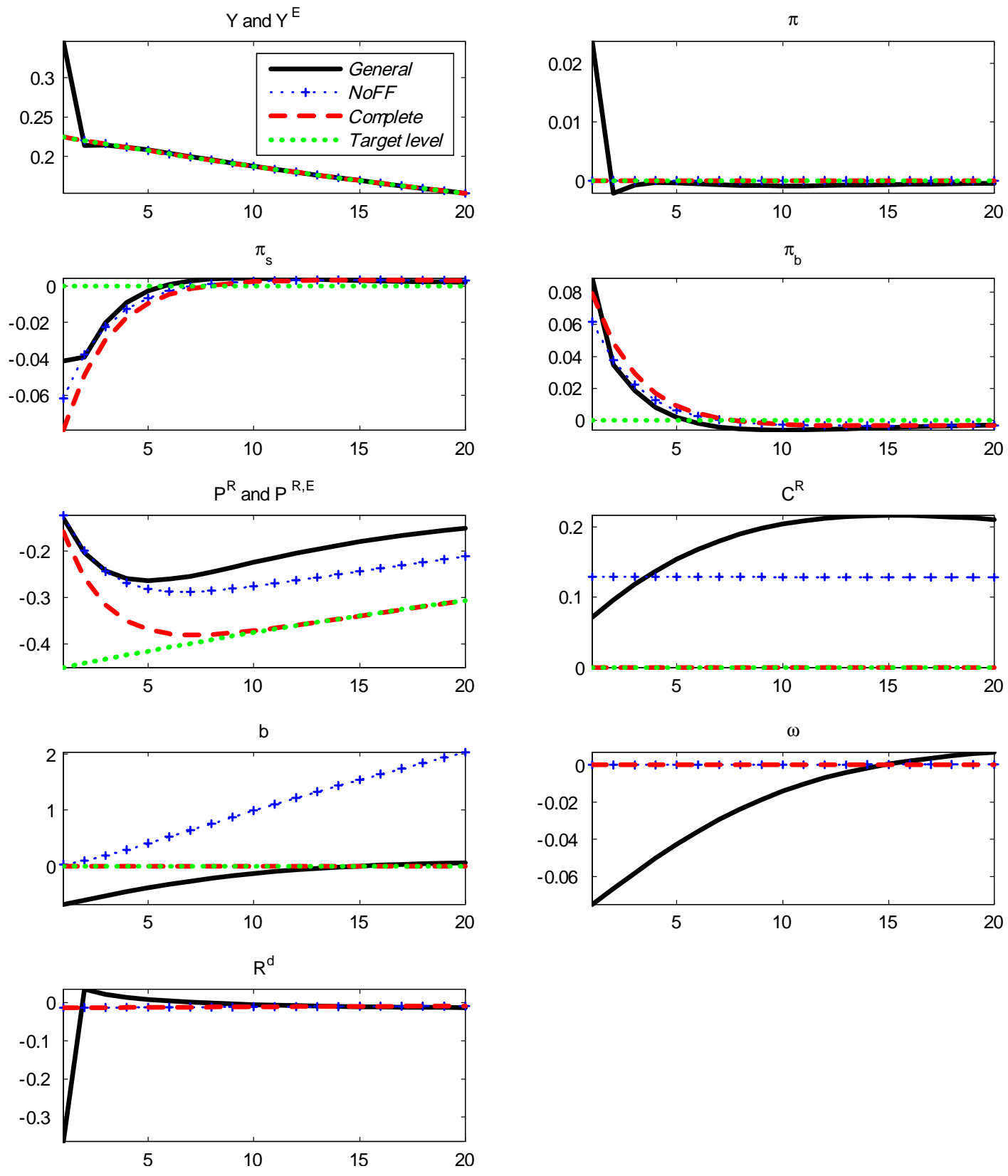

Figure 3: Impulse responses to a one standard deviation increase in $A_{s, t}$. 

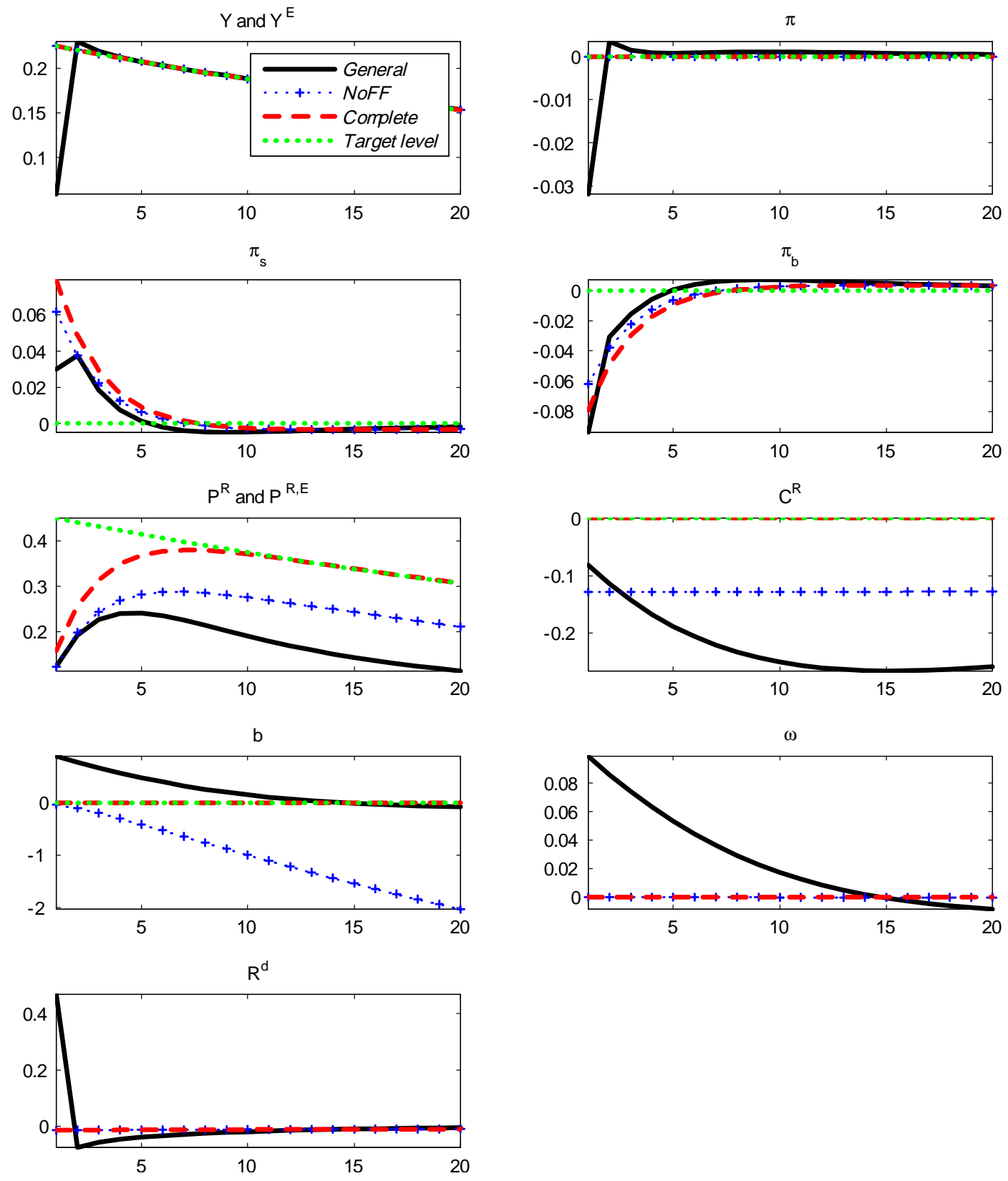

Figure 4: Impulse responses to a one standard deviation increase in $A_{b, t}$. 

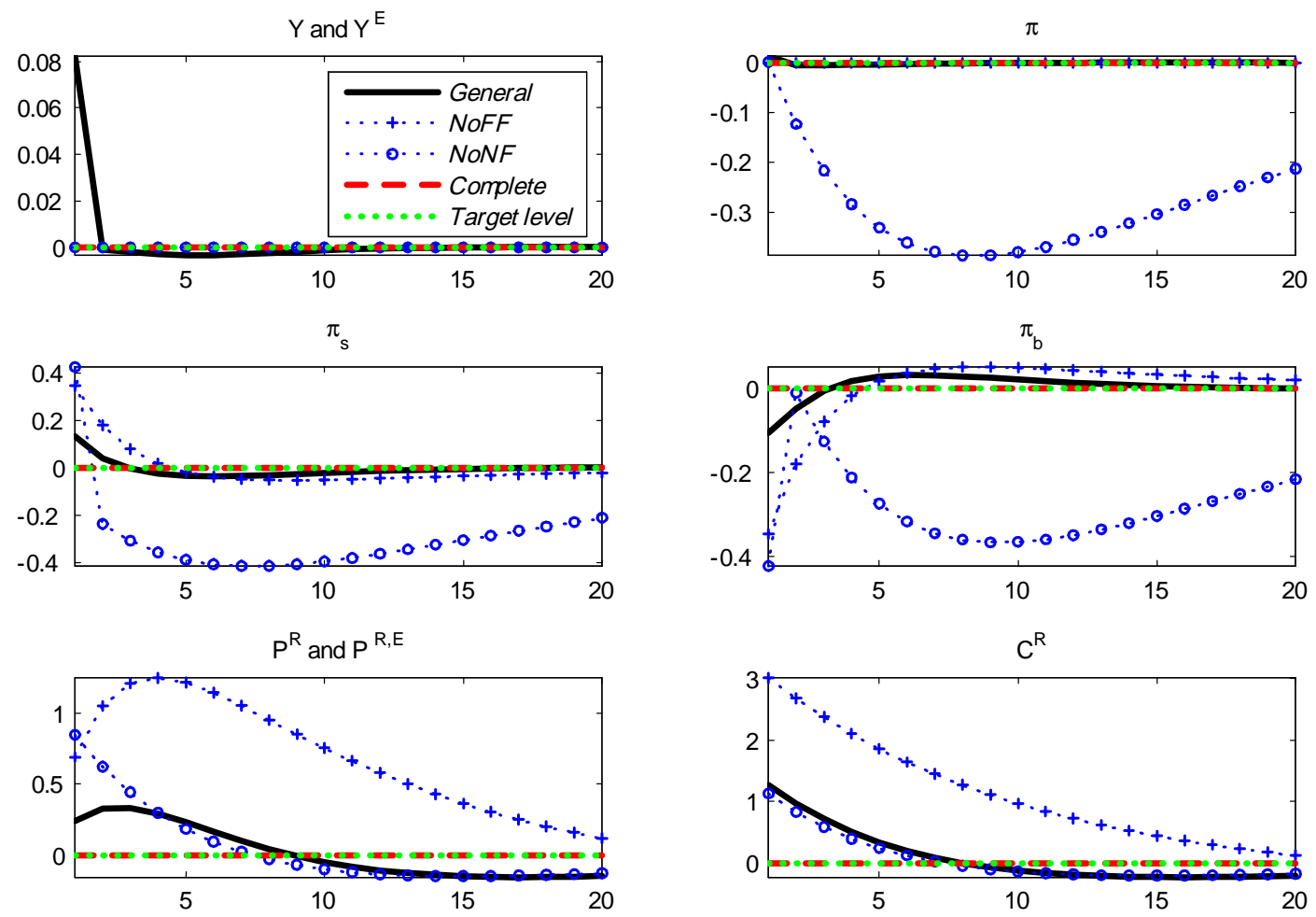

b
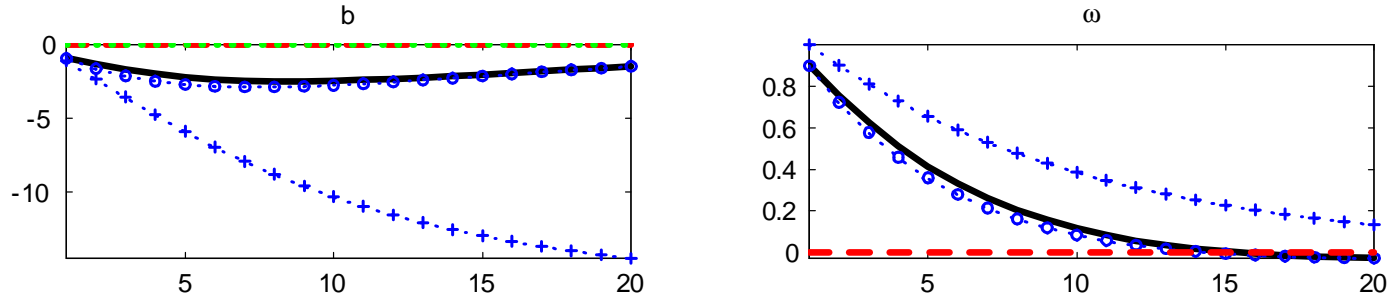

$\mathrm{R}^{\mathrm{d}}$

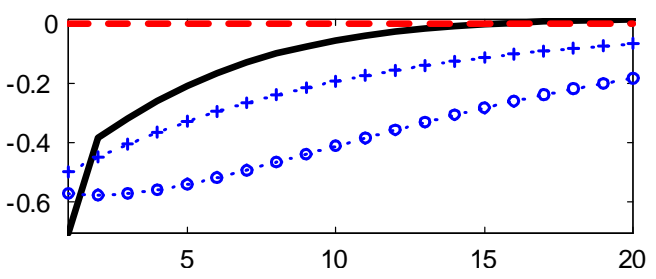

Figure 5: Impulse responses to a one standard deviation increase in $\chi_{t}$. 

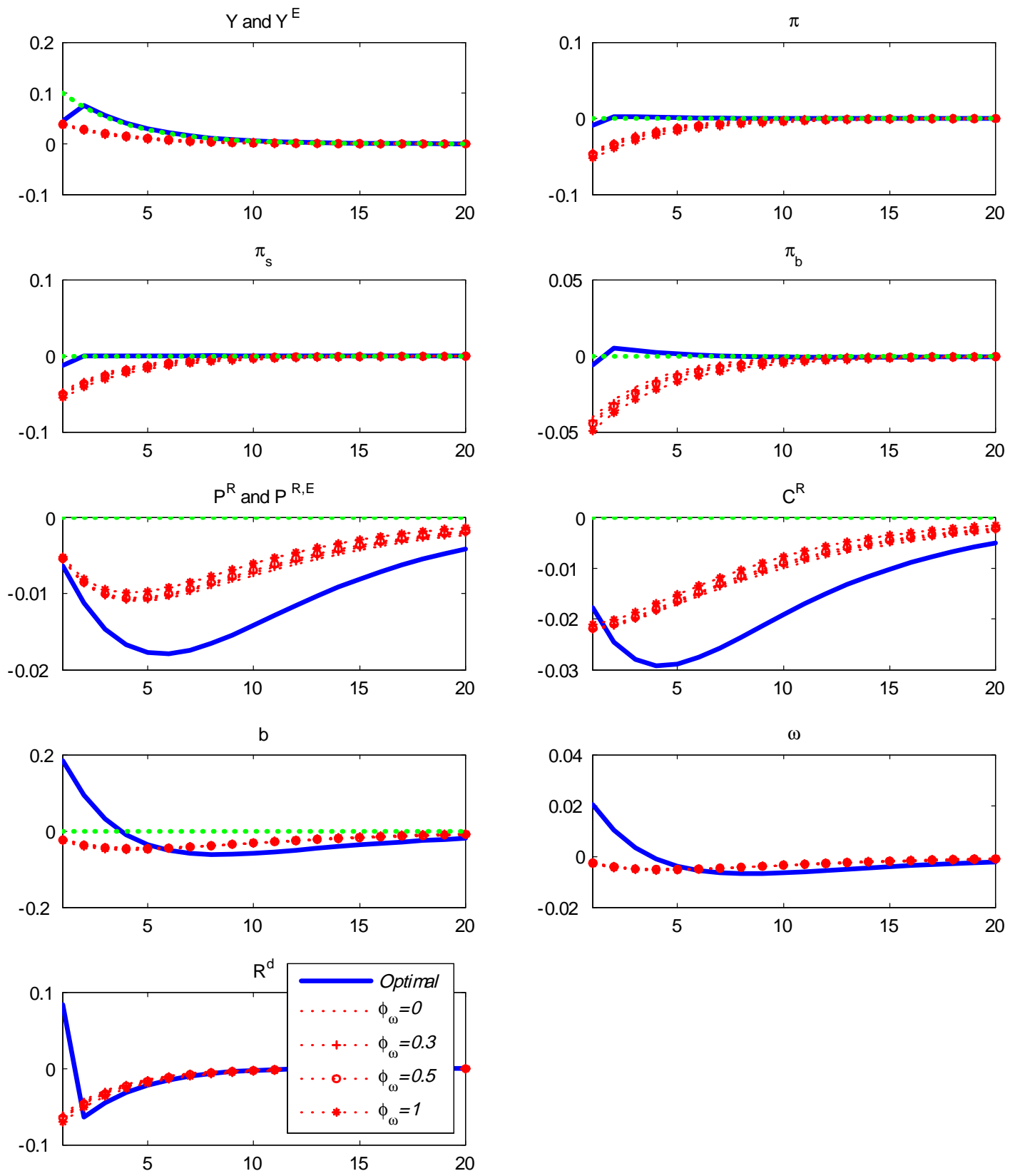

Figure 6: Impulse responses to a one standard deviation increase in $A_{t}$, under optimal policy and under Taylor rule with alternative degrees of spread adjustment. 

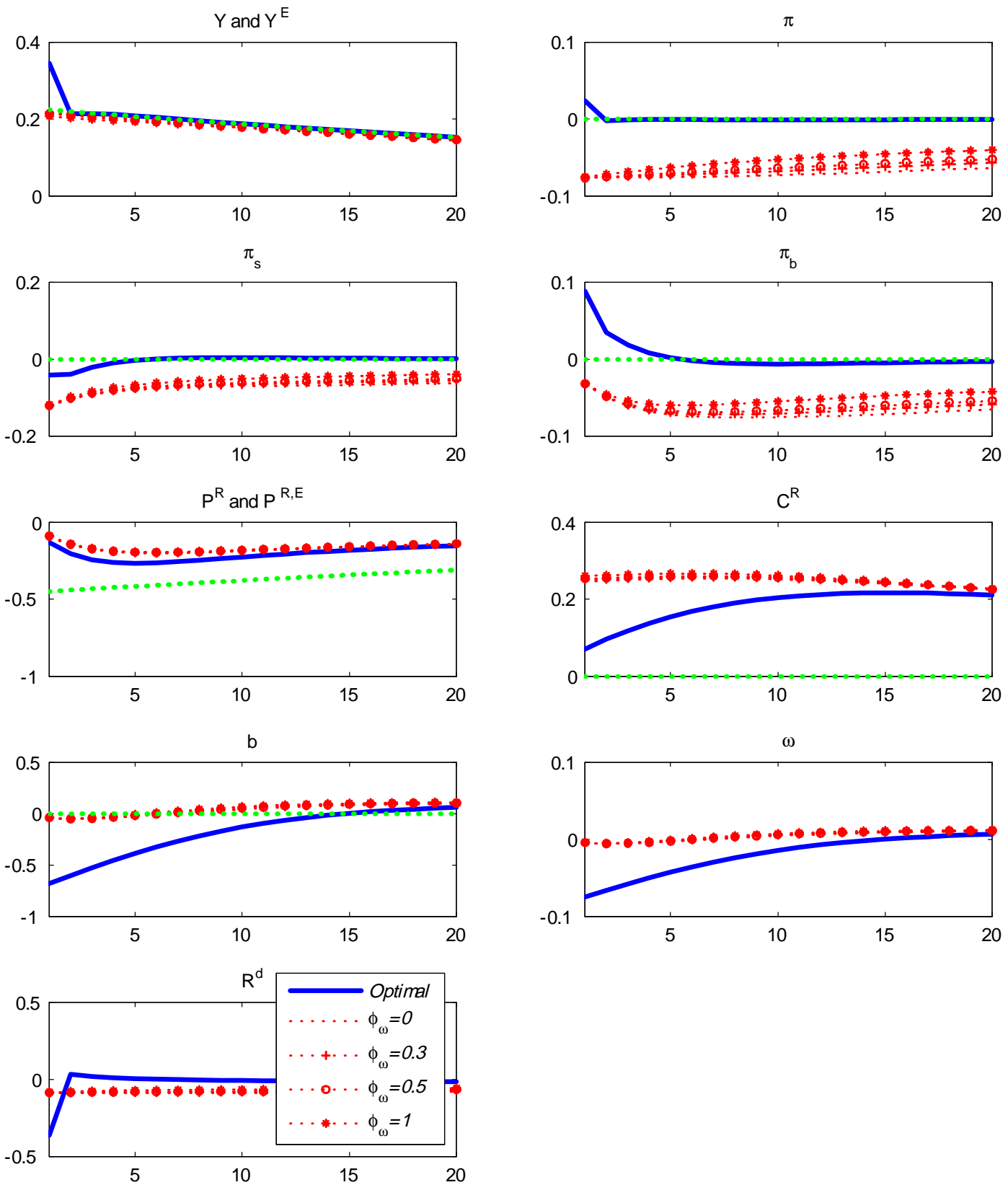

Figure 7: Impulse responses to a one standard deviation increase in $A_{s, t}$, under optimal policy and under Taylor rule with alternative degrees of spread adjustment. 

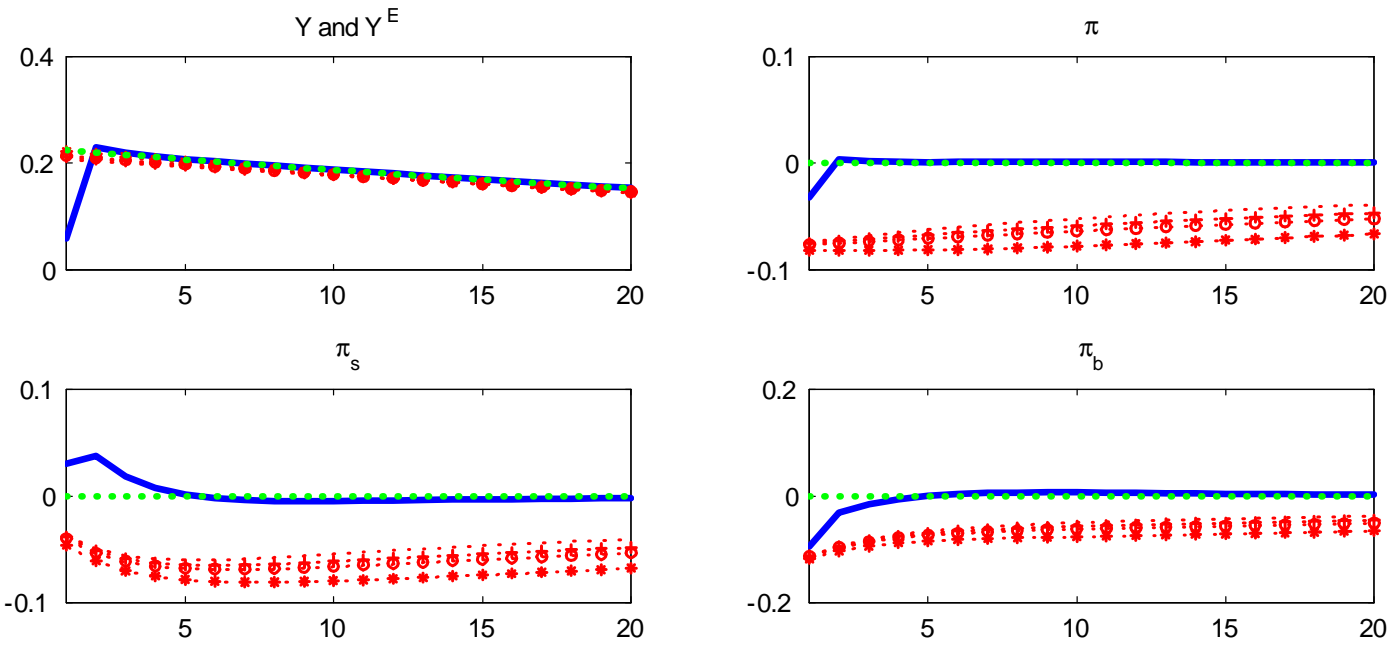

$\pi$
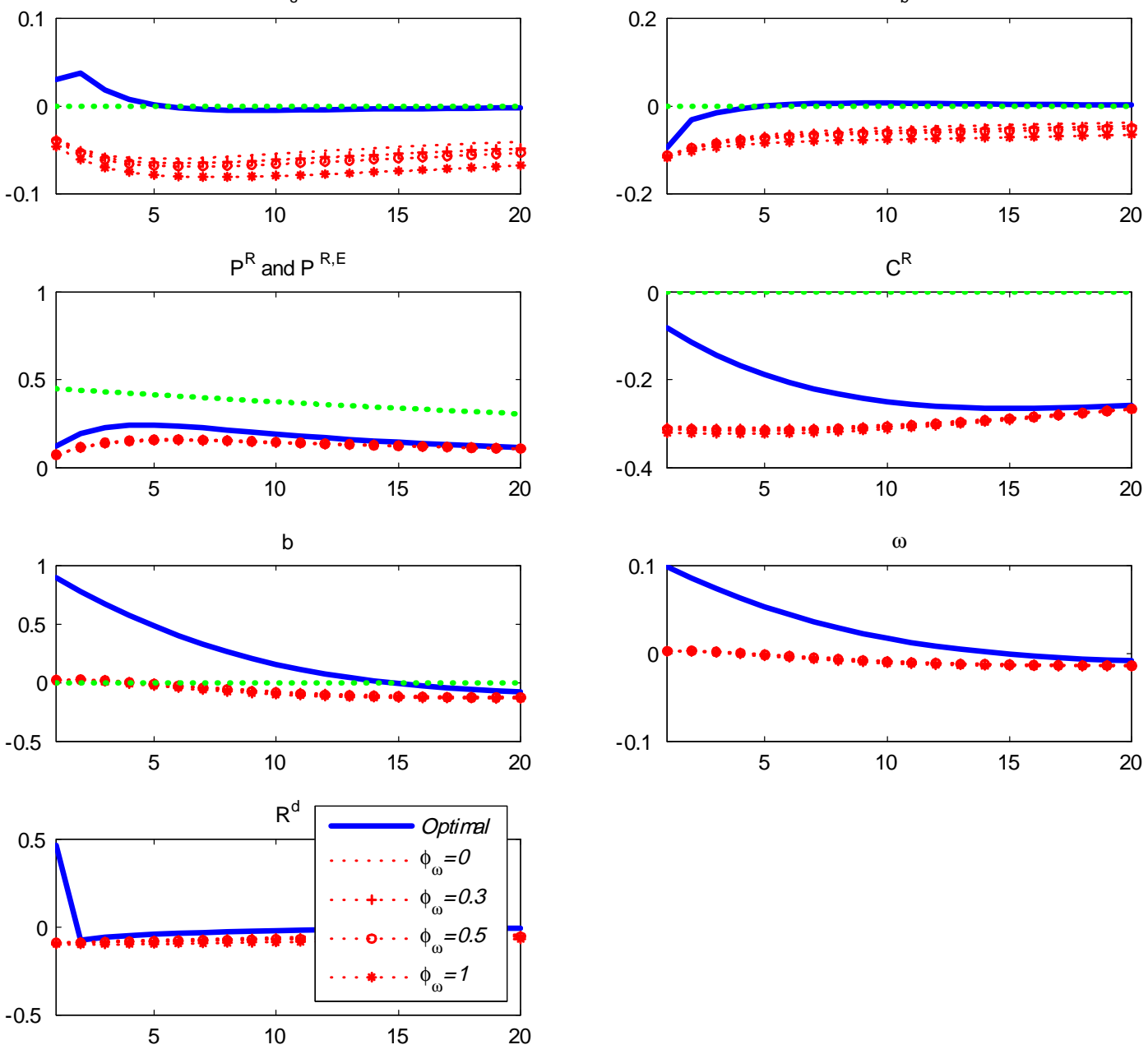

Figure 8: Impulse responses to a one standard deviation increase in $A_{b, t}$, under optimal policy and under Taylor rule with alternative degrees of spread adjustment. 

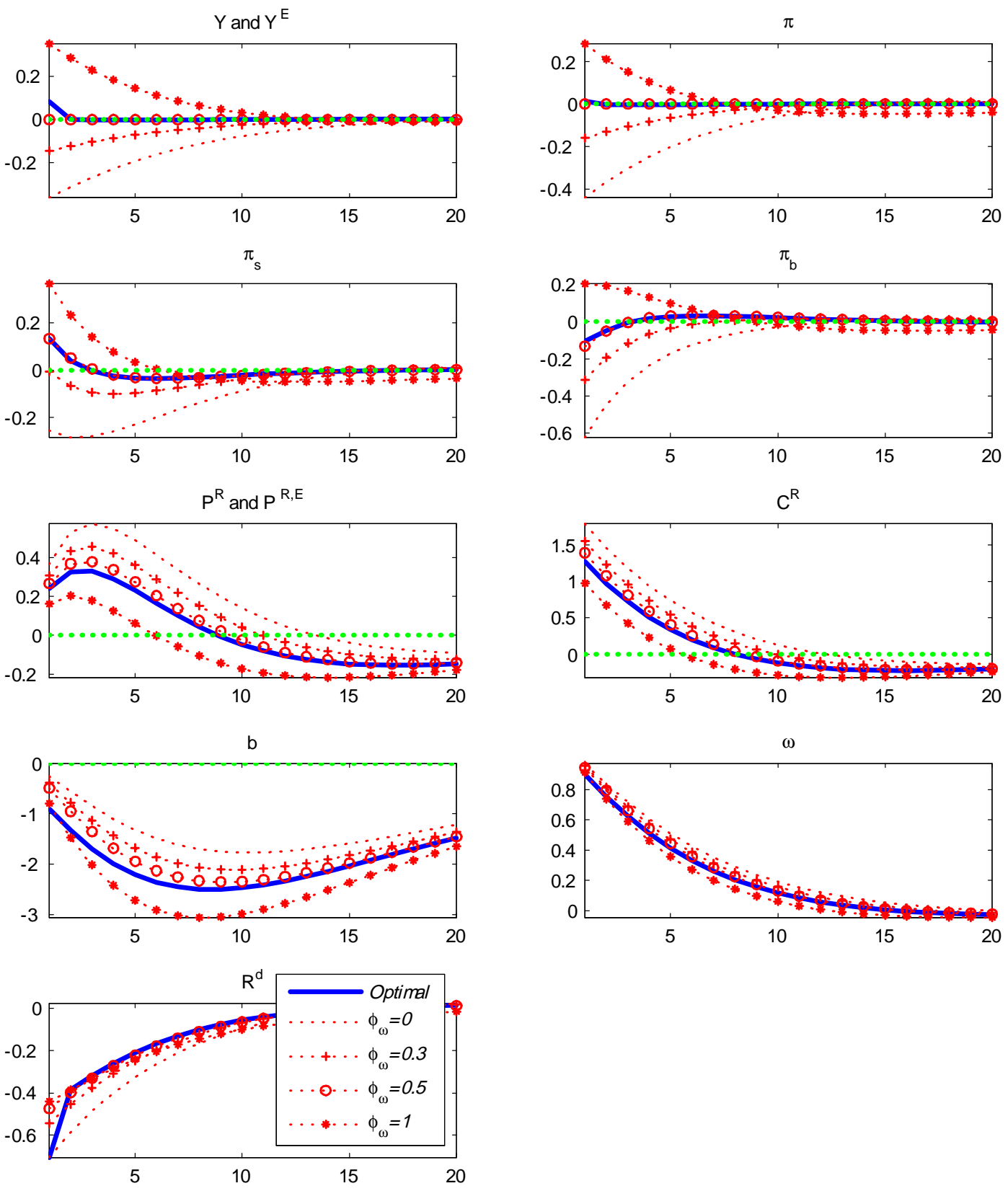

Figure 9: Impulse responses to a one standard deviation increase in $\chi_{t}$, under optimal policy and under Taylor rule with alternative degrees of spread adjustment. 


\section{Appendix}

\section{A Steady state}

This section details a steady-state allocation around which we (log-)linearize the model. For simplicity, we make some assumptions that deliver a steady state in which allocation is efficient and symmetric across countries - except net bond holding. As mentioned in the main text, the government imposes a proportional tax on sales of goods, which removes the inefficiency originated from imperfect competition with a constant tax rate, $\tau=1 / \theta$. Similarly, the government receives (or gives) non-state-contingent and non-time-varying international transfers from (to) other countries that equalizes steady-state consumption and labor hours across countries - despite asymmetric net asset positions. ${ }^{46}$ In addition, we assume that the steady-state levels of country-specific productivities are the same across countries and the credit spread is zero in steady state: specifically, $\bar{A}_{s}=\bar{A}_{b}=\bar{A}=1$ without loss of generality and $\bar{\chi}=0$.

Since there are no wasted resources in steady state $(\bar{\Xi} \equiv \Xi(\bar{b})=0)$, each country's consumption is a fraction of output:

$$
\bar{C}_{s}=\lambda_{s}^{C} \bar{Y} \text { and } \bar{C}_{b}=\lambda_{b}^{C} \bar{Y}
$$

where $n_{s} \lambda_{s}^{C}+n_{b} \lambda_{b}^{C}=1$. In the absence of shocks, household (and government) net asset positions are constant at the initial condition. We assume without loss of generality that the initial condition are given as $b_{s,-1}^{P} \geq 0 \geq b_{b,-1}^{P}$ (and hence $\left.b_{s,-1}^{G} \geq 0 \geq b_{b,-1}^{G}\right) .{ }^{47}$ This implies that

$$
\begin{aligned}
& \bar{d}=n_{s}\left(\bar{b}_{s}^{p}+\bar{b}_{s}^{G}\right)=n_{s}\left(b_{s,-1}^{P}+b_{s,-1}^{G}\right) \geq 0, \\
& \bar{b}=-n_{b}\left(\bar{b}_{b}^{P}+\bar{b}_{b}^{G}\right)=-n_{b}\left(b_{b,-1}^{P}+b_{b,-1}^{G}\right) \geq 0 .
\end{aligned}
$$

Given (25), country $j$ 's production and price in unit of consumption good are given by:

$$
\begin{aligned}
\frac{\bar{P}_{j}}{\bar{P}} & =\left(\lambda_{j}^{C}\right)^{\frac{\sigma}{1+\eta \varphi}} \bar{Y}^{\frac{\sigma+\varphi}{1+\eta \varphi}}, \\
n_{j}^{-1} \bar{Y}_{j} & =\left(\lambda_{j}^{C}\right)^{-\frac{\sigma \eta}{1+\eta \varphi}} \bar{Y}^{\frac{1-\eta \sigma}{1+\eta \varphi}} .
\end{aligned}
$$

The steady-state value of "relative" variables can be obtained from (25)-(27):

$$
\begin{aligned}
\bar{C}^{R} & =\frac{\lambda_{s}^{C}}{\lambda_{b}^{C}} \\
\bar{P}^{R} & =\left(\frac{\lambda_{s}^{C}}{\lambda_{b}^{C}}\right)^{\frac{\sigma}{1+\eta \varphi}}, \\
\bar{Y}^{R} & =\frac{n_{s}}{n_{b}}\left(\bar{P}^{R}\right)^{-\eta}=\frac{n_{s}}{n_{b}}\left(\frac{\lambda_{s}^{C}}{\lambda_{b}^{C}}\right)^{-\frac{\eta \sigma}{1+\eta \varphi}}, \\
\bar{N}^{R} & =\left(\frac{\lambda_{s}^{C}}{\lambda_{b}^{C}}\right)^{-\frac{\eta \sigma}{1+\eta \varphi}} .
\end{aligned}
$$

Aggregate output is in turn obtained as:

$$
\bar{Y}=\left[n_{s}\left(\lambda_{s}^{C}\right)^{-\frac{\sigma(\eta-1)}{1+\eta \varphi}}+n_{b}\left(\lambda_{b}^{C}\right)^{-\frac{\sigma(\eta-1)}{1+\eta \varphi}}\right]^{\frac{1+\eta \varphi}{(\eta-1)(\sigma+\varphi)}}
$$

From the consumption Euler equations 6 and 5, we obtain the steady state level of the nominal interest rate:

$$
\bar{R}^{d}=\bar{R}^{b}=\beta^{-1}
$$

\footnotetext{
${ }^{46}$ Pescatori (2012) also uses a similar transfer scheme in a closed economy model with agents that have ex-ante asymmetric asset positions.

${ }^{47}$ Here $b_{j}^{l} \equiv B_{j}^{l} / P$ for $l=P, G$ and $j=s, b$.
} 
Finally, we consider $\lambda_{s}^{C}$ and $\lambda_{b}^{C}$, which depend on net asset positions, the level of production in each country, and the amount of international transfers. Let us consider household budget constraint (3). In steady state, (3) - after substituting out lump-sum transfers using (12) - is simplified to:

$$
\begin{aligned}
& \bar{C}_{s}=\lambda_{s}^{C} \bar{Y}=(1-\beta)\left(\bar{b}_{s}^{P}+\bar{b}_{s}^{G}\right)+\frac{1}{n_{s}} \frac{\bar{P}_{s}}{\bar{P}} \bar{Y}_{s}+T R_{s}, \\
& \bar{C}_{b}=\lambda_{b}^{C} \bar{Y}=(1-\beta)\left(\bar{b}_{b}^{P}+\bar{b}_{b}^{G}\right)+\frac{1}{n_{b}} \frac{\bar{P}_{b}}{\bar{P}} \bar{Y}_{b}+T R_{b}
\end{aligned}
$$

From the equations above, we can find the value of $T R_{s}\left(=-\frac{n_{b}}{n_{s}} T R_{b}\right)$ that equalizes steady-state consumption across countries $\left(\lambda_{s}^{C}=\lambda_{b}^{C}=1\right)$ :

$$
\begin{aligned}
& T R_{s}=-(1-\beta)\left(\bar{b}_{s}^{P}+\bar{b}_{s}^{G}\right) \leq 0 \\
& T R_{b}=-(1-\beta)\left(\bar{b}_{b}^{P}+\bar{b}_{b}^{G}\right) \geq 0
\end{aligned}
$$

In this case, the steady-state cross-country distributions are characterized simply as:

$$
\bar{C}^{R}=\bar{P}^{R}=\bar{N}^{R}=1,
$$

while the size of the economy is normalized to one:

$$
\bar{Y}=1 \text {. }
$$

\section{B Log-linear approximation}

We present below the equations characterizing the first-order approximation of the equilibrium of our model.

- Euler equations:

$$
\begin{gathered}
\hat{Y}_{t}=E_{t}\left[\hat{Y}_{t+1}\right]-\frac{1}{\sigma}\left\{\hat{R}_{t}^{d}+n_{b} \hat{\omega}_{t}-E_{t}\left[\pi_{t+1}\right]\right\} \\
\hat{C}_{t}^{R}=E_{t}\left[\hat{C}_{t+1}^{R}\right]+\frac{1}{\sigma} \hat{\omega}_{t}
\end{gathered}
$$

- Phillips curves:

$$
\begin{aligned}
& \pi_{s, t}=\beta E_{t}\left[\pi_{s, t+1}\right]+\kappa\left[\hat{Y}_{t}-\hat{Y}_{t}^{E}\right]+\kappa\left(\frac{\sigma}{\sigma+\varphi} n_{b}\right)\left[\hat{C}_{t}^{R}\right]-\kappa\left(\frac{1+\eta \varphi}{\sigma+\varphi} n_{b}\right)\left[\hat{P}_{t}^{R}-\hat{P}_{t}^{R, E}\right] \\
& \pi_{b, t}=\beta E_{t}\left[\pi_{b, t+1}\right]+\kappa\left[\hat{Y}_{t}-\hat{Y}_{t}^{E}\right]-\kappa\left(\frac{\sigma}{\sigma+\varphi} n_{s}\right)\left[\hat{C}_{t}^{R}\right]+\kappa\left(\frac{1+\eta \varphi}{\sigma+\varphi} n_{s}\right)\left[\hat{P}_{t}^{R}-\hat{P}_{t}^{R, E}\right]
\end{aligned}
$$

- Law of motion for aggregate debt:

$$
\hat{b}_{t}=\beta^{-1} \hat{b}_{t-1}+\lambda^{B} \hat{R}_{t}^{d}-\beta^{-1} \lambda^{B} \hat{\pi}_{t}-\beta^{-1} n_{s} n_{b}(\eta-1) \hat{P}_{t}^{R}-\beta^{-1} n_{s} n_{b} \hat{C}_{t}^{R}+\left(1-n_{b}\right) \lambda^{B} \hat{\omega}_{t}
$$

- Credit spread:

$$
\hat{\omega}_{t}=\hat{\chi}_{t}+\eta_{B} \hat{b}_{t}
$$

- Identities:

$$
\pi_{t}=n_{s} \pi_{s, t}+n_{b} \pi_{b, t} \quad \hat{P}_{t}^{R}=\hat{P}_{t-1}^{R}+\pi_{s, t}-\pi_{b, t}
$$

- Country-specific consumption:

$$
\hat{C}_{s, t}=n_{b} \hat{C}_{t}^{R}+\hat{Y}_{t} \quad \hat{C}_{b, t}=-n_{s} \hat{C}_{t}^{R}+\hat{Y}_{t}
$$

- Country-specific production:

$$
\hat{Y}_{s, t}=-\eta n_{b} \hat{P}_{t}^{R}+\hat{Y}_{t} \quad \hat{Y}_{b, t}=\eta n_{s} \hat{P}_{t}^{R}+\hat{Y}_{t}
$$

- Country-specific net asset position:

$$
\hat{b}_{s, t}=\frac{1}{n_{s}} \hat{b}_{t} \quad \hat{b}_{b, t}=-\frac{1}{n_{b}} \hat{b}_{t}
$$


- Exogenous processes

$$
\begin{gathered}
\hat{Y}_{t}^{E}=\frac{1+\varphi}{\sigma+\varphi}\left(n_{s} \hat{A}_{s, t}+n_{b} \hat{A}_{b, t}+\hat{A}_{t}\right) \quad \hat{P}_{t}^{R, E}=-\frac{1+\varphi}{1+\eta \varphi}\left(\hat{A}_{s, t}-\hat{A}_{b, t}\right) \\
\hat{\chi}_{t}=\rho_{\chi} \hat{\chi}_{t-1}+\varepsilon_{\chi, t} \quad \hat{A}_{t}=\rho_{A} \hat{A}_{t-1}+\varepsilon_{A, t} \\
\hat{A}_{s, t}=\rho_{A s} \hat{A}_{s, t-1}+\varepsilon_{A_{s}, t} \quad \hat{A}_{b, t}=\rho_{A_{b}} \hat{A}_{b, t-1}+\varepsilon_{A_{b}, t}
\end{gathered}
$$

\section{Proofs}

\section{C.1 Proposition 1 (Welfare-theoretic loss function)}

We follow Woodford (2003) in deriving the utility-based loss function. We take a Taylor expansion of each term of the utility function. Taking a second order expansion around the steady state, we obtain

$$
U\left(C_{j, t}\right)=U(\bar{C})+U_{C}\left(C_{j, t}-\bar{C}\right)+\frac{1}{2} U_{C C}\left(C_{j, t}-\bar{C}\right)^{2}+t . i . p+O\left(\|\xi\|^{3}\right)
$$

where $O\left(\|\xi\|^{3}\right)$ represents all relevant terms that are of third or higher order, and t.i.p denotes all the terms independent of monetary policy. We also take a second order Taylor expansion of $C_{j, t}$. Then we have

$$
C_{j, t}=\bar{C}\left(1+\hat{C}_{j, t}+\frac{1}{2} \hat{C}_{j, t}^{2}\right)+O\left(\|\xi\|^{3}\right)
$$

where $\hat{C}_{j, t} \equiv \log C_{j, t}-\log \bar{C}$. This implies

$$
C_{j, t}-\bar{C}=\bar{C} \hat{C}_{j, t}+\frac{1}{2} \bar{C} \hat{C}_{j, t}^{2}+O\left(\|\xi\|^{3}\right)
$$

Substituting (30) into (28) gives

$$
U\left(C_{j, t}\right)=U\left(\bar{C}_{j}\right)+U_{C} \bar{C} \hat{C}_{j, t}+\frac{1}{2} U_{C} \bar{C} \hat{C}_{j, t}^{2}+\frac{1}{2} U_{C C} \bar{C}^{2} \hat{C}_{j, t}^{2}+t . i \cdot p+O\left(\|\xi\|^{3}\right)
$$

Note that $U(\bar{C})$ is independent of monetary policy. We rewrite (31) as

$$
U\left(C_{j, t}\right)=U_{C} \bar{C}\left\{\hat{C}_{j, t}+\frac{1}{2} \hat{C}_{j, t}^{2}+\frac{1}{2} \frac{U_{C C} \bar{C}}{U_{C}} \hat{C}_{j, t}^{2}\right\}+t . i . p+O\left(\|\xi\|^{3}\right)
$$

where t.i.p denotes all the terms independent of monetary policy. From the utility function we assume in the text, we have $\frac{U_{C C} \bar{C}}{U_{C}}=-\sigma$. Thus we obtain

$$
U\left(C_{j, t}\right)=U_{C} \bar{C}\left\{\hat{C}_{j, t}+\frac{1}{2}(1-\sigma) \hat{C}_{j, t}^{2}\right\}+t . i . p+O\left(\|\xi\|^{3}\right)
$$

Now we also take a second order Taylor expansion of $V\left(N_{j, t}(i)\right)$.

$$
V\left(N_{j, t}(i)\right)=V(\bar{N})+V_{N}\left(N_{j, t}(i)-\bar{N}\right)+V_{N N}\left(N_{j, t}(i)-\bar{N}\right)^{2}+t . i . p+O\left(\|\xi\|^{3}\right)
$$

The second order approximation of $N_{j, t}(i)$ is:

$$
\frac{N_{j, t}(i)}{\bar{N}}=1+\hat{N}_{j, t}(i)+\frac{1}{2} \hat{N}_{j, t}(i)^{2}+O\left(\|\xi\|^{3}\right)
$$

Substituting (34) into (33) gives

$$
\begin{aligned}
V\left(N_{j, t}(i)\right) & =V_{N} \bar{N}\left\{\hat{N}_{j, t}(i)+\frac{1}{2} \hat{N}_{j, t}(i)^{2}+\frac{1}{2} \frac{V_{N N} \bar{N}}{V_{N}} \hat{N}_{j, t}(i)^{2}\right\} \\
& + \text { t.i.p. }+O\left(\|\xi\|^{3}\right)
\end{aligned}
$$


Since $\frac{V_{N N} \bar{N}}{V_{N}}=\varphi$, we rewrite $(35)$ as

$$
V\left(N_{j, t}(i)\right)=V_{N} \bar{N}\left\{\hat{N}_{j, t}(i)+\frac{1}{2}(1+\varphi) \hat{N}_{j, t}(i)^{2}\right\}+t . i . p .+O\left(\|\xi\|^{3}\right)
$$

From the production function, we have

$$
\hat{Y}_{j, t}(i)=\hat{A}_{t}+\hat{A}_{j, t}+\hat{N}_{j, t}(i) \Longrightarrow \hat{N}_{j, t}(i)=\hat{Y}_{j, t}(i)-\hat{A}_{t}-\hat{A}_{j, t}
$$

Substituting (37) into (36), we obtain

$$
\begin{aligned}
V\left(N_{j, t}(i)\right) & =V_{N} \bar{N}\left\{\begin{array}{c}
\hat{Y}_{j, t}(i)-\hat{A}_{t}-\hat{A}_{j, t} \\
+\frac{1}{2}(1+\varphi)\left[\begin{array}{c}
\hat{Y}_{j, t}(i)^{2}+\hat{A}_{t}^{2}+\hat{A}_{j, t}^{2} \\
-2 \hat{A}_{t} \hat{Y}_{j, t}(i)-2 \hat{A}_{j, t} \hat{Y}_{j, t}(i)-2 \hat{A}_{t} \hat{A}_{j, t}
\end{array}\right]
\end{array}\right\}+t . i . p .+O\left(\|\xi\|^{3}\right) \\
& =V_{N} \bar{N}\left\{\begin{array}{c}
\hat{Y}_{j, t}(i)+\frac{1}{2}(1+\varphi) \hat{Y}_{j, t}(i)^{2} \\
-(1+\varphi)\left[\hat{A}_{t} \hat{Y}_{j, t}(i)+\hat{A}_{j, t} \hat{Y}_{j, t}(i)\right]
\end{array}\right\}+t . i . p .+O\left(\|\xi\|^{3}\right)
\end{aligned}
$$

By integrating (38), we obtain

$$
\begin{aligned}
\frac{1}{n_{j}} \int_{\mathcal{I}_{j}} V\left(N_{j, t}(i)\right) d i & =V_{N} \bar{N}\left\{\begin{array}{r}
E_{i}^{j}\left[\hat{Y}_{j, t}(i)\right]+\frac{1}{2}(1+\varphi) \operatorname{Var}_{i}^{j}\left[\hat{Y}_{j, t}(i)\right]+ \\
\frac{1}{2}(1+\varphi) E_{i}^{j}\left[\hat{Y}_{j, t}(i)\right]^{2}-(1+\varphi)\left(\hat{A}_{t}+\hat{A}_{j, t}\right) E_{i}^{j}\left[\hat{Y}_{j, t}(i)\right]
\end{array}\right\} \\
& + \text { t.i.p. }+O\left(\|\xi\|^{3}\right)
\end{aligned}
$$

Taking a second order approximation of the aggregators gives

$$
\hat{Y}_{j, t}(i)=E_{i}^{j}\left[\hat{Y}_{j, t}(i)\right]+\frac{1}{2}\left(\frac{\theta-1}{\theta}\right) \operatorname{Var}_{i}^{j}\left[\hat{Y}_{j, t}(i)\right]+O\left(\|\xi\|^{3}\right),
$$

which implies

$$
\begin{aligned}
E_{i}^{j}\left[\hat{Y}_{j, t}(i)\right] & =\hat{Y}_{j, t}-\frac{1}{2}\left(\frac{\theta-1}{\theta}\right) \operatorname{Var}_{i}^{j}\left[\hat{Y}_{j, t}(i)\right]+O\left(\|\xi\|^{3}\right) \\
E_{i}^{j}\left[\hat{Y}_{j, t}(i)\right]^{2} & =\hat{Y}_{j, t}^{2}+O\left(\|\xi\|^{3}\right)
\end{aligned}
$$

We substitute (40) and (41) into (39) obtaining

$$
\left.\begin{array}{rl}
\frac{1}{n_{j}} \int_{\mathcal{I}_{j}} V\left(N_{j, t}(i)\right) d i & =V_{N} \bar{N}\left\{\begin{array}{c}
\hat{Y}_{j, t}+\frac{1}{2}(1+\varphi) \hat{Y}_{j, t}^{2}-(1+\varphi)\left(\hat{A}_{t}+\hat{A}_{j, t}\right) \hat{Y}_{j, t} \\
+\frac{1}{2}\left(\varphi+\theta^{-1}\right) \operatorname{Var}_{i}^{j}\left[\hat{Y}_{j, t}(i)\right]
\end{array}\right\} \\
& + \text { t.i.p. }+O\left(\|\xi\|^{3}\right)
\end{array}\right\}
$$

Now recall that $\bar{N}=\frac{\bar{Y}}{\bar{A}_{j} A}=\bar{Y}$. From the household's labor supply relation, we have

$$
-\frac{V_{N}}{U_{C}}=\frac{\bar{W}}{\bar{P}}=\bar{A}_{j} \bar{A}=1 \Longrightarrow-V_{N} \bar{Y}=U_{C} \bar{Y}=U_{C} \bar{C}
$$


Country- $j$ household's period utility is then given by

$$
\begin{aligned}
\tilde{U}_{j, t} & \equiv\left\{U\left(C_{j, t}\right)-\frac{1}{n_{j}} \int_{\mathcal{I}_{j}} V\left(N_{j, t}(i)\right) d i\right\} \\
& =U_{C} \bar{Y}\left\{\hat{C}_{j, t}+\frac{1}{2}(1-\sigma) \hat{C}_{j, t}^{2}\right\} \\
& -U_{C} \bar{Y}\left\{\begin{array}{c}
\hat{Y}_{j, t}+\frac{1}{2}(1+\varphi) \hat{Y}_{j, t}^{2}-(1+\varphi)\left(\hat{A}_{t}+\hat{A}_{j, t}\right) \hat{Y}_{j, t} \\
+\frac{1}{2}\left(\varphi+\theta^{-1}\right) \operatorname{Var}_{i}^{j}\left[\hat{Y}_{j, t}(i)\right]
\end{array}\right\}+t . i . p .+O\left(\|\xi\|^{3}\right) \\
& =U_{C} \bar{Y}\left\{\begin{array}{c}
\hat{C}_{j, t}+\left(\frac{1-\sigma}{2}\right) \hat{C}_{j, t}^{2} \\
-\left(\frac{1+\varphi}{2}\right) \hat{Y}_{j, t}^{2}+(1+\varphi)\left(\hat{A}_{t}+\hat{A}_{j, t}\right) \hat{Y}_{j, t} \\
-\left(\frac{\varphi+\theta^{-1}}{2}\right) \operatorname{Var}_{i}^{j}\left[\hat{Y}_{j, t}(i)\right]
\end{array}\right\}+t . i . p .+O\left(\|\xi\|^{3}\right)
\end{aligned}
$$

Finally, the weighted sum of period utilities is:

$$
\begin{aligned}
& \sum_{j=s, b} n_{j} \tilde{U}_{j, t} \equiv \sum_{j=s, b}\left\{U\left(C_{j, t}\right)-\frac{1}{n_{j}} \int_{\mathcal{I}_{j}} V\left(N_{j, t}(i)\right) d i\right\} \\
&= U_{C} \bar{Y}\left\{\begin{array}{c}
\sum_{j}\left(n_{j} \hat{C}_{j, t}-n_{j} \hat{Y}_{j, t}\right)+\left(\frac{1-\sigma}{2}\right) \sum_{j} n_{j} \hat{C}_{j, t}^{2}-\left(\frac{1+\varphi}{2}\right) \sum_{j} n_{j} \hat{Y}_{j, t}^{2} \\
+(1+\varphi) \sum_{j} n_{j}\left(\hat{A}_{t}+\hat{A}_{j, t}\right) \hat{Y}_{j, t}-\left(\frac{\varphi+\theta^{-1}}{2}\right) \sum_{j} n_{j} \operatorname{Var}_{i}^{j}\left[\hat{Y}_{j, t}(i)\right]
\end{array}\right\} \\
&+ \text { t.i.p. }+O\left(\|\xi\|^{3}\right) \\
&= U_{C} \bar{Y}\left\{\begin{array}{c}
\sum_{j}\left(n_{j} \hat{C}_{j, t}-n_{j} \hat{Y}_{j, t}\right)+\left(\frac{1-\sigma}{2}\right) \sum_{j} n_{j} \hat{C}_{j, t}^{2}-\left(\frac{1+\varphi}{2}\right) \sum_{j} n_{j} \hat{Y}_{j, t}^{2} \\
+(1+\varphi) \sum_{j} n_{j}\left(\hat{A}_{t}+\hat{A}_{j, t}\right) \hat{Y}_{j, t}-\left(\frac{\varphi+\theta^{-1}}{2}\right) \sum_{j} n_{j} \operatorname{Var}_{i}^{j}\left[\hat{Y}_{j, t}(i)\right]
\end{array}\right\} \\
&+ \text { t.i.p. }+O\left(\|\xi\|^{3}\right)
\end{aligned}
$$

Recall that the economy's resource constraint is:

$$
Y_{t}=n_{s} C_{s, t}+n_{b} C_{b, t}+\Xi\left(b_{t}\right)
$$

which implies:

$$
\begin{aligned}
\bar{Y}\left(\frac{Y_{t}-\bar{Y}}{\bar{Y}}\right) & =n_{s} \bar{C}\left(\frac{C_{s, t}-\bar{C}_{s}}{\bar{C}_{s}}\right)+n_{b} \bar{C}\left(\frac{C_{b, t}-\bar{C}_{b}}{\bar{C}_{b}}\right) \\
& +\underbrace{\bar{Y} \Xi_{b}(\bar{b})\left(\frac{b_{t}-\bar{b}}{\bar{Y}}\right)}_{=0}+\frac{1}{2} \bar{Y}^{2} \Xi_{b b}(\bar{b})\left(\frac{b_{t}-\bar{b}}{\bar{Y}}\right)^{2}+O\left(\|\xi\|^{3}\right),
\end{aligned}
$$

where $\Xi_{b}(\bar{b})$ is assumed to be zero. This implies

$$
\hat{Y}_{t}+\frac{1}{2} \hat{Y}_{t}^{2}=n_{s} \hat{C}_{s, t}+n_{b} \hat{C}_{b, t}+\frac{1}{2}\left(n_{s} \hat{C}_{s, t}^{2}+n_{b} \hat{C}_{b, t}^{2}\right)+\frac{1}{2} \bar{\Xi}_{b b} \hat{b}_{t}^{2}+\text { t.i.p. }+O\left(\|\xi\|^{3}\right)
$$

From the demand for sectoral goods, we have

$$
\hat{Y}_{j, t}=-\eta\left(\hat{P}_{j, t}-\hat{P}_{t}\right)+\hat{Y}_{t}
$$

The second order expansion of the price aggregator is:

$$
\hat{P}_{t}+\left(\frac{1-\eta}{2}\right) \hat{P}_{t}^{2}=n_{s} \hat{P}_{s, t}+n_{b} \hat{P}_{b, t}+\frac{1-\eta}{2}\left(n_{s} \hat{P}_{s, t}^{2}+n_{b} \hat{P}_{b, t}^{2}\right)+O\left(\|\xi\|^{3}\right)
$$


Rearranging (45) gives

$$
\begin{aligned}
& \hat{P}_{s, t}-\hat{P}_{t}=n_{b} \hat{P}_{t}^{R}-\frac{1-\eta}{2}\left(n_{s} \hat{P}_{s, t}^{2}+n_{b} \hat{P}_{b, t}^{2}-\hat{P}_{t}^{2}\right)+O\left(\|\xi\|^{3}\right) \\
& \hat{P}_{b, t}-\hat{P}_{t}=-n_{s} \hat{P}_{t}^{R}-\frac{1-\eta}{2}\left(n_{s} \hat{P}_{s, t}^{2}+n_{b} \hat{P}_{b, t}^{2}-\hat{P}_{t}^{2}\right)+O\left(\|\xi\|^{3}\right)
\end{aligned}
$$

Also, we have that

$$
\begin{aligned}
\hat{P}_{t} & =n_{s} \hat{P}_{s, t}+n_{b} \hat{P}_{b, t}+O\left(\|\xi\|^{2}\right) \\
\Longrightarrow \hat{P}_{t}^{2} & =n_{s}^{2} \hat{P}_{s, t}^{2}+n_{b}^{2} \hat{P}_{b, t}^{2}+2 n_{s} n_{b} \hat{P}_{s, t} \hat{P}_{b, t}+O\left(\|\xi\|^{3}\right)
\end{aligned}
$$

Substituting (48) into (46) and (47), we obtain

$$
\begin{aligned}
& \hat{P}_{s, t}-\hat{P}_{t}=n_{b} \hat{P}_{t}^{R}-n_{s} n_{b} \frac{1-\eta}{2}\left(\hat{P}_{t}^{R}\right)^{2}+O\left(\|\xi\|^{3}\right) \\
& \hat{P}_{b, t}-\hat{P}_{t}=-n_{s} \hat{P}_{t}^{R}-n_{s} n_{b} \frac{1-\eta}{2}\left(\hat{P}_{t}^{R}\right)^{2}+O\left(\|\xi\|^{3}\right)
\end{aligned}
$$

Let us substitute (49) and (50) into (44). Then

$$
\begin{aligned}
& \hat{Y}_{s, t}=-n_{b} \eta \hat{P}_{t}^{R}+\hat{Y}_{t}+n_{s} n_{b} \frac{\eta(1-\eta)}{2}\left(\hat{P}_{t}^{R}\right)^{2}+O\left(\|\xi\|^{3}\right) \\
& \hat{Y}_{b, t}=n_{s} \eta \hat{P}_{t}^{R}+\hat{Y}_{t}+n_{s} n_{b} \frac{\eta(1-\eta)}{2}\left(\hat{P}_{t}^{R}\right)^{2}+O\left(\|\xi\|^{3}\right)
\end{aligned}
$$

The equations (51) and (52) imply

$$
\begin{aligned}
& \hat{Y}_{s, t}^{2}=\left(n_{b} \eta \hat{P}_{t}^{R}\right)^{2}+\hat{Y}_{t}^{2}-2 n_{b} \eta \hat{P}^{R} \hat{Y}_{t}+O\left(\|\xi\|^{3}\right) \\
& \hat{Y}_{b, t}^{2}=\left(n_{s} \eta \hat{P}_{t}^{R}\right)^{2}+\hat{Y}_{t}^{2}+2 n_{s} \eta \hat{P}_{t}^{R} \hat{Y}_{t}+O\left(\|\xi\|^{3}\right)
\end{aligned}
$$

Then, we have

$$
\begin{aligned}
\frac{1}{U_{C} Y} \sum_{j=s, b} n_{j} \tilde{U}_{j, t}= & \left\{\begin{array}{c}
\sum_{j}\left(n_{j} \hat{C}_{j, t}-n_{j} \hat{Y}_{j, t}\right)+\left(\frac{1-\sigma}{2}\right) \sum_{j} n_{j} \hat{C}_{j, t}^{2}-\left(\frac{1+\varphi}{2}\right) \sum_{j} n_{j} \hat{Y}_{j, t}^{2} \\
+(1+\varphi) \sum_{j} n_{j}\left(\hat{A}_{t}+\hat{A}_{j, t}\right) \hat{Y}_{j, t}-\left(\frac{\varphi+\theta}{2}\right) \sum_{j} n_{j} \operatorname{Var}_{i}^{j}\left[\hat{Y}_{j, t}(i)\right]
\end{array}\right\} \\
= & \left\{\begin{array}{c}
\left(\frac{1}{2} \hat{Y}_{t}^{2}-\frac{\sigma}{2}\left(n_{s} \hat{C}_{s, t}^{2}+n_{b} \hat{C}_{b, t}^{2}\right)-\frac{1}{2} \bar{\Xi}_{b b} \hat{b}_{t}^{2}\right)-n_{s} n_{b} \frac{\eta(1-\eta)}{2}\left(\hat{P}_{t}^{R}\right)^{2} \\
-\left(\frac{1+\varphi}{2}\right) n_{s} n_{b} \eta^{2}\left(\hat{P}_{t}^{R}\right)^{2}-\left(\frac{1+\varphi}{2}\right) \hat{Y}_{t}^{2} \\
+(1+\varphi)\left(\hat{A}_{t}+n_{s} \hat{A}_{s, t}+n_{b} \hat{A}_{b, t}\right) \hat{Y}_{t}+(1+\varphi) n_{s} n_{b} \eta\left(\hat{A}_{b, t}-\hat{A}_{s, t}\right) \hat{P}_{t}^{R} \\
-\left(\frac{\varphi+\theta}{2}\right) \sum_{j} n_{j} \operatorname{Var}_{i}^{j}\left[\hat{Y}_{j, t}(i)\right]
\end{array}\right. \\
= & \left\{\begin{array}{c}
-n_{s} n_{b} \frac{\sigma}{2}\left(\hat{C}_{s, t}-\hat{C}_{b, t}\right)^{2}-n_{s} n_{b} \eta\left(\frac{1+\eta \varphi}{2}\right)\left(\hat{P}_{t}^{R}\right)^{2}-\left(\frac{\sigma+\varphi}{2}\right) \hat{Y}_{t}^{2}-\frac{1}{2} \bar{\Xi}_{b b} \hat{b}_{t}^{2} \\
+(1+\varphi)\left(\hat{A}_{t}+n_{s} \hat{A}_{s, t}+n_{b} \hat{A}_{b, t}\right) \hat{Y}_{t}+(1+\varphi) n_{s} n_{b} \eta\left(\hat{A}_{b, t}-\hat{A}_{s, t}\right) \hat{P}_{t}^{R} \\
-\left(\frac{\varphi+\theta}{2}\right) \sum_{j} n_{j} \operatorname{Vrr}_{i}^{j}\left[\hat{Y}_{j, t}(i)\right]
\end{array}\right.
\end{aligned}
$$

where the terms t.i.p. $+O\left(\|\xi\|^{3}\right)$ were omitted. Note that

$$
\begin{aligned}
\hat{A}_{t}+n_{s} \hat{A}_{s, t}+n_{b} \hat{A}_{b, t} & =\left(\frac{\sigma+\varphi}{1+\varphi}\right) \hat{Y}_{t}^{E}+O\left(\|\xi\|^{2}\right) \\
\hat{A}_{b, t}-\hat{A}_{s, t} & =\left(\frac{1+\eta \varphi}{1+\varphi}\right) \hat{P}_{t}^{R, E}+O\left(\|\xi\|^{2}\right)
\end{aligned}
$$


Substituting (54) and (55) into (53) gives

$$
\begin{aligned}
\frac{1}{U_{C} Y} \sum_{j=s, b} n_{j} \tilde{U}_{j, t}= & -n_{s} n_{b} \frac{\sigma}{2}\left(\hat{C}_{s, t}-\hat{C}_{b, t}\right)^{2}-\left(\frac{\sigma+\varphi}{2}\right) \hat{Y}_{t}^{2}+(\sigma+\varphi) \hat{Y}_{t}^{E} \hat{Y}_{t} \\
& +n_{s} n_{b} \eta(1+\eta \varphi) \hat{P}_{t}^{R, E} \hat{P}_{t}^{R}-n_{s} n_{b} \eta\left(\frac{1+\eta \varphi}{2}\right)\left(\hat{P}_{t}^{R}\right)^{2}-\frac{1}{2} \bar{\Xi}_{b b} \hat{b}_{t}^{2} \\
& -\left(\frac{\varphi+\theta^{-1}}{2}\right) \sum_{j} n_{j} \operatorname{Var}_{i}^{j}\left[\hat{Y}_{j, t}(i)\right]+t . i . p .+O\left(\|\xi\|^{3}\right) \\
= & -n_{s} n_{b} \frac{\sigma}{2}\left(\hat{C}_{t}^{R}\right)^{2}-\frac{\sigma+\varphi}{2}\left\{\hat{Y}_{t}^{2}-2 \hat{Y}_{t}^{E} \hat{Y}_{t}+\left(\hat{Y}_{t}^{E}\right)^{2}-\left(\hat{Y}_{t}^{E}\right)^{2}\right\} \\
& -n_{s} n_{b} \eta \frac{1+\eta \varphi}{2}\left\{\left(\hat{P}_{t}^{R}\right)^{2}-2 \hat{P}_{t}^{R, E} \hat{P}_{t}^{R}+\left(\hat{P}_{t}^{R, E}\right)^{2}-\left(\hat{P}_{t}^{R, E}\right)^{2}\right\}-\frac{1}{2} \bar{\Xi}_{b b} \hat{b}_{t}^{2} \\
& -\left(\frac{\varphi+\theta^{-1}}{2}\right) \sum_{j} n_{j} \operatorname{Var}_{i}^{j}\left[\hat{Y}_{j, t}(i)\right]+t . i . p .+O\left(\|\xi\|^{3}\right)
\end{aligned}
$$

Since $\left(\hat{Y}_{t}^{E}\right)^{2}$ and $\left(\hat{P}_{t}^{R, E}\right)^{2}$ belong to t.i.p, we obtain

$$
\begin{aligned}
\sum_{j=s, b} n_{j} \tilde{U}_{j, t} & =-\frac{U_{C} Y}{2}\left[\begin{array}{r}
n_{s} n_{b} \sigma\left(\hat{C}_{t}^{R}\right)^{2}+(\sigma+\varphi)\left(\hat{Y}_{t}-\hat{Y}_{t}^{E}\right)^{2}+n_{s} n_{b} \eta(1+\eta \varphi)\left(\hat{P}_{t}^{R}-\hat{P}_{t}^{R, E}\right)^{2} \\
+\bar{\Xi}_{b b} \hat{b}_{t}^{2}+\left(\varphi+\theta^{-1}\right) \sum_{j} n_{j} \operatorname{Var}_{i}^{j}\left[\hat{Y}_{j, t}(i)\right]
\end{array}\right] \\
& + \text { t.i.p. }+O\left(\|\xi\|^{3}\right)
\end{aligned}
$$

The demand for $Y_{j, t}(i)$ is given by

$$
Y_{j, t}(i)=\left(\frac{P_{j, t}(i)}{P_{j, t}}\right)^{-\theta}\left(\frac{P_{j, t}}{P_{t}}\right)^{-\eta} Y_{t}
$$

Then

$$
\hat{Y}_{j, t}(i)=-\theta\left(\hat{P}_{j, t}(i)-\hat{P}_{j, t}\right)-\eta\left(\hat{P}_{j, t}-\hat{P}_{t}\right)+\hat{Y}_{t}
$$

This implies that

$$
\operatorname{Var}_{i}^{j}\left[\hat{Y}_{j, t}(i)\right]=\theta^{2} \operatorname{Var}_{i}^{j}\left[\hat{P}_{j, t}(i)\right]
$$

where $\Delta_{t}^{j} \equiv \operatorname{Var}_{i}^{j}\left[\hat{P}_{j, t}(i)\right]$ is a measure of price dispersion within a country. When prices are staggered as in the discrete time Calvo fashion, Woodford (2003) has shown that

$$
\begin{aligned}
\Delta_{t}^{j} & =\alpha_{j} \Delta_{t-1}^{j}+\frac{\alpha_{j}}{1-\alpha_{j}} \pi_{j, t}^{2}+O\left(\|\xi\|^{3}\right) \Longrightarrow \\
& =\alpha_{j}^{t+1} \Delta_{-1}^{j}+\sum_{k=0}^{t} \alpha_{j}^{t-s}\left(\frac{\alpha_{j}}{1-\alpha_{j}}\right) \pi_{j, k}^{2}+O\left(\|\xi\|^{3}\right)
\end{aligned}
$$

If a new policy is conducted from $t \geqslant 0$, the first term, $\alpha_{j}^{t+1} \Delta_{-1}^{j}$, is independent of policy. If we take the discounted sum over time, we obtain

$$
\sum_{t=0}^{\infty} \beta^{t} \Delta_{t}^{j}=\frac{\alpha_{j}}{\left(1-\alpha_{j}\right)\left(1-\alpha_{j} \beta\right)} \sum_{t=0}^{\infty} \beta^{t} \pi_{j, t}^{2}+t . i . p .+O\left(\|\xi\|^{3}\right)
$$

Now, consider

$$
\sum_{t=0}^{\infty} \beta^{t} \sum_{j=s, b} n_{j} \tilde{U}_{j, t}
$$




$$
\begin{aligned}
& =-\frac{U_{C} \bar{Y}}{2} \sum_{t=0}^{\infty} \beta^{t}\left[n_{s} n_{b} \sigma\left(\hat{C}_{t}^{R}\right)^{2}+(\sigma+\varphi)\left(\hat{Y}_{t}-\hat{Y}_{t}^{E}\right)^{2}+n_{s} n_{b} \eta(1+\eta \varphi)\left(\hat{P}_{t}^{R}-\hat{P}_{t}^{R, E}\right)^{2}+\bar{\Xi}_{b b} \hat{b}_{t}^{2}\right] \\
& -\frac{U_{C} \bar{Y}}{2}\left(\varphi+\theta^{-1}\right) \theta^{2} \sum_{j=s, b} n_{j} \sum_{t=0}^{\infty} \beta^{t} \Delta_{t}^{j}+t . i . p .+O\left(\|\xi\|^{3}\right) \\
& =-\frac{U_{C} \bar{Y}}{2} \sum_{t=0}^{\infty} \beta^{t}\left[n_{s} n_{b} \sigma\left(\hat{C}_{t}^{R}\right)^{2}+(\sigma+\varphi)\left(\hat{Y}_{t}-\hat{Y}_{t}^{E}\right)^{2}+n_{s} n_{b} \eta(1+\eta \varphi)\left(\hat{P}_{t}^{R}-\hat{P}_{t}^{R, E}\right)^{2}+\bar{\Xi}_{b b} \hat{b}_{t}^{2}\right] \\
& -\frac{U_{C} \bar{Y}}{2} \sum_{t=0}^{\infty} \beta^{t} \sum_{j=s, b} n_{j} \frac{\alpha_{j} \theta(1+\varphi \theta)}{\left(1-\alpha_{j}\right)\left(1-\alpha_{j} \beta\right)} \pi_{j, t}^{2}+t . i . p .+O\left(\|\xi\|^{3}\right) \\
& =-\frac{U_{C} \bar{Y}}{2} \sum_{t=0}^{\infty} \beta^{t}\left[\begin{array}{c}
\sum_{j=s, b} n_{j} \frac{\theta(\sigma+\varphi)}{\kappa_{j}^{y}} \pi_{j, t}^{2}+n_{s} n_{b} \sigma\left(\hat{C}_{t}^{R}\right)^{2}+(\sigma+\varphi)\left(\hat{Y}_{t}-\hat{Y}_{t}^{E}\right)^{2} \\
+n_{s} n_{b} \eta(1+\eta \varphi)\left(\hat{P}_{t}^{R}-\hat{P}_{t}^{R, E}\right)^{2}+\bar{\Xi}_{b b} \hat{b}_{t}^{2}
\end{array}\right]+\text { t.i.p. }+O\left(\|\xi\|^{3}\right)
\end{aligned}
$$

Therefore

$$
\begin{aligned}
L_{t} & =n_{s} \frac{\theta(\sigma+\varphi)}{\kappa_{s}} \pi_{s, t}^{2}+n_{b} \frac{\theta(\sigma+\varphi)}{\kappa_{b}} \pi_{b, t}^{2} \\
& +n_{s} n_{b} \sigma\left(\hat{C}_{t}^{R}\right)^{2}+(\sigma+\varphi)\left(\hat{Y}_{t}-\hat{Y}_{t}^{E}\right)^{2}+n_{s} n_{b} \eta(1+\eta \varphi)\left(\hat{P}_{t}^{R}-\hat{P}_{t}^{R, E}\right)^{2} \\
& +\bar{\Xi}_{b b} \hat{b}_{t}^{2} .
\end{aligned}
$$

\section{C.2 Proof of Proposition 2}

It is straightforward to take the derivatives.

\section{C.3 Proof of Proposition 3}

(a) As discussed in the previous section, it is clear that the system of the equations, (14)-(19), determines $\left\{\hat{C}_{t}^{R}, \hat{P}_{t}^{R}, \hat{Y}_{t}^{R}, b_{t}\right\}$ as a function of $\hat{\chi}_{t}$ and $\hat{P}_{t}^{R, E}$ (only) in the limiting case, $\bar{\Xi}_{b b} \rightarrow 0$ and $\lambda^{B} \rightarrow 0$.

(b) The loss function (21) can be written as

$$
L_{t}=\phi_{\pi} \pi_{t}^{2}+\phi_{Y}\left(\hat{Y}_{t}-\hat{Y}_{t}^{E}\right)^{2}+n_{s} n_{b} \phi_{\pi}\left(\pi_{t}^{R}\right)^{2}+\phi_{P}\left(\hat{P}_{t}^{R}-\hat{P}_{t}^{R, E}\right)^{2}+\phi_{C}\left(\hat{C}_{t}^{R}\right)^{2}+\phi_{B} \hat{b}_{t}^{2}
$$

where $\phi_{\pi}=\frac{\theta(\sigma+\varphi)}{\kappa}$. Note that $n_{s} n_{b} \phi_{\pi}\left(\pi_{t}^{R}\right)^{2}+\phi_{P}\left(\hat{P}_{t}^{R}-\hat{P}_{t}^{R, E}\right)^{2}+\phi_{C}\left(\hat{C}_{t}^{R}\right)^{2}$ are independent of monetary policy and $\phi_{B}=0$ when $\bar{\Xi}_{b b}=0$.

(c) From (14), the central bank can set $\pi_{t}=0$ and $\hat{Y}_{t}=\hat{Y}_{t}^{E}$, which minimizes the loss function.

(d) Finally, to show that the optimal monetary policy does not attain the efficient outcome, note that

$$
n_{s} \hat{P}_{t}^{R}=n_{s} \hat{P}_{t-1}^{R}+\pi_{t}-\pi_{b, t} .
$$

Suppose the optimal policy leads to the efficient outcome. Then it must be that

$$
\pi_{b, t}=-n_{s}\left(\hat{P}_{t}^{R, E}-\hat{P}_{t-1}^{R, E}\right) .
$$

Then one can easily show using a country's Phillips curve that $\hat{C}_{t}^{R} \neq 0$, which contradicts the supposition. 


\section{C.4 Proof of Proposition 4}

Under flexible prices $(\kappa=\infty)$, the first two inflation terms drop out from (21). Moreover, since $\hat{Y}_{t}=\hat{Y}_{t}^{E}$, this third term drops out as well. This means that the loss function now simplifies to:

$$
L_{t}=\phi_{P}\left(\hat{P}_{t}^{R}-\hat{P}_{t}^{R, E}\right)^{2}+\phi_{C}\left(\hat{C}_{t}^{R}\right)^{2}+\phi_{B} \hat{b}_{t}^{2}
$$

where

$$
\phi_{P}=n_{s} n_{b} \eta(1+\eta \varphi) ; \quad \phi_{C}=n_{s} n_{b} \sigma ; \quad \phi_{B}=\bar{\Xi}_{b b}
$$

Next, note the relationship between $\hat{P}_{t}^{R}-\hat{P}_{t}^{R, E}$ and $\hat{C}_{t}^{R}$ given in (20). Using this we can rewrite the loss function as

$$
L_{t}=\underbrace{\left(\phi_{P}\left(\frac{\sigma}{1+\eta \varphi}\right)^{2}+\phi_{C}\right)}_{=\tilde{\phi}_{C}}\left(\hat{C}_{t}^{R}\right)^{2}+\phi_{B} \hat{b}_{t}^{2},
$$

with the following reduced system of equations as constraints:

$$
\begin{gathered}
\hat{C}_{t}^{R}=E_{t}\left[\hat{C}_{t+1}^{R}\right]+\frac{1}{\sigma}\left(\hat{\chi}_{t}+\eta_{B} \hat{b}_{t}\right), \\
\hat{b}_{t}=\beta^{-1} \hat{b}_{t-1}+\lambda^{B} \hat{R}_{t}^{d}-\beta^{-1} \lambda^{B} \hat{\pi}_{t}-\beta^{-1} n_{s} n_{b}\left(\frac{\sigma(\eta-1)}{1+\eta \varphi}+1\right) \hat{C}_{t}^{R} \\
+\left(1-n_{b}\right) \lambda^{B}\left(\hat{\chi}_{t}+\eta_{B} \hat{b}_{t}\right)-\beta^{-1} n_{s} n_{b}(\eta-1)\left(\frac{1+\varphi}{1+\eta \varphi}\left(\hat{A}_{s, t}-\hat{A}_{b, t}\right)\right), \\
\hat{Y}_{t}^{E}=E_{t} \hat{Y}_{t+1}^{E}-\frac{1}{\sigma}\left\{\hat{R}_{t}^{d}-E_{t} \pi_{t+1}+n_{b}\left(\hat{\chi}_{t}+\eta_{B} \hat{b}_{t}\right)\right\} .
\end{gathered}
$$

The first order conditions from the central bank's minimization problem under commitment are given as:

$$
\begin{aligned}
& 0=\tilde{\phi}_{C} \hat{C}_{t}^{R}+q_{1, t}-\beta^{-1} q_{1, t-1}+\beta^{-1} n_{s} n_{b}\left(\frac{\sigma(\eta-1)}{1+\eta \varphi}+1\right) q_{2, t}, \\
& 0=\phi_{B} \hat{b}_{t}-\frac{1}{\sigma} \eta_{B} q_{1, t}+\left(1-\left(1-n_{b}\right) \lambda^{B} \eta_{B}\right) q_{2, t}-E_{t} q_{2, t+1}+\frac{1}{\sigma} n_{b} \eta_{B} q_{3, t}, \\
& 0=\beta^{-1} \lambda^{B} q_{2, t}-\beta^{-1} \frac{1}{\sigma} q_{3, t-1}, \\
& 0=-\lambda^{B} q_{2, t}+\frac{1}{\sigma} q_{3, t}
\end{aligned}
$$

where $\left\{q_{1, t}\right\},\left\{q_{2, t}\right\}$ and $\left\{q_{3, t}\right\}$ are the sequence of Lagrange multipliers associated respectively with (56), (57) and (58). The last two equations implies that $q_{2, t}=q_{3, t}=0$. It is then straightforward to show that the first order conditions are reduced to a simple targeting rule:

$$
\tilde{\phi}_{C} \hat{C}_{t}^{R}=-\phi_{B} \frac{\sigma}{\eta_{B}}\left[\hat{b}_{t}-\beta^{-1} \hat{b}_{t-1}\right]=-\sigma \beta\left[\hat{b}_{t}-\beta^{-1} \hat{b}_{t-1}\right] .
$$

We can plug the targeting rule into (56) to obtain:

$$
\beta E_{t} \hat{b}_{t+1}-\left[1+\beta+\eta_{B} \frac{\tilde{\phi}_{C}}{\sigma \phi_{B}}\right] \hat{b}_{t}+\hat{b}_{t-1}=\frac{\tilde{\phi}_{C}}{\sigma \phi_{B}} \hat{\chi}_{t} .
$$

The solution of the second order difference equation is:

$$
\hat{b}_{t}=\gamma \hat{b}_{t-1}-\gamma \frac{\tilde{\phi}_{C}}{\sigma \phi_{B}} \hat{\chi}_{t}
$$


and we thus have:

$$
\begin{aligned}
\tilde{\phi}_{C} \hat{C}_{t}^{R} & =-\phi_{B} \frac{\sigma}{\eta_{B}}\left[\hat{b}_{t}-\beta^{-1} \hat{b}_{t-1}\right]=\sigma \beta\left[\left(\beta^{-1}-\gamma\right) \hat{b}_{t-1}+\gamma \frac{\tilde{\phi}_{C}}{\sigma \phi_{B}} \hat{\chi}_{t}\right] \\
& \Longrightarrow \hat{C}_{t}^{R}=\frac{\sigma(1-\beta \gamma)}{\tilde{\phi}_{C}} \hat{b}_{t-1}+\gamma \frac{\beta}{\phi_{B}} \hat{\chi}_{t},
\end{aligned}
$$

where $\gamma \in(0,1)$ is a smaller root of the characteristic polynomial:

$$
f(\gamma)=\beta \gamma^{2}-\left(1+\beta+\eta_{B} \frac{\tilde{\phi}_{C}}{\sigma \phi_{B}}\right) \gamma+1=0
$$

In particular, $\gamma$ is given as

$$
\gamma=\frac{\left(1+\beta+\eta_{B} \frac{\tilde{\phi}_{C}}{\sigma \phi_{B}}\right)-\sqrt{\left(1+\beta+\eta_{B} \frac{\tilde{\phi}_{C}}{\sigma \phi_{B}}\right)^{2}-4 \beta}}{2 \beta} .
$$

Since $\hat{C}_{t}^{R} \neq 0$, the optimal policy does not achieve the efficiency.

\section{Optimal policy problem in general case}

In this section, we detail optimal policy problem. Consider the Lagrangian (omitting exogenous shocks for brevity):

$$
\begin{aligned}
& \mathcal{L}= \frac{1}{2} E_{0} \sum_{t=0}^{\infty} \beta^{t}\left[\phi_{s} \pi_{s, t}^{2}+\phi_{b} \pi_{b, t}^{2}+\phi_{Y}\left(\hat{Y}_{t}-\hat{Y}_{t}^{E}\right)^{2}+\phi_{P}\left(\hat{P}_{t}^{R}-\hat{P}_{t}^{R, E}\right)^{2}+\phi_{C}\left(\hat{C}_{t}^{R}\right)^{2}+\phi_{B} \hat{b}_{t}^{2}\right] \\
&+E_{0} \sum_{t=0}^{\infty} \beta^{t} q_{1, t}\left\{\pi_{s, t}-\beta \pi_{s, t+1}-\kappa_{s}\left[\hat{Y}_{t}-\hat{Y}_{t}^{E}\right]-\kappa_{s}\left(\frac{\sigma}{\sigma+\varphi} n_{b}\right)\left[\hat{C}_{t}^{R}\right]+\kappa_{s}\left(\frac{1+\eta \varphi}{\sigma+\varphi} n_{b}\right)\left[\hat{P}_{t}^{R}-\hat{P}_{t}^{R, E}\right]\right\} \\
&+E_{0} \sum_{t=0}^{\infty} \beta^{t} q_{2, t}\left\{\pi_{b, t}-\beta \pi_{b, t+1}-\kappa_{b}\left[\hat{Y}_{t}-\hat{Y}_{t}^{E}\right]+\kappa_{b}\left(\frac{\sigma}{\sigma+\varphi} n_{s}\right)\left[\hat{C}_{t}^{R}\right]-\kappa_{b}\left(\frac{1+\eta \varphi}{\sigma+\varphi} n_{s}\right)\left[\hat{P}_{t}^{R}-\hat{P}_{t}^{R, E}\right]\right\} \\
&+E_{0} \sum_{t=0}^{\infty} \beta^{t} q_{3, t}\left\{\left(\hat{P}_{t}^{R}-\hat{P}_{t}^{R, E}\right)-\left(\hat{P}_{t-1}^{R}-\hat{P}_{t-1}^{R, E}\right)-\pi_{s, t}+\pi_{b, t}\right\} \\
&+E_{0} \sum_{t=0}^{\infty} \beta^{t} q_{4, t}\left\{\hat{C}_{t}^{R}-E_{t}\left[\hat{C}_{t+1}^{R}\right]-\frac{1}{\sigma} \eta_{B} \hat{b}_{t}\right\} \\
&+E_{0} \sum_{t=0}^{\infty} \beta^{t} q_{5, t}\left\{\left(\hat{Y}_{t}-\hat{Y}_{t}^{E}\right)-\left(\hat{Y}_{t+1}-\hat{Y}_{t+1}^{E}\right)+\frac{1}{\sigma} \hat{R}_{t}^{d}+\frac{1}{\sigma} n_{b} \eta_{B} \hat{b}_{t}-\frac{1}{\sigma} n_{s} \pi_{s, t+1}-\frac{1}{\sigma} n_{b} \pi_{b, t+1}\right\} \\
&+E_{0} \sum_{t=0}^{\infty} \beta^{t} q_{6, t}\left\{\left(1-\left(1-n_{b}\right) \lambda^{B} \eta_{B}\right) \hat{b}_{t}-\beta^{-1} \hat{b}_{t-1}-\lambda^{B} \hat{R}_{t}^{d}+\beta^{-1} \lambda^{B}\left[n_{s} \pi_{s, t}+n_{b} \pi_{b, t}\right]\right\} \\
&+\beta^{-1} n_{s} n_{b}(\eta-1)\left(\hat{P}_{t}^{R}-\hat{P}_{t}^{R, E}\right)+\beta^{-1} n_{s} n_{b} \hat{C}_{t}^{R}
\end{aligned}
$$

where $\left\{q_{1, t}\right\},\left\{q_{2, t}\right\}, \ldots,\left\{q_{6, t}\right\}$ are the sequence of Lagrange multipliers. 
First order conditions are given as:

$$
\begin{aligned}
\partial \pi_{s, t}: 0 & =\phi_{s} \pi_{s, t}+q_{1, t}-q_{1, t-1}-q_{3, t}-\beta^{-1} \frac{1}{\sigma} n_{s} q_{5, t-1}+\beta^{-1} \lambda^{B} n_{s} q_{6, t} \\
\partial \pi_{b, t}: 0 & =\phi_{b} \pi_{b, t}+q_{2, t}-q_{2, t-1}+q_{3, t}-\beta^{-1} \frac{1}{\sigma} n_{b} q_{5, t-1}+\beta^{-1} \lambda^{B} n_{b} q_{6, t} \\
\partial\left(\hat{Y}_{t}-\hat{Y}_{t}^{E}\right): 0 & =\phi_{Y}\left(\hat{Y}_{t}-\hat{Y}_{t}^{E}\right)-\kappa_{s} q_{1, t}-\kappa_{b} q_{2, t}+q_{5, t}-\beta^{-1} q_{5, t-1} \\
\partial\left(\hat{P}_{t}^{R}-\hat{P}_{t}^{R, E}\right): 0 & =\phi_{P}\left(\hat{P}_{t}^{R}-\hat{P}_{t}^{R, E}\right)+\kappa_{s}\left(\frac{1+\eta \varphi}{\sigma+\varphi} n_{b}\right) q_{1, t}-\kappa_{b}\left(\frac{1+\eta \varphi}{\sigma+\varphi} n_{s}\right) q_{2, t} \\
+ & q_{3, t}-\beta E_{t} q_{3, t+1}+\beta^{-1} n_{s} n_{b}(\eta-1) q_{6, t} \\
\partial \hat{C}_{t}^{R}: 0 & =\phi_{C} \hat{C}_{t}^{R}-\kappa_{s}\left(\frac{\sigma}{\sigma+\varphi} n_{b}\right) q_{1, t}+\kappa_{b}\left(\frac{\sigma}{\sigma+\varphi} n_{s}\right) q_{2, t}+q_{4, t}-\beta^{-1} q_{4, t-1}+\beta^{-1} n_{s} n_{b} q_{6, t} \\
\partial \hat{b}_{t}: 0 & =\bar{\Xi}_{b b} \hat{b}_{t}-\frac{1}{\sigma} \eta_{B} q_{4, t}+\frac{1}{\sigma} n_{b} \eta_{B} q_{5, t}+\left(1-\left(1-n_{b}\right) \lambda^{B} \eta_{B}\right) q_{6, t}-E_{t} q_{6, t+1} \\
\partial \hat{R}_{t}^{d}: 0 & =\frac{1}{\sigma} q_{5, t}-\lambda^{B} q_{6, t} .
\end{aligned}
$$

Consequently, the equilibrium time path of

$$
\left\{\hat{Y}_{t}, \hat{R}_{t}^{d}, \pi_{t}, \pi_{s, t}, \pi_{b, t}, \hat{b}_{t}, \hat{\omega}_{t}, \hat{C}_{t}^{R}, \hat{P}_{t}^{R}, q_{1, t}, q_{2, t}, q_{3, t}, q_{4, t}, q_{5, t}, q_{6, t}\right\}_{t=0}^{\infty}
$$

are characterized by the following 15 equations

$$
\begin{aligned}
\pi_{s, t} & =\beta E_{t}\left[\pi_{s, t+1}\right]+\kappa_{s}\left[\hat{Y}_{t}-\hat{Y}_{t}^{E}\right]+\kappa_{s}\left(\frac{\sigma}{\sigma+\varphi} n_{b}\right)\left[\hat{C}_{t}^{R}\right]-\kappa_{s}\left(\frac{1+\eta \varphi}{\sigma+\varphi} n_{b}\right)\left[\hat{P}_{t}^{R}-\hat{P}_{t}^{R, E}\right], \\
\pi_{b, t} & =\beta E_{t}\left[\pi_{b, t+1}\right]+\kappa_{b}\left[\hat{Y}_{t}-\hat{Y}_{t}^{E}\right]-\kappa_{b}\left(\frac{\sigma}{\sigma+\varphi} n_{s}\right)\left[\hat{C}_{t}^{R}\right]+\kappa_{b}\left(\frac{1+\eta \varphi}{\sigma+\varphi} n_{s}\right)\left[\hat{P}_{t}^{R}-\hat{P}_{t}^{R, E}\right], \\
\hat{Y}_{t} & =E_{t}\left[\hat{Y}_{t+1}\right]-\frac{1}{\sigma}\left\{\hat{R}_{t}^{d}+n_{b} \hat{\omega}_{t}-E_{t}\left[\pi_{t+1}\right]\right\} \\
\hat{C}_{t}^{R} & =E_{t}\left[\hat{C}_{t+1}^{R}\right]+\frac{1}{\sigma} \hat{\omega}_{t}, \\
\hat{b}_{t} & =\beta^{-1} \hat{b}_{t-1}+\lambda^{B} \hat{R}_{t}^{d}-\beta^{-1} \lambda^{B} \hat{\pi}_{t}-\beta^{-1} n_{s} n_{b}(\eta-1) \hat{P}_{t}^{R}-\beta^{-1} n_{s} n_{b} \hat{C}_{t}^{R}+\left(1-n_{b}\right) \lambda^{B} \hat{\omega}_{t}, \\
\hat{\omega}_{t} & =\hat{\chi}_{t}+\eta_{B} \hat{b}_{t}, \\
\hat{P}_{t}^{R} & =\hat{P}_{t-1}^{R}+\pi_{s, t}-\pi_{b, t}, \\
\pi_{t} & =n_{s} \pi_{s, t}+n_{b} \pi_{b, t},
\end{aligned}
$$

$$
\begin{aligned}
& 0=\phi_{s} \pi_{s, t}+q_{1, t}-q_{1, t-1}-q_{3, t}-\beta^{-1} \frac{1}{\sigma} n_{s} q_{5, t-1}+\beta^{-1} \lambda^{B} n_{s} q_{6, t} \\
& 0=\phi_{b} \pi_{b, t}+q_{2, t}-q_{2, t-1}+q_{3, t}-\beta^{-1} \frac{1}{\sigma} n_{b} q_{5, t-1}+\beta^{-1} \lambda^{B} n_{b} q_{6, t}, \\
& 0=\phi_{Y}\left(\hat{Y}_{t}-\hat{Y}_{t}^{E}\right)-\kappa_{s} q_{1, t}-\kappa_{b} q_{2, t}+q_{5, t}-\beta^{-1} q_{5, t-1}, \\
& 0=\phi_{P}\left(\hat{P}_{t}^{R}-\hat{P}_{t}^{R, E}\right)+\kappa_{s}\left(\frac{1+\eta \varphi}{\sigma+\varphi} n_{b}\right) q_{1, t}-\kappa_{b}\left(\frac{1+\eta \varphi}{\sigma+\varphi} n_{s}\right) q_{2, t}+q_{3, t}-\beta E_{t} q_{3, t+1}+\beta^{-1} n_{s} n_{b}(\eta-1) q_{6, t}, \\
& 0=\phi_{C} \hat{C}_{t}^{R}-\kappa_{s}\left(\frac{\sigma}{\sigma+\varphi} n_{b}\right) q_{1, t}+\kappa_{b}\left(\frac{\sigma}{\sigma+\varphi} n_{s}\right) q_{2, t}+q_{4, t}-\beta^{-1} q_{4, t-1}+\beta^{-1} n_{s} n_{b} q_{6, t}, \\
& 0=\bar{\Xi}_{b b} \hat{b}_{t}-\frac{1}{\sigma} \eta_{B} q_{4, t}+\frac{1}{\sigma} n_{b} \eta_{B} q_{5, t}+\left(1-\left(1-n_{b}\right) \lambda^{B} \eta_{B}\right) q_{6, t}-E_{t} q_{6, t+1}, \text { and } \\
& 0=\frac{1}{\sigma} q_{5, t}-\lambda^{B} q_{6, t},
\end{aligned}
$$

given exogenous processes and initial conditions. We assume that all the variables are in the steady state initially: $\hat{Z}_{-1}=0$ and $q_{-1}=0$. 


\section{E Estimation of $\eta_{B}$ and productivity shock processes}

Below we detail the estimation strategy that we used to estimate $\eta_{B}=\bar{\Xi}_{b b} / \beta$ and the parameters related to the productivity shocks.

\section{E.1 Estimation of $\eta_{B}$}

The parameter $\eta_{B}$ implies a change in $\hat{\omega}_{t}$ associated with a unit change in $\hat{b}_{t}$ while all other variables are fixed. We set $\eta_{B}$ at the long-run impact of a unit increase in the net foreign asset-to-GDP ratio on the interest rate spread estimated using a panel of the seven countries in Table 1 (France, Germany, Greece, Ireland, Italy, Portugal, and Spain). The panel consists of annual data on interest rate spreads (the excess return of the 10-year government bond over EONIA or the Euro OverNight Index Average) and the ratio of net foreign asset to output for each country over the period from 2007 through 2010. The estimated long-run impact is 0.11 .

\section{E.2 Estimation of productivity shocks}

Our model implies that

$$
\begin{aligned}
& \hat{A}_{t}+\hat{A}_{s, t}=\hat{Y}_{s, t}-\hat{N}_{s, t} \\
& \hat{A}_{t}+\hat{A}_{b, t}=\hat{Y}_{b, t}-\hat{N}_{b, t}
\end{aligned}
$$

where

$$
\begin{aligned}
\hat{A}_{t} & =\rho_{A} \hat{A}_{t-1}+\varepsilon_{A, t}, \\
\hat{A}_{s, t} & =\rho_{A s} \hat{A}_{s, t-1}+\varepsilon_{A s, t}, \\
\hat{A}_{b, t} & =\rho_{A b} \hat{A}_{b, t-1}+\varepsilon_{A b, t},
\end{aligned}
$$

and the innovations $\varepsilon_{A, t}, \varepsilon_{A s, t}$ and $\varepsilon_{A b, t}$ are i.i.d. and have mean zero and variance $\sigma_{A}^{2}, \sigma_{A_{S}}^{2}$ and $\sigma_{A_{b}}^{2}$, respectively. For simplicity, we further assume that the country-specific shocks follow the same process: $\rho_{A s}=\rho_{A b}=\rho_{A i}$ and $\sigma_{A s}^{2}=\sigma_{A b}^{2}=\sigma_{A i}^{2}$.

To calibrate the parameters, we use the quarterly per-capita output data of six countries (France, Germany, Ireland, Italy, Portugal, and Spain) over the period from 2000 through 2011 and estimate the following model

$$
Z_{i, t}=\bar{Z}_{i}+g \cdot t+\hat{A}_{t}+\hat{A}_{i, t}
$$

and

$$
\begin{aligned}
\hat{A}_{t} & =\rho_{A} \hat{A}_{t-1}+\varepsilon_{A, t}, \\
\hat{A}_{i, t} & =\rho_{A_{i}} \hat{A}_{i, t-1}+\varepsilon_{A i, t},
\end{aligned}
$$

for $i=1,2, \cdots, 10$ where $Z_{i, t}$ is per-capita output in each country, $\varepsilon_{A, t} \sim N\left(0, \sigma_{A}^{2}\right)$ and $\varepsilon_{A i, t} \sim N\left(0, \sigma_{A_{i}}^{2}\right)$. The data were taken from the OECD database. Note that the country-specific productivity shocks are restricted so that they have the same autocorrelation coefficient and the same innovation variance. We include $\bar{Z}_{i}$ and $g \cdot t$ to demean per-capita output and remove a common linear time trend.

The model is estimated using Bayesian methods with a quite loose prior distribution. In particular, we use a uniform distribution over $(0,1)$ for $\rho_{A}$ and $\rho_{A_{i}}$ and a uniform distribution over [0,0.2] for $\sigma_{A}$ and $\sigma_{A_{i}}$. The posterior mean is estimated to be 0.73 and 0.98 for $\rho_{A}$ and $\rho_{A_{i}}$, respectively, and 0.002 and 0.009 for $\sigma_{A}$ and $\sigma_{A_{i}}$, respectively. 


\section{F Additional figures}
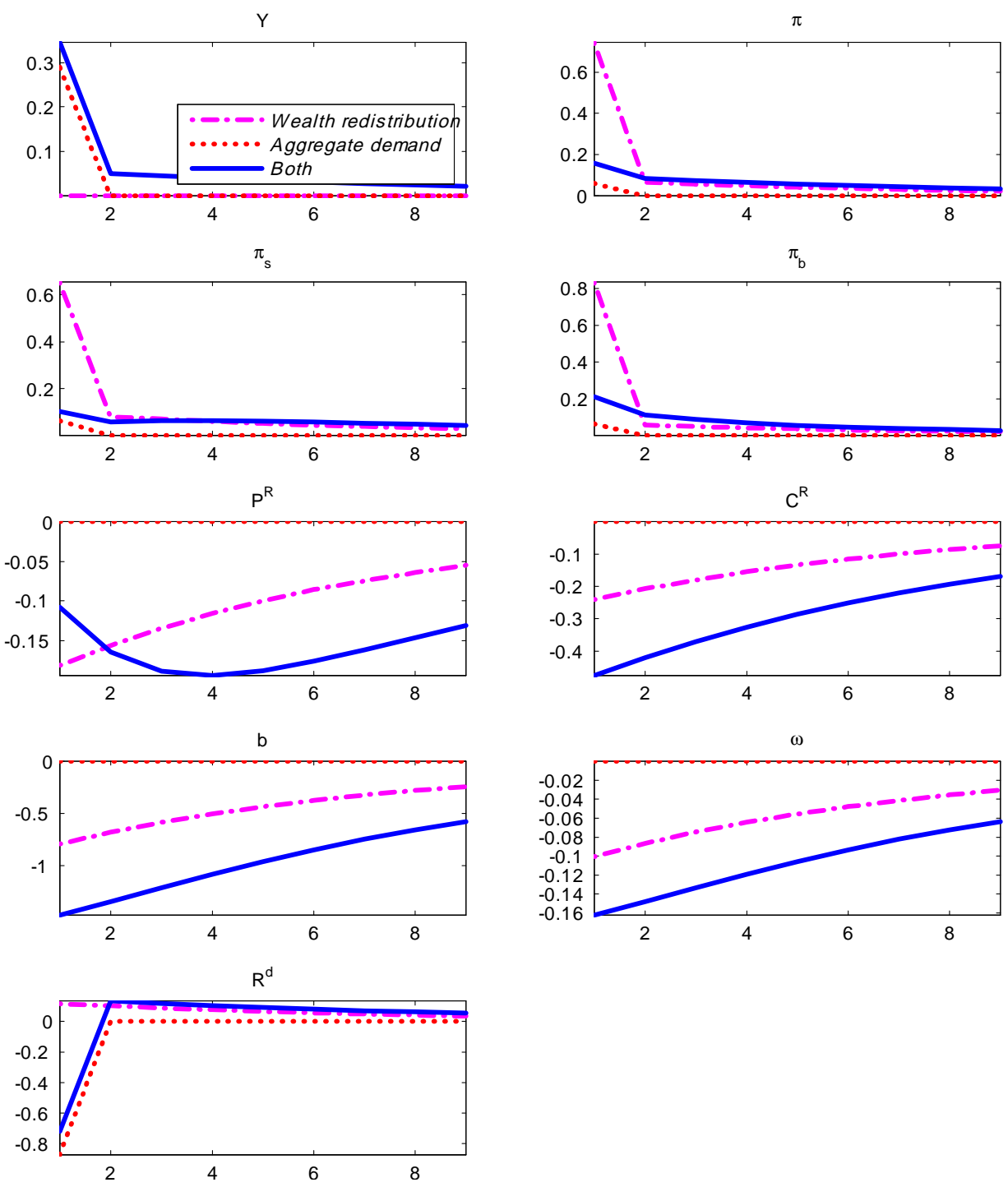

Figure 10: Impulse responses to an expansionary monetary shock. Monetary policy is a standard Taylor rule with an i.i.d shock and no interest smoothing term: $\hat{R}_{t}^{d}=\Phi_{\pi} \pi_{t}+\Phi_{y} \hat{Y}_{t}+\varepsilon_{R, t}$. "Wealth redistribution" corresponds to the special case that features only the wealth redistribution channel due to the absence of nominal rigidities, while "Aggregate demand" corresponds to the other special case that features only the aggregate demand channel. 